\title{
GROWTH MEDIA AND LIPID DETERMINATION COMPARISON OF HIGH RATE ALGAE PONDS
}

\author{
A Thesis \\ presented to \\ the Faculty of California Polytechnic State University, \\ San Luis Obispo \\ In Partial Fulfillment \\ of the Requirements for the Degree \\ Master of Science in Civil and Environmental Engineering
}

By

Eric Alexander Nicolai

December 2014 
(C) 2014

Eric Alexander Nicolai

ALL RIGHTS RESERVED 
COMMITTEE MEMBERSHIP

TITLE:

AUTHOR:

DATE SUBMITTED:

COMMITTEE CHAIR:

COMMITTEE MEMBER:

COMMITTEE MEMBER
Growth Media and Lipid Determination Comparison of High Rate Algae Ponds

Eric Alexander Nicolai

December 2014

Dr. Tryg Lundquist, Associate Professor

Civil \& Environmental Engineering Department

Dr. Rebekah Oulton, Assistant Professor

Civil \& Environmental Engineering Department

Dr. Corinne Lehr, Associate Professor

Chemistry \& Biochemistry Department 


\section{ABSTRACT \\ Growth Media and Lipid Determination Comparison \\ of High Rate Algae Ponds}

\section{Eric Alexander Nicolai}

The feasibility of algal biofuel production relies on the use of a non-potable water source. Municipal wastewater is nutrient-rich and a cost effective option as a growth media in algae ponds. However, this resource may be too valuable for algal biomass production, as reclaimed wastewater is needed for surface irrigation and groundwater recharge. This thesis compares the performance of $4.2 \mathrm{~m}^{2}$ high rate algal raceway ponds (HRAPs) to 33 $\mathrm{m}^{2}$ HRAPs grown on primary settled wastewater during a media recycling study and a growth media comparison study using wastewater and reclaimed water. The comparative metrics of performance for this study included: pond productivity, settling efficiency, and nutrient removal. This thesis also discusses the variability of algal lipid content from wastewater ponds using three different lipid determination methods. Six $4.2-\mathrm{m}^{2}, 0.3 \mathrm{~m}$ deep HRAPs were compared to nine 33- $\mathrm{m}^{2}$ HRAPs located at the San Luis Obispo Water Resource Recovery Facility (SLOWRRF). During the media recycling study, the first round of growth (Round 1) included ponds operating at 2-day and 3-day hydraulic retention times (HRTs) for both pond sizes. The pond arrangements for the second round of growth (Round 2) were the same with the exception of no 2-day HRT for the 33- $\mathrm{m}^{2}$ pond set. Net biomass productivity in the $4.2-\mathrm{m}^{2}$ ponds under predicted the productivity of the $33-\mathrm{m}^{2}$ ponds. Settling efficiency was comparable between the different rounds of growth for both pond sizes. Total soluble nitrogen removal was predicted using $4.2-\mathrm{m}^{2}$ ponds. Of the three lipid determination methods, the fatty acid methyl esters (FAMEs) quantification was the most precise between replicates. However, this method determined the lowest lipid content because it quantifies a better representative lipid content by excluding other constituents not relevant to biofuel production. 


\section{TABLE OF CONTENTS}

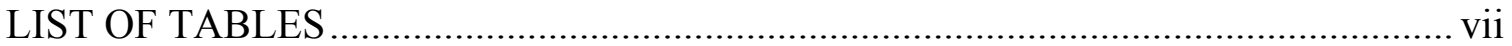

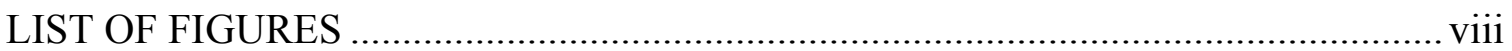

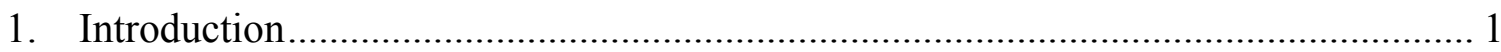

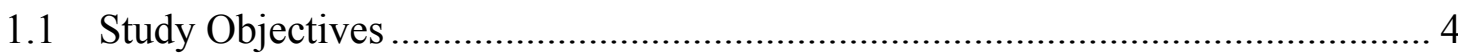

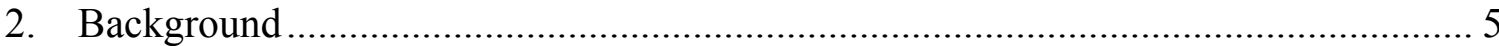

2.1 Water Usage and Media Recycling Potential in Algae Ponds ........................... 5

2.2 Algae Pond Scale-up Comparison ....................................................................... 9

2.3 Algal Biofuels and Lipid Determination...................................................... 10

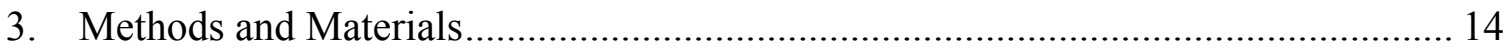

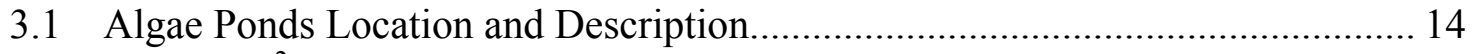

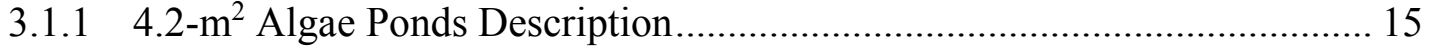

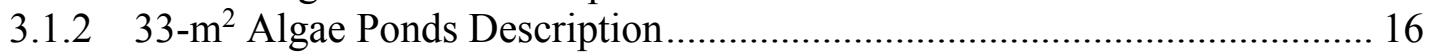

3.2 Media Recycling Experiment ...................................................................... 16

3.2.1 Facility Description for Media Recycling Experiment .............................. 17

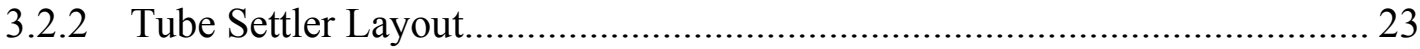

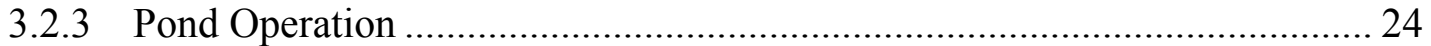

3.2.4 Pond Sampling Procedure ....................................................................... 25

3.3 Growth Media Comparison Experiments ....................................................... 26

3.3.1 Facility Description for $100 \%$ WW vs. $100 \%$ RW vs. 50\%/50\%

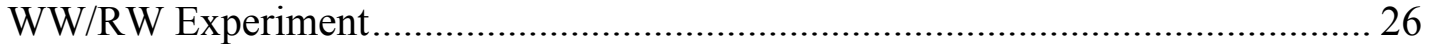

3.3.2 Pond Operation for $100 \% \mathrm{WW}$ vs. $100 \% \mathrm{RW}$ vs. $50 / 50 \% \mathrm{WW} / \mathrm{RW}$

Experiment ................................................................................................... 28

3.3.3 Pond Sampling Procedure for $100 \%$ WW vs. $100 \%$ RW vs. $50 \% / 50 \%$

WW/RW Experiment..................................................................................... 29

3.3.4 Facility Description for Wastewater vs. Defined Medium Experiment ....... 29

3.3.5 Pond Operation for Wastewater vs. Defined Media Experiment ................. 31

3.3.6 Pond Sampling Procedure for Wastewater vs. Defined Media

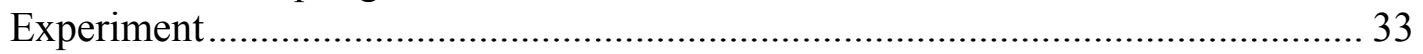

3.4 Water Analyses and Quality Control ........................................................ 33

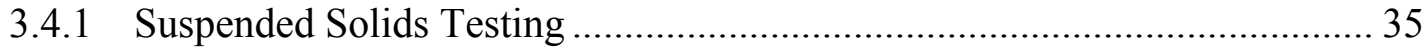

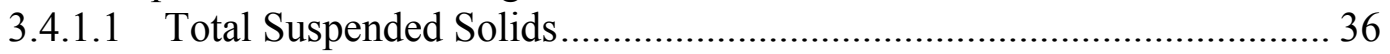

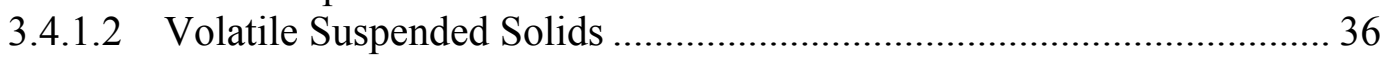

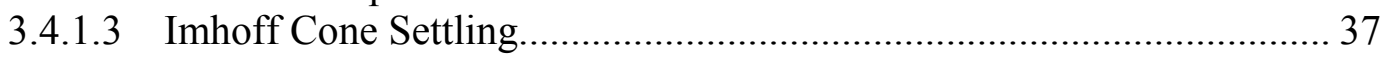

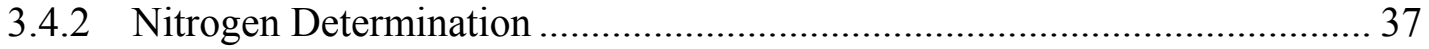

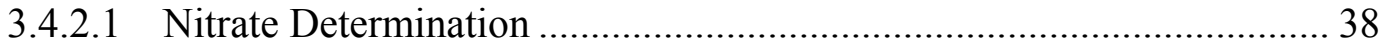

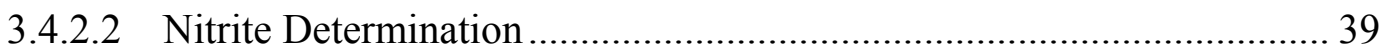

3.4.2.3 Total Ammonia Determination ....................................................... 40

3.4.2.4 Total Kjeldahl Nitrogen Determination ............................................ 40

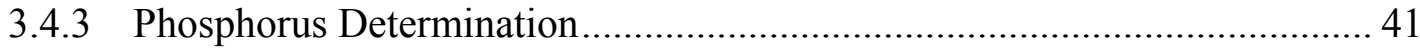

3.5 Lipid Determination Method Comparison .................................................... 41

3.5.1 Algal Biomass Collection, Centrifugation, and Lyophilization................... 42

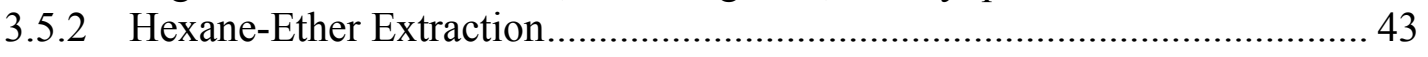




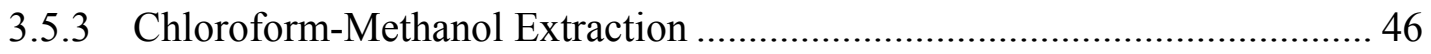

3.5.4 Fatty Acid Methyl Esters (FAMEs) ........................................................ 48

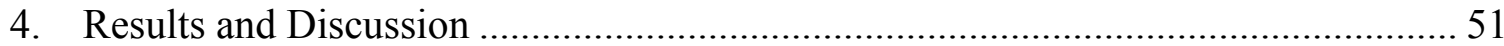

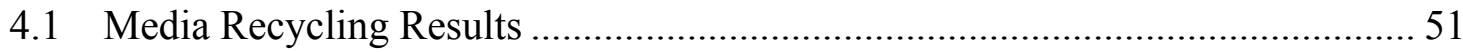

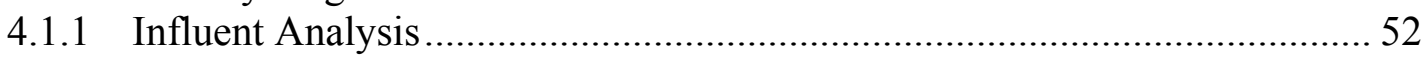

4.1.2 Net Biomass Productivity ................................................................ 53

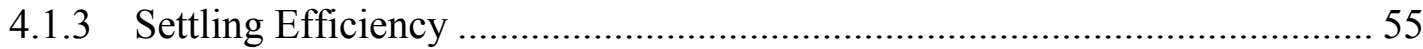

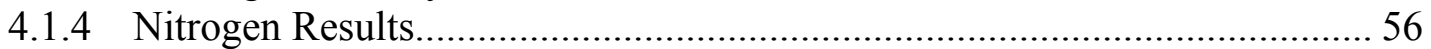

4.2 Growth Media Comparison Results .............................................................. 57

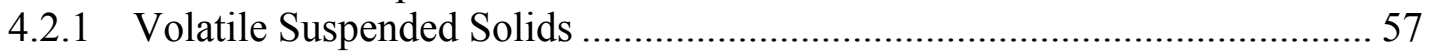

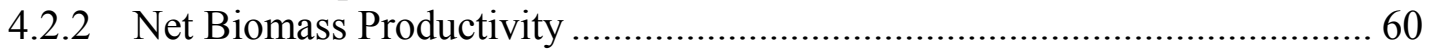

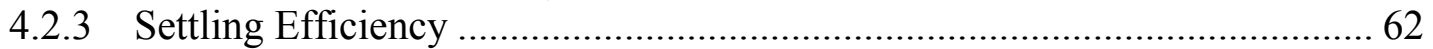

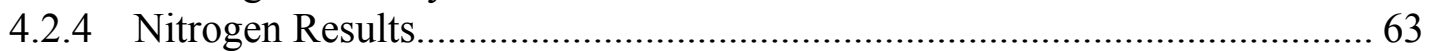

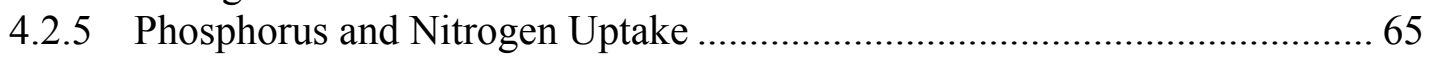

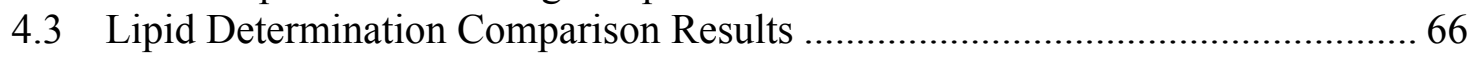

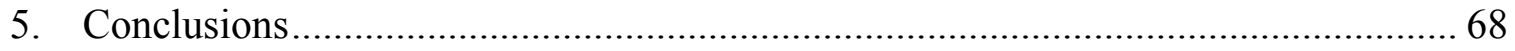

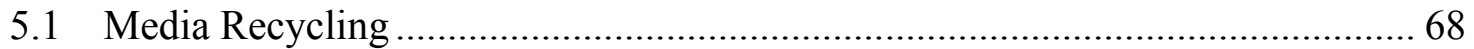

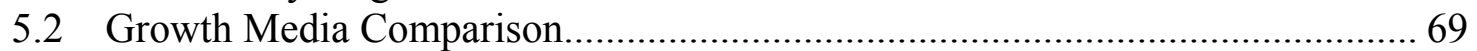

5.3 Lipid Determination Comparison ............................................................... 70

5.4 Limitations of the Study............................................................................ 73

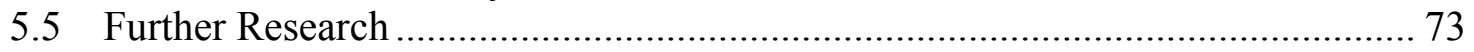

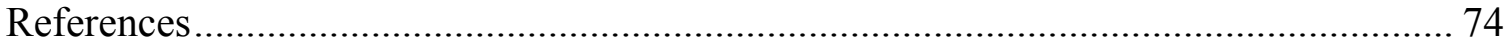

APPENDICES

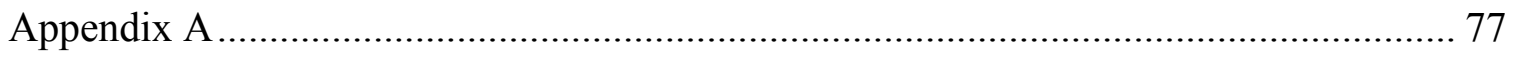

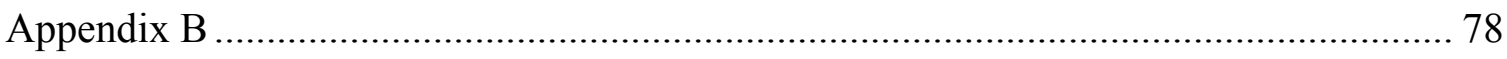

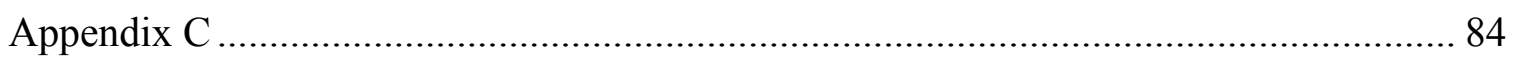

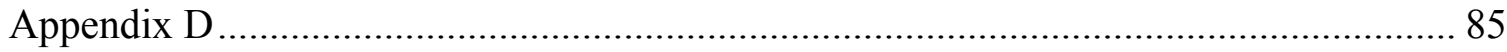




\section{LIST OF TABLES}

Table 2.1: Projected oil yield from algae per acre of land per year compared to oil yields observed from conventional biofuel feedstocks (DOE, 2010) 10

Table 3.1: Target flow rate and acceptable ranges ( $+/-10 \%$ of target) for pond influent.

Table 3.2: Concentrations of each stock solution of NCMA BG11 recipe added to ponds

Table 3.3: Water quality analyses performed for all samples for media recycling experiment.

Table 3.4: Water quality analyses performed for all samples for growth media comparison experiment (June 24, 2013 - July 15, 2013)

Table 3.5: Water quality analyses performed for all samples for growth media comparison experiment (August 7, 2013 - September 8, 2013)

Table 4.1: Round 1 influent characterization from January 30, 2014 to

March 13, 2014 52

Table 4.2: Round 2 pond influent (2-day) characterization from January 30, 2014 to March 13, 2014

Table 4.3: Round 2 pond influent (3-day) characterization from January 30, 2014 to March 13, 2014

Table 4.4: Net productivities for this experiment were determined from the steepest portion

of the VSS growth curve.

Table 4.5: Nitrogen and phosphorus contents were highest in the 100\% WW pond set.

Table 5.1: Average lipid content, standard deviation and relative standard error were reported for the triplicate biomass sample analyzed on each sampling event for the chloroform-methanol extraction method.

Table 5.2: Average lipid content, standard deviation, and relative standard error were reported for the triplicate biomass sample analyzed on each sampling event for the hexane-diethyl ether extraction method.

Table 5.3: Average lipid contents, standard deviations, and relative standard errors were averaged for all duplicates for each sampling event for the FAMEs quantification method. 


\section{LIST OF FIGURES}

Figure 1.1: Red curve represents the mole fraction of carbon dioxide in dry air, which fluctuated during different seasons of the year. Data was corrected for these seasonal changes and represented as the black curve. Data were collected at an altitude of $3400 \mathrm{~m}$ from Mauna Loa, Hawaii (NOAA, 2014) ..........................................................

Figure 1.2: Electricity production and transportation are the primary sources $(60 \%)$ of greenhouse gas emissions in the United States (A). Carbon dioxide is the primary greenhouse gas emitted in the United States in 2012 (B). (EPA, 2014)........................ 2 Figure 1.3: Hypothetical process for algae production with anaerobic digestion and oil extraction (Lundquist, Woertz, Quinn, \& Benemann, 2010) ...................................... 3 Figure 2.1: Water shortages throughout the nation in 2006 (DOE, 2006)...................... 5 Figure 2.2: Exceptional drought intensity observed in the western and southwestern regions of the United States (National Drought Mitigation Center, 2014)....................... 6 Figure 2.3: Symbiotic relationship between microalgae and heterotrophic aerobic bacteria enhance wastewater treatment in algae ponds (Guieysse \& Muñoz, 2006)......... 7 Figure 2.4: Water quality of recycled water depends on the level of wastewater

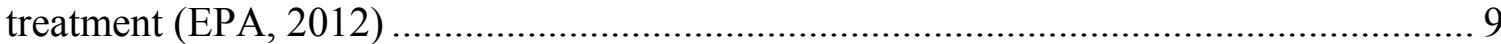

Figure 2.5: Example of a TAG molecule structure .................................................... 12 Figure 2.6: Ester bonds on TAGs are replaced with ester bonds between free fatty acids and methyl groups to form biodiesel as FAMEs (Moser, 2009) ........................... 13

Figure 3.1: Aerial view of algae ponds (left) on-site near the primary clarifier (right) 15

Figure 3.2: Facility layout and pond arrangement for the media recycling experiment.

Figure 3.3: Primary treated wastewater constant head tank distribution system.

Water level maintained at $48 \mathrm{~cm}$ (75\% of tank height) using standpipe. Flow rate held constant throughout the experiment.

Figure 3.4: Effluent from both 2-day Round 1 ponds were mixed in a 3" PVC manifold connected to the drains of both ponds. This mixing was necessary so that the tube settlers received the same influent. The combined Round 1 effluent was pumped out of the PVC manifold using peristaltic pumps and tubing inserted into the end of the pipe. The pumps moved the Round 1 effluent to two tube settlers. Effluent from the 3-day Round 1 pond was collected in the green tube connected to the pond drain.

Figure 3.5: Peristaltic pumps in the pump house. The pumps on the top shelf pumped primary effluent to the Round 1 ponds. The pumps on the bottom shelf pumped Round 1 pond effluent to the tube settlers 20

Figure 3.6: Tube settlers were positioned near the Round 2 ponds for convenience and minimal tubing....

Figure 3.7: Growth media without algae inoculum: 100\% RW (A), 50\%/50\%

WW/RW (B), 100\% WW (C)

Figure 3.8: Growth media with algae inoculum: NCMA BG11 defined media (A), $100 \%$ wastewater (B)

Figure 3.9: $60-\mathrm{mL}$ vials containing extract after centrifuging. Hexane-ether extracts varied in appearance due to the different algal biomass conditions in each pond.... 
Figure 3.10: Lipid content was a dried residue in the vials after solvent was evaporated.

Figure 3.11: $60-\mathrm{mL}$ vials containing lipid extract from ASE. Different concentrations of extract in each vial were most likely caused by variability in extraction process using the ASE. Biomass for Pond 6 (Vials 6, 7, and 8) was tested in triplicate for

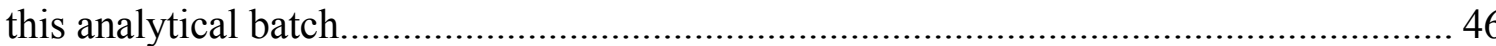

Figure 3.12: Upper and lower phases clearly displayed after one hour of settling.......... 47 Figure 3.13: Lipid content was a dried residue in the vials after solvent was evaporated. 48

Figure 4.1: Net productivity comparison for $4.2-\mathrm{m} 2$ ponds and $33-\mathrm{m} 2$ ponds. The vertical black line represents the estimated start of steady state conditions for the algae. Steady state was reached at approximately three times the 3-day HRT ( 9 days) after the inoculation date. 54

Figure 4.2: Settling efficiencies for 4.2- $\mathrm{m} 2$ ponds were averaged during steady state conditions from February 19, 2014 to March 13, 2014. Settling efficiencies for 33-m2 ponds were averaged from January 29, 2014 to March 19, 2014 55

Figure 4.3: Total soluble nitrogen decreased in $4.2 \mathrm{~m} 2$ ponds and $33 \mathrm{~m} 2$ ponds due to decrease in TAN from volatilization and nitrification.

Figure 4.4: Defined media pond set was in the exponential growth phase for nine days longer than the wastewater pond set. Daily dilutions caused a decrease in net VSS for both pond sets.

Figure 4.5: $50 \% / 50 \% \mathrm{WW} / \mathrm{RW}$ pond set achieved fastest growth rate before other pond sets and resulted in a higher final VSS concentration.

Figure 4.6: Net biomass productivity of the 4.2-m2 ponds decreased after daily dilutions initiated until the ponds reached steady state and achieved stable productivities

Figure 4.7: Settling efficiency increased for both growth media sets in 4.2-m2 ponds until daily dilutions initiated. Daily dilutions in $100 \% \mathrm{WW}$ ponds began August 19, 2013. Daily dilutions in defined media ponds began August 28, 2013......... 62 Figure 4.8: Settling efficiency for $50 \% / 50 \% \mathrm{WW} / \mathrm{RW}$ was higher than the other pond sets for a majority of the experiment.

Figure 4.9: TAN reached depleted conditions before daily dilutions began. TAN increased after daily dilutions began due to additional nutrients in the fresh media... 64 Figure 4.10: Total soluble nitrogen decreased in ponds as expected due to batch operation. Ponds were nearly nitrogen-depleted by July 11, 2013, which may have caused the VSS growth curve to enter stationary phase.

Figure 4.11: Lipid content trends were similar between all three determination methods. Methods arranged from highest to lowest lipid content determination: Chloroform:Methanol (4.12a), Hexane:Diethyl ether (4.12b), FAMEs (4.12c).

Figure 5.1: Net productivity decreased as effective HRT increased. Effective HRT represents the total retention time for a volume of water spent in both rounds of growth

Figure 5.2: Samples arranged from highest to lowest average lipid content. Comparison of lipid content for all three determination methods averaged for all three sampling events 


\section{Introduction}

The concentration of carbon dioxide in the atmosphere continues to rise each year and surpassed 400 ppm in 2014 (Figure 1.1) (NOAA, 2014). The rise of atmospheric carbon dioxide is largely contributed by the combustion of fossil fuels. Electricity production and transportation are the primary sources for greenhouse gas emissions in the United Stated, which comprised 82\% carbon dioxide in 2012 (Figure 1.2) (EPA, 2014). The need to reduce carbon emissions and lessen global dependence on fossil fuels has sparked widespread research and implementation of renewable energy sources. Along side solar and wind energy, commercial-scale production of liquid biofuels are being considered as a solution to the global climate crisis.

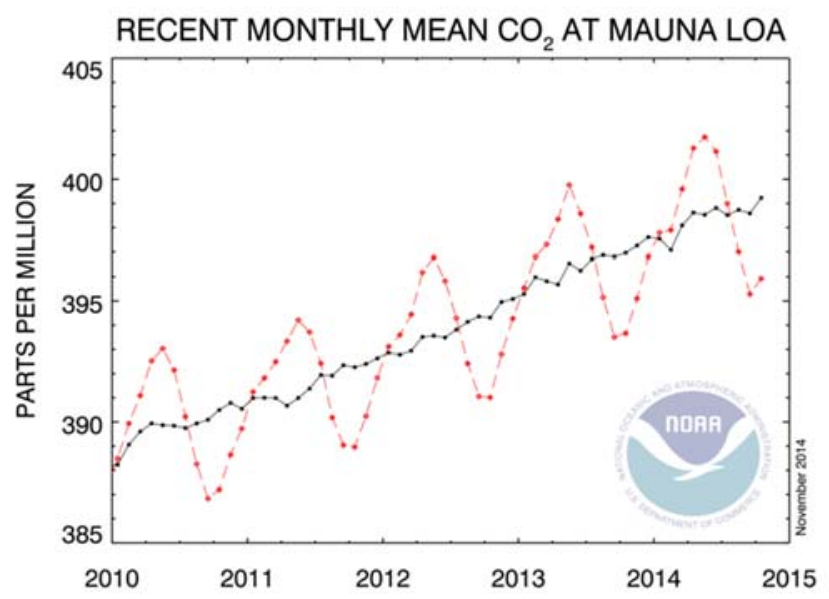

Figure 1.1: Red curve represents the mole fraction of carbon dioxide in dry air, which fluctuated during different seasons of the year. Data was corrected for these seasonal changes and represented as the black curve. Data were collected at an altitude of $3400 \mathrm{~m}$ from Mauna Loa, Hawaii (NOAA, 2014). 


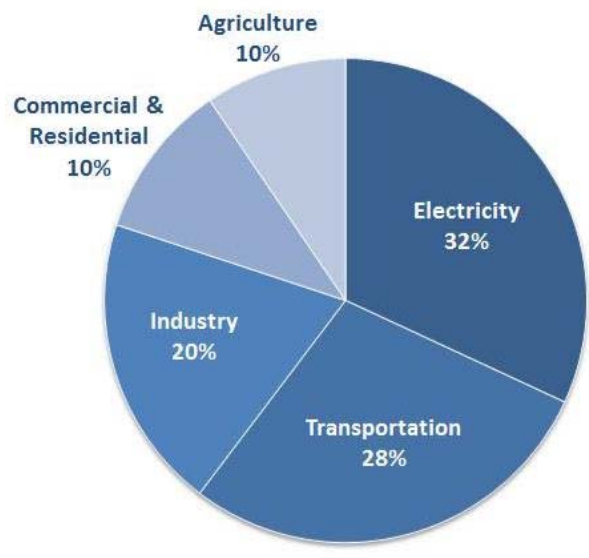

(A)

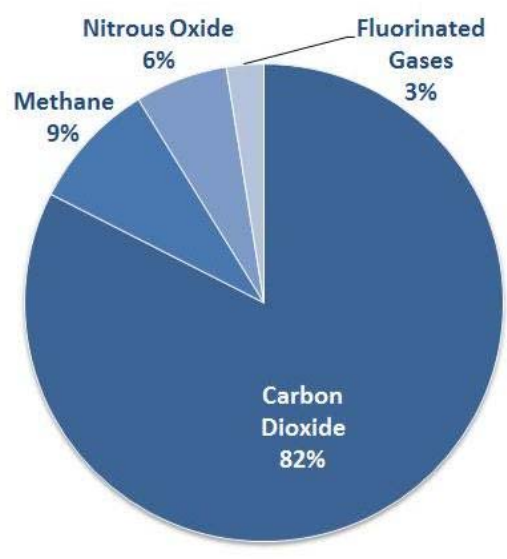

(B)

Figure 1.2: Electricity production and transportation are the primary sources $(60 \%)$ of greenhouse gas emissions in the United States (A). Carbon dioxide is the primary greenhouse gas emitted in the United States in 2012 (B). (EPA, 2014).

The EPA 2014 Renewable Fuel Standards proposed the production of 15.2 billion gallons of renewable fuels, which includes the production of 1.28 billion gallons of biomass-based biofuels (EPA, 2013). Biofuel is a promising alternative to petroleum fuel because it is derived from vegetable oil, which is nontoxic and biodegradable. Renewable biological materials are used for the production of biofuels, such as corn, sugarcane, soybean, rapeseed, animal fats, and microalgae (Andersen, 2005). Fermentation of starch and sugar crops produce bioalcohols, such as ethanol; oils and animal fats produce biodiesel. Algae as a biofuel feedstock is a promising opportunity compared to other crops due to higher oil yields, less land requirements, and its ability to sequester carbon from the atmosphere and treat wastewater ( $\mathrm{Hu}, 2008)$.

In a holistic management perspective, all products from algal biofuel production must be utilized to achieve a sustainable and economically feasible future. This process includes nutrient recycling and the use of byproducts to continue algae production. After oil is extracted from algal biomass, it is anaerobically digested to produce biogas, such as 
carbon dioxide and methane. Methane combustion can assist with energy and heating needs, and carbon dioxide can be distributed to the algae ponds for biomass synthesis and $\mathrm{pH}$ control. Digestate from the anaerobic digester is added into the ponds to provide nutrients to sustain algae growth (Figure 1.3).

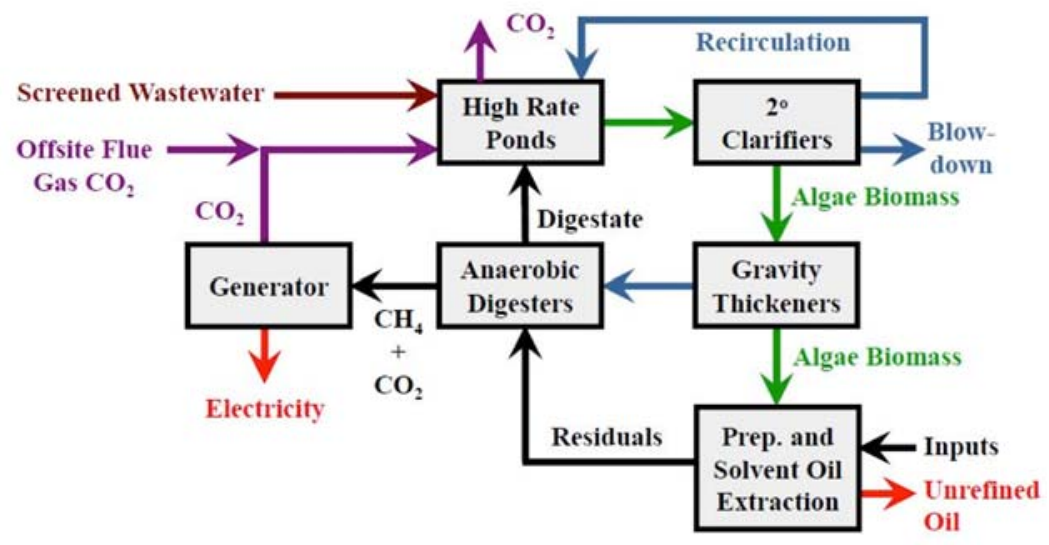

Figure 1.3: Hypothetical process for algae production with anaerobic digestion and oil extraction (Lundquist, Woertz, Quinn, \& Benemann, 2010)

This thesis focused on comparing the performance of a pilot scale pond set to a larger scale pond set. Comparative metrics to determine pond performance included biomass productivity, settling efficiency, and nutrient removal. In addition, this thesis focused on comparing the lipid content of algal biomass using three determination methods. 


\subsection{Study Objectives}

Questions investigated in this thesis:

1. Can $4.2-\mathrm{m}^{2}$ reactors be used to predict pond performance (productivity, settling efficiency, and nutrient removal) of larger reactors?

2. What effect does reused pond supernatant have on pond performance?

3. What effect do different hydraulic retention times have on pond performance?

4. What effect does growth media have on pond performance?

5. Are different lipid determination methods comparable in terms of lipid yield?

6. Which lipid determination method is most efficient and reproducible based on precision? 


\section{Background}

This chapter discusses previous research conducted regarding outdoor raceways, media recycling, and lipid determination for algal biofuel production.

\subsection{Water Usage and Media Recycling Potential in Algae Ponds}

The potential of commercial-scale algal biofuel production is dependent on its impact on water resources. Water shortages throughout the nation contribute to the challenges that algal biofuels face to become a sustainable energy source. A majority of the nation is facing issues with water supply, which is expected to worsen over the next decade (DOE, 2006).
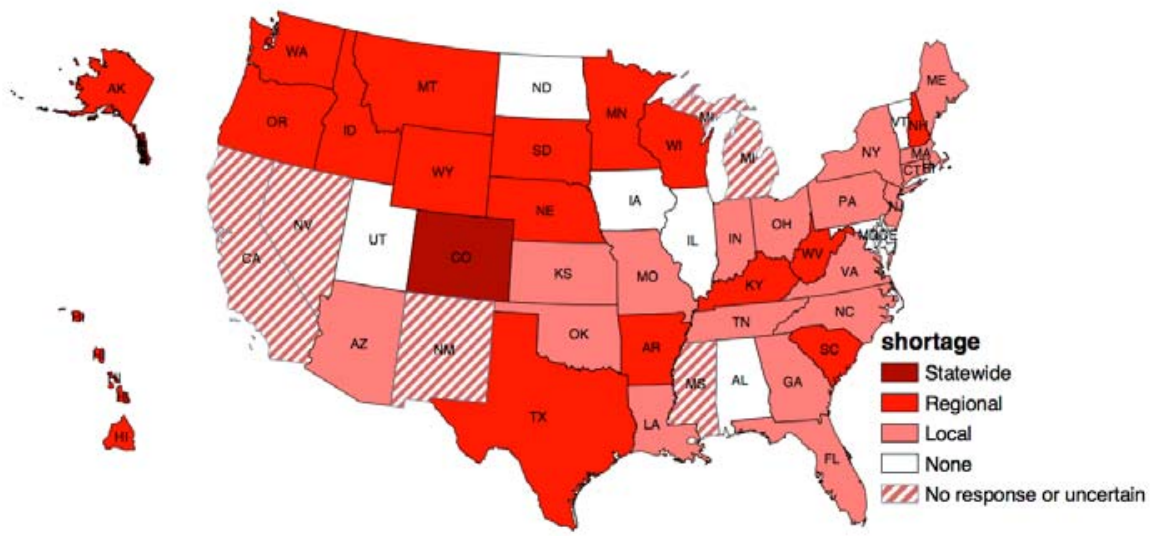

Figure 2.1 shows the severity of water shortage in each state. More recently, the U.S.

Drought Monitor program presents the current water crisis that the United States is facing with exceptional drought conditions throughout most of California (Figure 2.2).

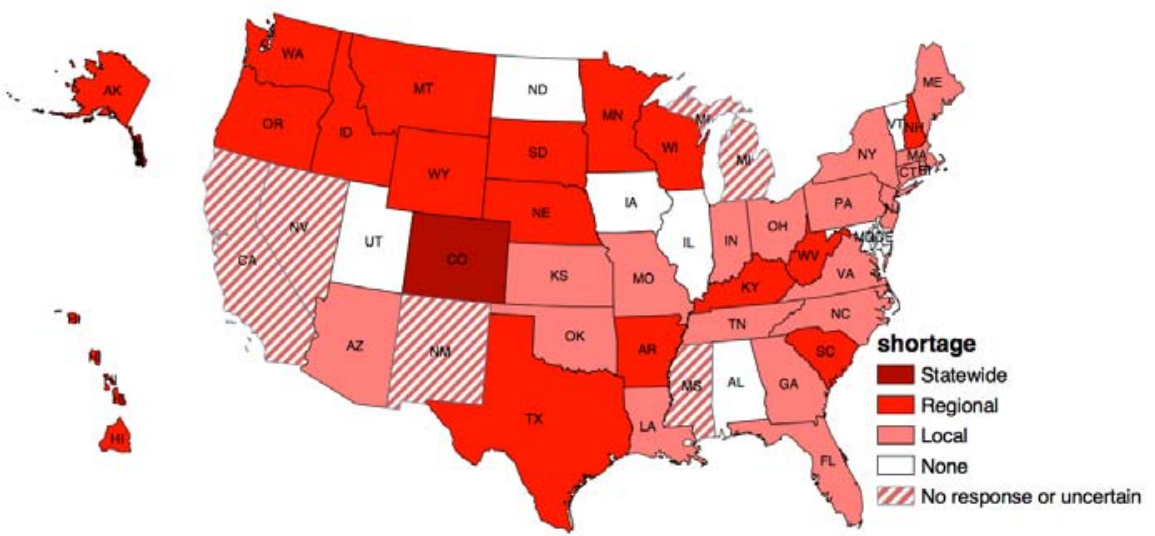

Figure 2.1: Water shortages throughout the nation in 2006 (DOE, 2006). 


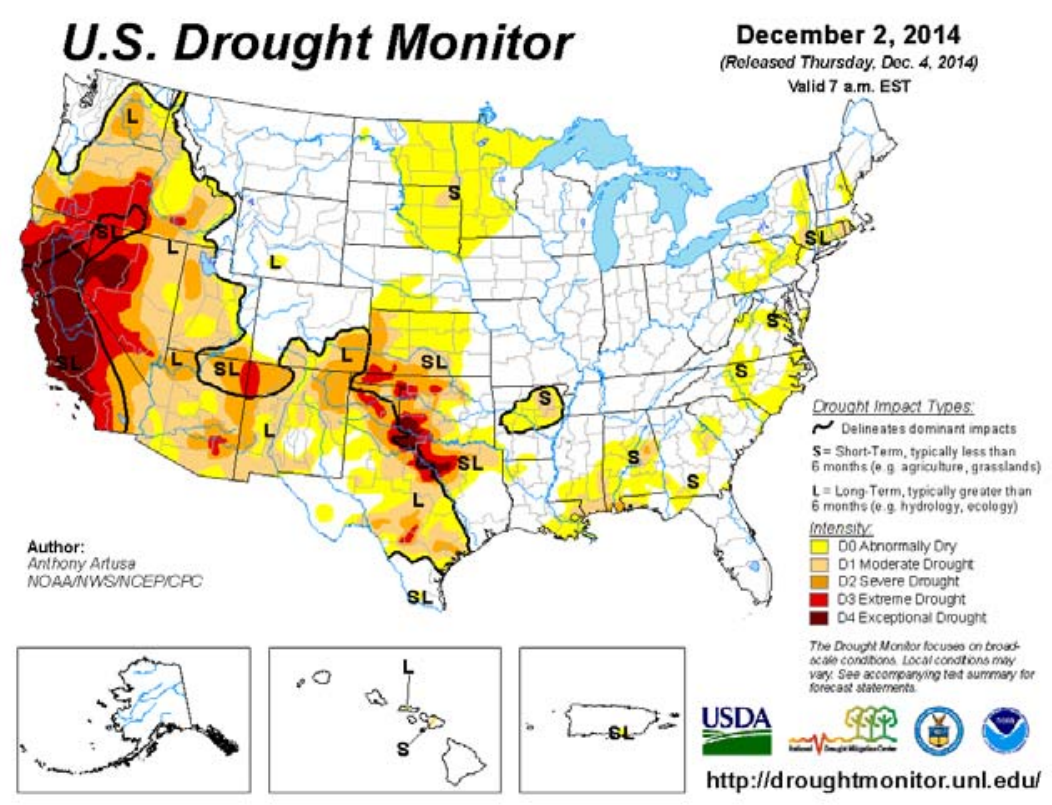

Figure 2.2: Exceptional drought intensity observed in the western and southwestern regions of the United States (National Drought Mitigation Center, 2014)

Growing feedstock is the most water-intensive component to biofuel production. Furthermore, processing algal biomass into biofuels requires less water than the quantity of water lost from evaporation in outdoor ponds (National Research Council, 2012). Low freshwater intensity is possible for some biofuel feedstock if it is grown without irrigation or from a nontraditional water source (DOE, 2006). In the United States, 85 percent of all consumptive water use is for agricultural demand (National Research Council, 2012). The feasibility of algal biofuel production relies on the use of a non-potable water source to avoid competition for freshwater, which is used for drinking water supplies and agriculture. Some non-potable water sources include saline water and municipal wastewater as a growth media for algae ponds. When wastewater is used as the growth media, algae assist with the wastewater treatment process by providing oxygen from photosynthesis for heterotrophic aerobic bacteria, which consume organic matter in the wastewater and produce carbon dioxide (Guieysse \& Muñoz, 2006). 


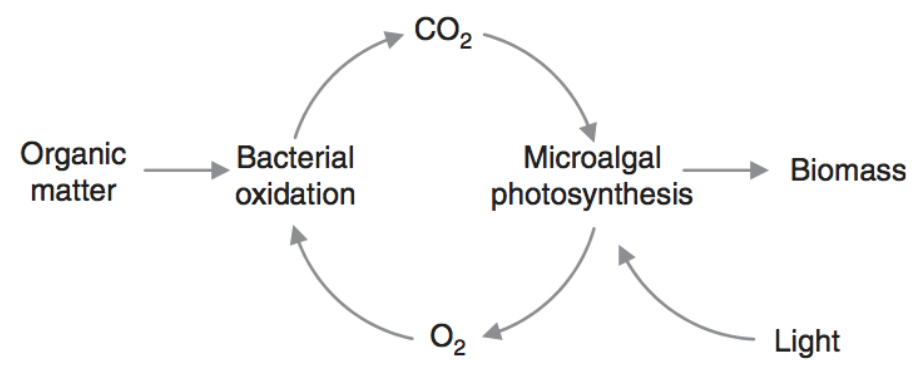

Figure 2.3: Symbiotic relationship between microalgae and heterotrophic aerobic bacteria enhance wastewater treatment in algae ponds (Guieysse \& Muñoz, 2006).

Algae growth requires a nutrient rich growth media for high productivity. Wastewater consists of high nitrogen and phosphorus concentrations, which are two of the principal nutrients for algae growth. Algae growth in wastewater is advantageous because nutrients in the wastewater are removed as a result of biomass production. Subsequent to primary wastewater treatment, algae ponds can significantly reduce nutrient concentrations in wastewater without the use of chemical treatment or mechanical aeration (Golueke \& Oswald, 1959) (Guieysse \& Muñoz, 2006).

This thesis helps address the goals of the Department of Energy's National Algal Biofuels Technology Roadmap by studying water recycling in algae ponds. Overall sustainability of algal biofuel production can be increased by reusing water for multiple rounds of algae growth. The use of wastewater for multiple rounds of algae growth in ponds enhances wastewater treatment. However, biomass productivity decreases in ponds using recycled media (Chang, 2014). Net biomass productivity is calculated as follows: 
Net Productivity $=\frac{\left(V_{\text {SS }} \text { Pond }-V S S_{\text {Inf }}\right) * Q}{\text { Area }}$

(Equation 2.1)

where

$\mathrm{VSS}_{\text {pond }}=$ volatile suspended solids concentration of pond sample $(\mathrm{mg} / \mathrm{L})$

$\mathrm{VSS}_{\mathrm{inf}}=$ volatile suspended solids concentration of primary clarifier effluent sample $(\mathrm{mg} / \mathrm{L})$

$\mathrm{Q}=$ flowrate of pond influent (L/day)

Area $=$ surface area of pond $\left(\mathrm{m}^{2}\right)$

In both urban and rural communities, the reuse of treated wastewater has the potential to reduce water shortages throughout the nation. Increasing population is increasing the demand for freshwater, and groundwater aquifers used by over half the world population are over drafted (EPA, 2012). Using recycled water for applications that do not require a high quality water source can reduce this freshwater demand. Recycled water is defined as the water reclaimed after wastewater treatment and satisfies water qualities regulations suitable for another purpose (Levine \& Asano, 2004). California's Title 22 regulations state that the use of recycled wastewater for surface irrigation of crops not consumed by humans must undergo undisinfected secondary treatment (CDPH, 2014). This level of reclaimed water quality requires the least amount of treatment, making reclaimed water an economically viable option for algae ponds. Figure 2.4 compares the water quality of each level of treatment for recycled water. 


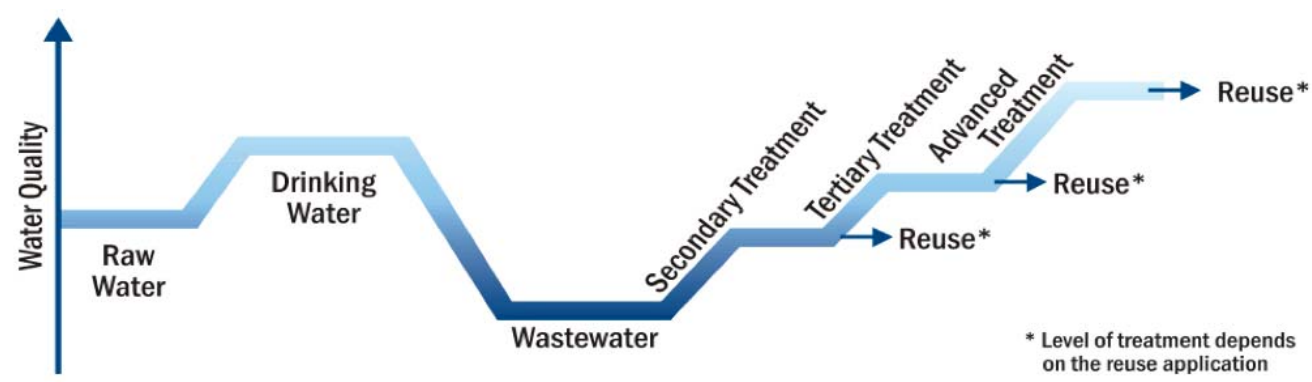

Figure 2.4: Water quality of recycled water depends on the level of wastewater treatment (EPA, 2012)

Although treatment of conventional constituents in wastewater is highly efficient, some constituents remain in the effluent. Undisinfected secondary treated reclaimed water typically contains $1-10 \mathrm{mg} / \mathrm{L}$ nitrate and $0.1-0.5 \mathrm{mg} / \mathrm{L}$ phosphorus (Metcalf \& Eddy, Inc., 2003). Although these concentrations are lower than typical algal growth media, reclaimed water as a growth media may help achieve sustainable, commercialscale algal biofuel production.

\subsection{Algae Pond Scale-up Comparison}

The literature shows a significant amount of research conducted on pilot-scale ponds, however there is a disconnect between pilot scale and commercial-scale ponds. Scaling up to high-volume algae production has associated challenges such as high capital costs, high operational costs, and light limitations that affect growth (Biomass Magazine, 2014). In addition, photobioreactors (PBRs) are not suitable for large-scale production, but practical for seed culture production (Lundquist, Woertz, Quinn, \& Benemann, 2010). Outdoor pond systems are estimated to be ten times lower in cost than PBRs (Benemann, 2009). This thesis investigates the feasibility of using the performance from smaller ponds to predict the performance of larger ponds growing algae on primary 
settled wastewater. The scale up comparison for this study was approximately a ten-fold increase in pond volume $(1,460 \mathrm{~L}$ to $10,000 \mathrm{~L})$.

\subsection{Algal Biofuels and Lipid Determination}

Algal biomass composition consists mainly of lipids, carbohydrates, and proteins. While the protein from biomass can be used for animal feed, the lipid content can be refined to biodiesel and the carbohydrate (starch) content can be converted to ethanol through heterotrophic fermentation (DOE, 2010). Biodiesel is defined as any dieselequivalent biofuel produced from renewable biological materials consisting of long-chain saturated hydrocarbons (Oilgae, 2014). Like petroleum diesel, biodiesel is a mixture of hydrocarbon chains with 12 to 22 carbon atoms per molecule (EPA, 1999). Algal biomass is a promising biofuel feedstock compared to conventional agricultural crops used for biofuel production. The projected oil yield from algae surpasses yields of other crops by one to two orders of magnitude (Table 2.1). Algal biomass production does not require arable land; thus, it does not compete for food crop production such as corn or soybean.

Table 2.1: Projected oil yield from algae per acre of land per year compared to oil yields observed from conventional biofuel feedstocks (DOE, 2010)

\begin{tabular}{|cc|}
\hline CROP & $\begin{array}{c}\text { OIL YIELD } \\
\text { (GALLONS/ACRENR) }\end{array}$ \\
\hline Soybean & 48 \\
\hline Camelina & 62 \\
\hline Sunflower & 102 \\
\hline Jatropha & 202 \\
\hline Oil palm & 635 \\
\hline Algae & $1,000-6,500^{\circ}$ \\
\hline Adapted from Chisti (2007) & \\
${ }^{\circ}$ Estimated yields, this report &
\end{tabular}


The feasibility of algal biofuels relies heavily on the economic feasibility and sustainability of algae cultivation. PBRs are closed systems commonly used for algae production and are controlled to a much higher degree compared to open systems. Temperature, $\mathrm{pH}$, nutrient concentrations, growth media, and algal species are controlled variables within PBRs. PBRs are typically used for production of a monoculture due to lower risk of contamination compared to open systems. However, PBRs are not as economically feasible for commercial-scale cultivation as outdoor pond systems due to high capital and operational costs (Andersen, 2005). Open systems, such as outdoor raceway ponds, require large surface area in locations with high solar irradiance. The challenges of outdoor raceways include possible contamination issues, variable environmental conditions, and low cell density caused by shading effect (Scott, et al., 2010). Although large quantities of algal biomass are produced in outdoor raceways, biomass from these ponds often contains lower lipid content than desired for algal biofuel production (Scott, et al., 2010).

A multitude of lipid determination methods have been developed to assess the lipid content of algal biomass. However, lipid content in microalgae presented in biofuel research literature show a wide range of values depending on the determination method utilized. The vague concept of lipids is defined as biochemical compounds soluble in organic solvents, not water (Christie, 2003). Organic solvent extraction methods often misrepresent the actual lipid content because additional compounds extracted from the algal cells are included in the total quantification. In a lipophilic extraction, lipid contents often include other compounds such as carotenoids, steroids, and terpenes (Christie, 2003). Saponifiable lipids within algal cells can be classified as triacylglycerides (TAGs), 
phospholipids, glycolipids, and sphingolipids (Stoker, 2011). Acyl chains in TAGs determine theoretical algal biofuel potential, and lipid content is quantified by the sum of the fatty acid constituents (Laurens, Quinn, Van Wychen, Templeton, \& Wolfrum, 2012).

Neutral lipids, such as TAGs, are nonpolar and insoluble in water; therefore, this type of lipid is more readily converted into biodiesel. Under nutrient depleted conditions, algal cells accumulate neutral lipids, which increases the quantity of TAGs available for conversion to biodiesel. TAGs are molecules derived of three fatty acid hydrocarbon chains attached to a glycerol backbone by ester bonds, as shown in Figure 2.5 (Stoker, 2011). Transesterification is the process used to convert TAGs into fatty acid methyl esters (FAMEs) to quantify algal lipids for biofuel yields.

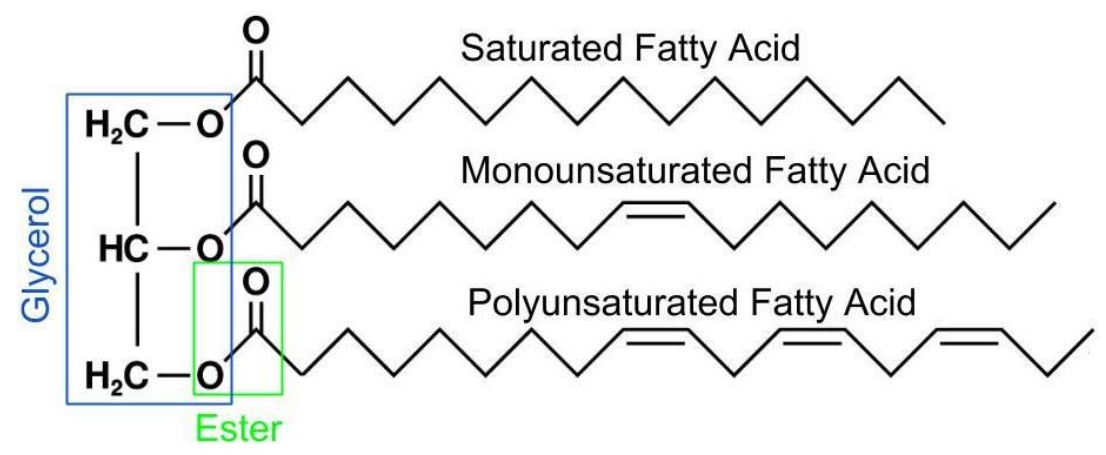

Figure 2.5: Example of a TAG molecule structure

An in situ transesterification procedure developed by the National Renewable Energy Laboratory (NREL) quantifies lipids as FAMEs in whole algal biomass. This process eliminates the need for extraction prior to lipid content determination. During an acid catalyst reaction, lipids are solubilized in solvent and methyl groups from methanol are transferred onto acyl chains to free fatty acids from TAGs (Laurens, Quinn, Van Wychen, Templeton, \& Wolfrum, 2012). Ester bonds on TAG molecules are replaced with ester bonds between free fatty acids and methyl groups. FAMEs and free glycerol 
are the products of this reaction. These products are separated by polarity. FAMEs are extracted from the polar layer containing methanol and glycerol. Figure 2.6 illustrates the reactions in the transesterification process. Purified glycerol can be recovered for food and cosmetic processes or used as a substrate for anaerobic digestion (EBTP, 2011).

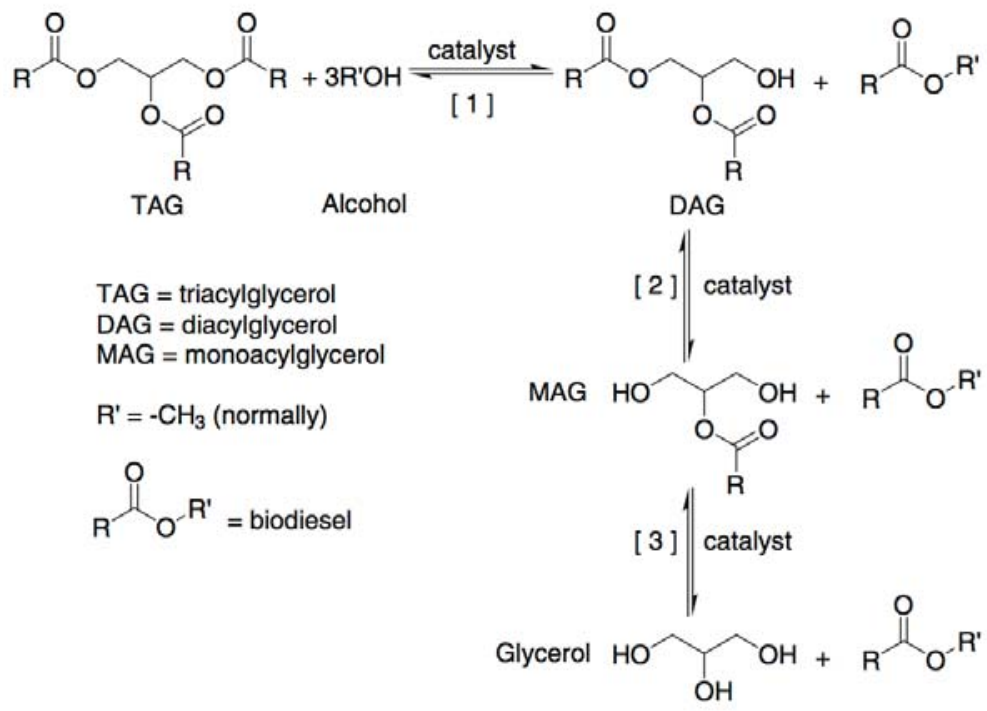

Figure 2.6: Ester bonds on TAGs are replaced with ester bonds between free fatty acids and methyl groups to form biodiesel as FAMEs (Moser, 2009) 


\section{Methods and Materials}

Pilot scale reactors are crucial to understanding the performance and efficiency of larger reactors used to grow algae for wastewater treatment and biofuel production. Six raceway ponds were used to examine media recycling and its effect on algal productivity and settling compared to productivity and settling of a larger wastewater pond system. In addition, these ponds were used to examine the effects of algal growth in different growth media. Lastly, the larger wastewater pond system was used to examine the variability of lipid extraction methods and a comparison of precision between the different methods. This chapter discusses the procedures for operation, maintenance, experimentation, and data analysis of the aforementioned experiments.

\subsection{Algae Ponds Location and Description}

During the experiments described in the following sections, two sets of ponds were compared to identify similarities in biomass productivity, settling efficiency, and nutrient removal between different sized pond reactors. The raceway algae ponds used during the course of this research were located at the San Luis Obispo Water Resource Recovery Facility (SLOWRRF) on the central coast of California. San Luis Obispo can be described as a cool Mediterranean climate experiencing yearly average highs of $20.5^{\circ} \mathrm{C}$ and average lows of $9.4^{\circ} \mathrm{C}$ with typical annual rainfall averages of $9 \mathrm{~cm}$ (WRCC, 2010). A typical year in San Luis Obispo sees 315 sunny days (VisitSLO, 2013). The ponds were installed adjacent to the primary clarifiers of the full-scale treatment plant, allowing access to primary effluent (Figure 3.1). 


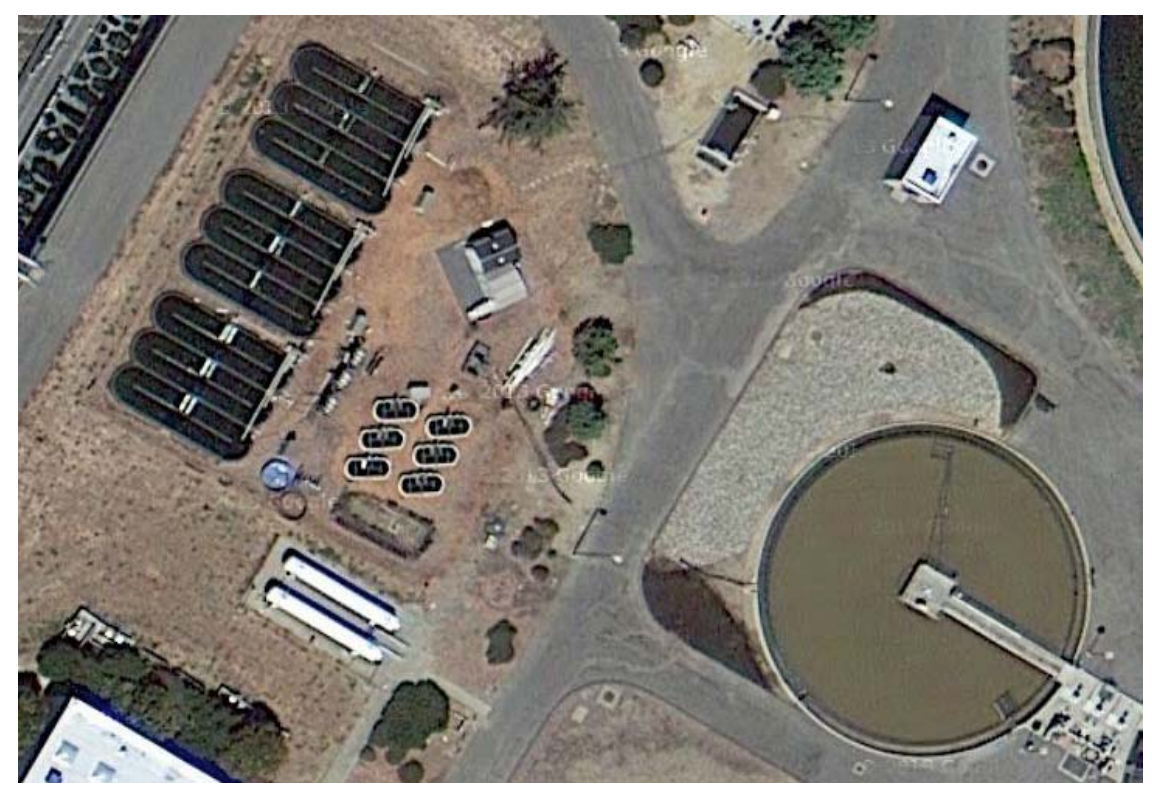

Figure 3.1: Aerial view of algae ponds (left) on-site near the primary clarifier (right)

\subsubsection{2- $\mathrm{m}^{2}$ Algae Ponds Description}

Six-raceway ponds (1,460 L with $4.2-\mathrm{m}^{2}$ water surface area) were maintained at 30.5-cm depth. During the early spring of 2014, the ponds were used for a wastewater media recycling experiment under continuous operating conditions. Tube settlers were used to separate the algae sludge and pond supernatant used in the second round of growth. Details regarding the media recycling experiment are given below in Section 3.2. During the summer of 2013, the ponds were used for a growth media comparison. The first experiment was a batch operation and compared algae growth on three different growth media: $100 \%$ wastewater media, $100 \%$ reclaimed water, and $50 \%$ wastewater $/ 50 \%$ reclaimed water. The second experiment compared algae growth on $100 \%$ wastewater and NCMA BG11 defined media. This experiment initiated in batch operation and transitioned to semi-continuous operation once batch operation reached stationary phase. Details regarding the growth media comparison experiments are given below in Section 3.3. 


\subsubsection{3- $\mathrm{m}^{2}$ Algae Ponds Description}

Nine-raceway ponds $\left(10,000 \mathrm{~L}\right.$ with $33-\mathrm{m}^{2}$ water surface area) were maintained at 30.5-cm depth. These ponds were divided into three sets of treatments: 3-day HRT Round 1, 3-day HRT Round 2, and 2-day HRT Round 1. Details about the pond treatments are described in Section 3.2. Additional information regarding the operational details for these ponds is referenced in Chang, 2014.

During the spring of 2014, three different lipid extraction methods were used to examine the lipid contents of the Algae Field Station (AFS) wastewater ponds. Samples were collected on April 10, 2014, April 28, 2014, and May 16, 2014. The extraction methods include: hexane/diethyl ether, chloroform/methanol, and fatty acid methyl esters (FAMEs) in-situ transesterification analysis. Details regarding the lipid extraction comparison are given below in Section 3.4.

\subsection{Media Recycling Experiment}

During this experiment, the ponds were configured in-series wherein the supernatant of settled pond water from the first set of ponds (Round 1) was recycled and re-distributed to a second set of ponds (Round 2). The purpose of this was to determine the feasibility of reusing water from one round of growth for growth of a second batch of algae on the original volume of water. More specifically, nutrient removal rates and algal growth rates were quantified and compared between Round 1 ponds and Round 2 ponds. Additionally, nutrient removal rates and algal growth rates were quantified and compared between two different hydraulic retention times, details of which will be discussed in

more depth in subsequent sections. Lastly, the performance of these $4.2-\mathrm{m}^{2}$ ponds was 
compared to the performance of the $33-\mathrm{m}^{2}$ ponds, previously described in Section 3.1.2, which operated simultaneously during this experiment.

\subsubsection{Facility Description for Media Recycling Experiment}

Two different hydraulic retention times (HRTs) were tested for the media recycling experiment. The 2-day HRT treatment set consisted of duplicates in each round of treatment; whereas, the 3-day HRT consisted of only a single pond per round of growth due to limited number of ponds. Figure 3.2 shows the pond and tube settler arrangement and the connection to the primary clarifier for this experiment.

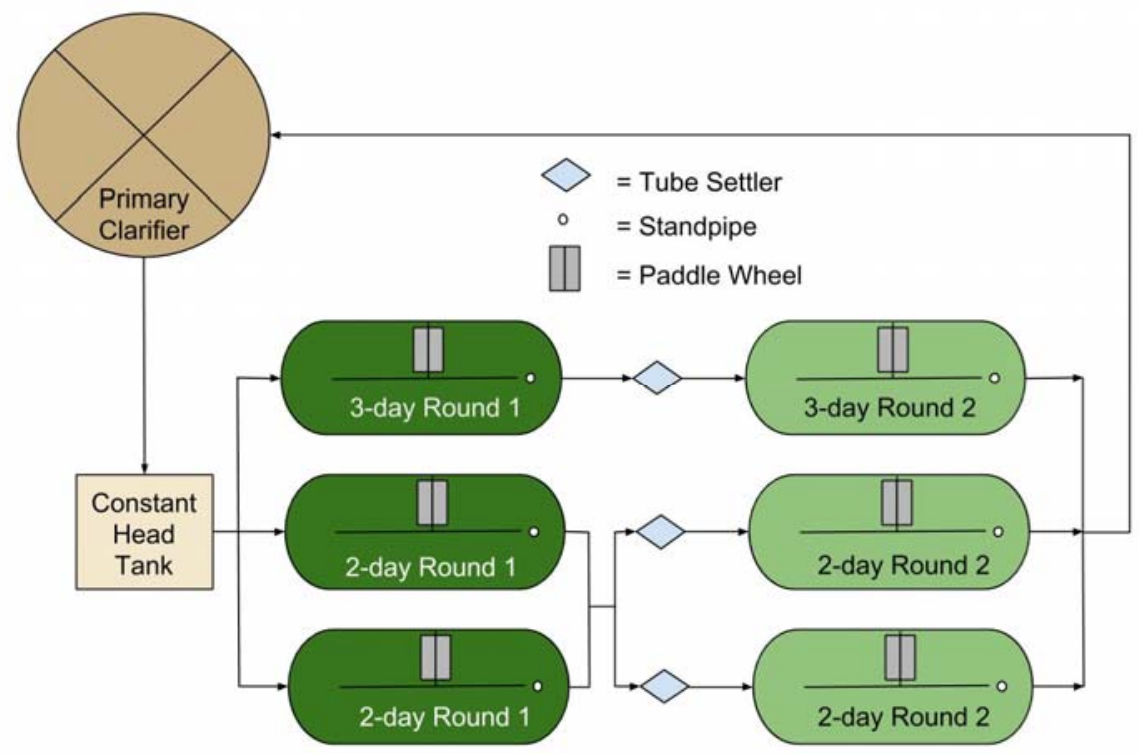

Figure 3.2: Facility layout and pond arrangement for the media recycling experiment

Primary clarifier effluent provided the original growth medium for the first round of ponds in both the 2-day and 3-day HRT treatments. This effluent was routed from the clarifier to a constant head tank (49-cm W x 64.5-cm H x 49-cm D) located on the north side of the ponds (Figure 3.3). A PVC pipe (2.54-cm I.D.) connected in the middle of the constant head tank transported the wastewater to the pump house; peristaltic pumps then distributed it to the first set of 2-day and 3-day HRT ponds, referred to as Round 1 ponds. 

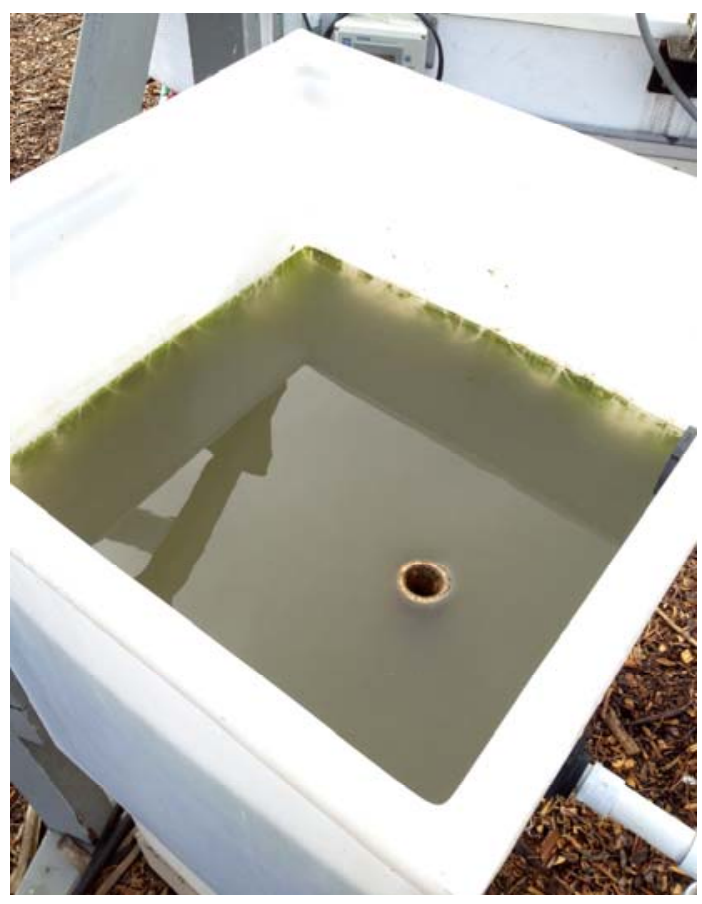

Figure 3.3: Primary treated wastewater constant head tank distribution system. Water level maintained at $48 \mathrm{~cm}$ (75\% of tank height) using standpipe. Flow rate held constant throughout the experiment

Standpipes installed in the Round 1 ponds controlled the depth of the ponds and distributed their effluent to a 3-inch diameter PVC manifold. Within the manifold, effluent from duplicate 2-day Round 1 ponds were combined to facilitate mixing before being pumped to tube settlers via peristaltic pumps (Figure 3.4). This manifold was unnecessary in the 3-day HRT treatment setup since the 3-day Round 1 treatment consisted of only one pond. 


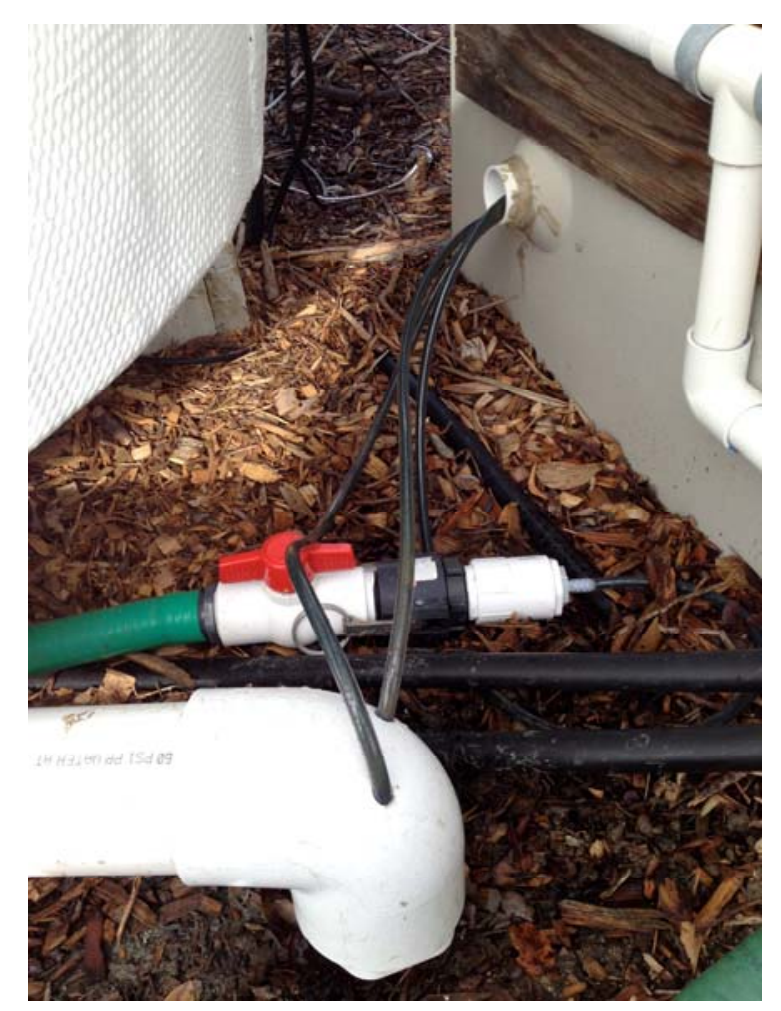

Figure 3.4: Effluent from both 2-day Round 1 ponds were mixed in a 3" PVC manifold connected to the drains of both ponds. This mixing was necessary so that the tube settlers received the same influent. The combined Round 1 effluent was pumped out of the PVC manifold using peristaltic pumps and tubing inserted into the end of the pipe. The pumps moved the Round 1 effluent to two tube settlers. Effluent from the 3-day Round 1 pond was collected in the green tube connected to the pond drain.

Variable frequency drives (VFD) controlled the paddle wheel speeds and operated at $7.4 \mathrm{rpm}$. Three trials were performed to determine how long the paddle wheel completed 5, 7, and 9 rotations and the results were averaged. Channel velocity was approximately $16.5 \mathrm{~cm} / \mathrm{s}$. Three trials were performed to determine how long it took for a floating object to travel across the $1.93 \mathrm{~m}$ long, straight section of a pond. The results were averaged.

Three Masterflex Digi-Staltic peristaltic pumps and one Masterflex analog peristaltic pump were located in the pump house north of Pond 1 (Figure 3.5). Masterflex Digi-Staltic dispensing pump system controller was used to control the flow rate of the three Digi-Staltic pumps. The analog pump was adjusted using a dial. 


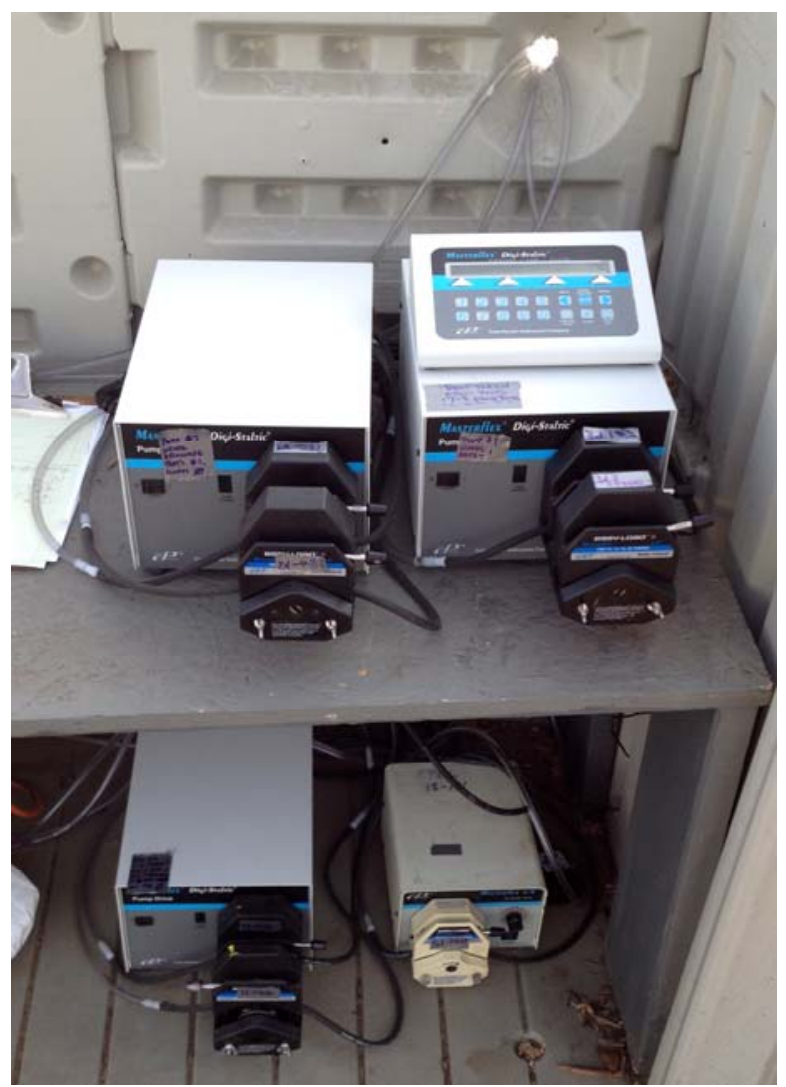

Figure 3.5: Peristaltic pumps in the pump house. The pumps on the top shelf pumped primary effluent to the Round 1 ponds. The pumps on the bottom shelf pumped Round 1 pond effluent to the tube settlers

YSI 5200A multiparameter continuous monitors installed on each pond monitored water quality parameters and a digital interface displayed data in real time from each sensor. Each YSI unit included a multi-sensor sonde that measured $\mathrm{pH}$, temperature, dissolved oxygen (DO), salinity, conductivity, and oxidation-reduction potential (ORP). Hourly data from these sensors was recorded and stored in a database onsite. AquaManager software generated time-series graphs for each parameter measured in the ponds.

When pond $\mathrm{pH}$ was greater than 7.9, an automated solenoid connected to the YSI unit opened and the ponds were sparged with $\mathrm{CO}_{2}$. The solenoids released $\mathrm{CO}_{2}$ to airstones, which sparged the ponds with micro-bubbles of gas that dissolved quickly to 
lower the $\mathrm{pH}$. Fifty-pound, pressurized $\mathrm{CO}_{2}$ cylinders supplied the gas to the solenoids on each pond.

Solids from the Round 1 pond effluent were allowed to settle in the tube settlers, described in more detail in the next section, and the supernatant from the tube settlers was distributed to Round 2 ponds by gravity (Figure 3.6).

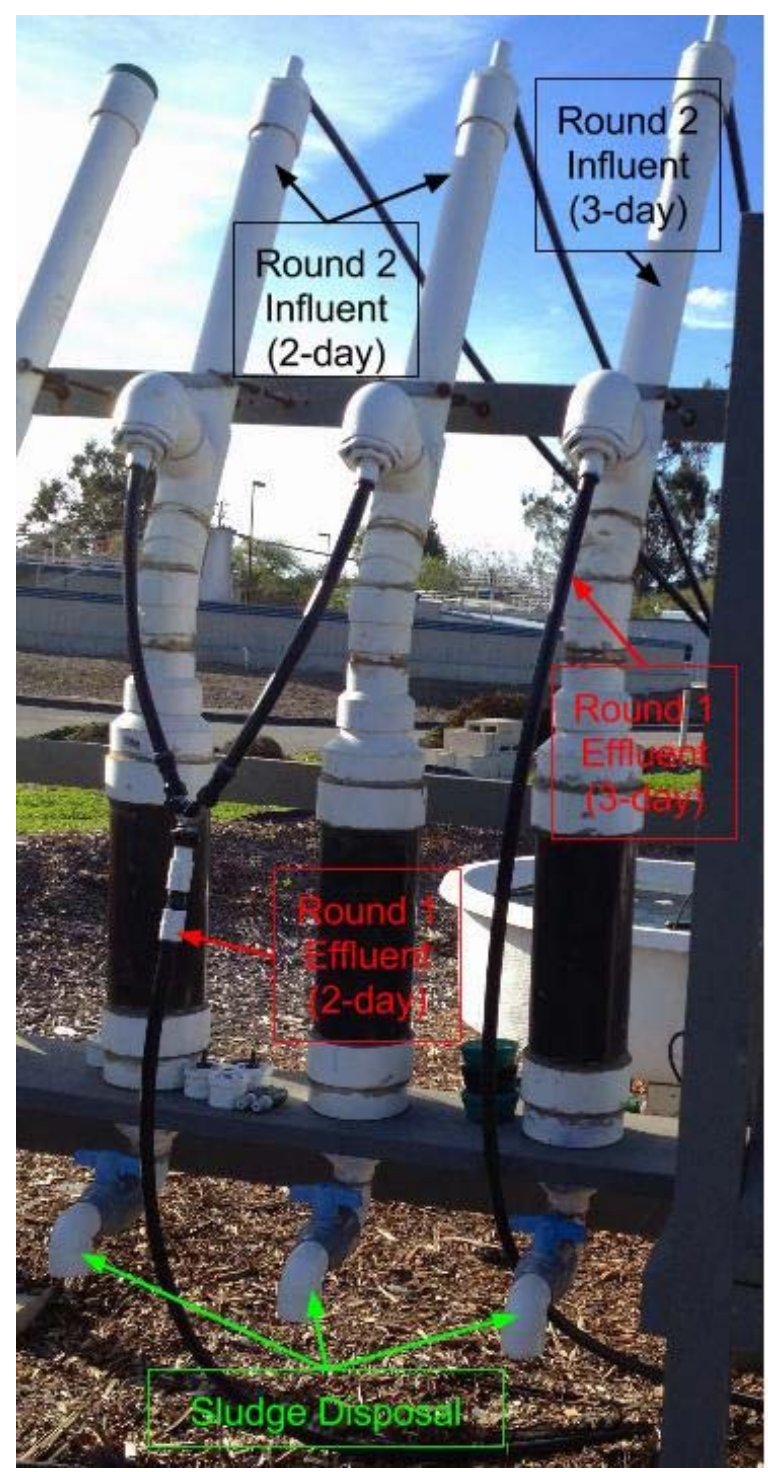

Figure 3.6: Tube settlers were positioned near the Round 2 ponds for convenience and minimal tubing 
Round 2 pond effluent water exited the ponds though a standpipe and flowed through an underground manifold to a disposal sump. Two float switches within the 1.5 $\mathrm{m}$ deep sump controlled the depth of disposed water. When the water level reached $1.4 \mathrm{~m}$ deep, the float switch turned on and a pump removed the water from the sump and directed it to the effluent weir of the primary clarifier. The pump turned off when the water level was $0.5 \mathrm{~m}$ deep. The sump was located within $10 \mathrm{~m}$ of the ponds. The use of the sump allowed the water to be further treated in the SLOWRRF.

In addition, the 3-day HRT treatment set consisted of single ponds in each round of treatment. The rounds of growth were the same setup as the 2-day HRT setup discussed above.

Pond maintenance described below was performed daily, Monday through Friday, unless otherwise noted. Daily maintenance included: influent flow rate and pond depth checks, sensor cleaning, YSI sensor calibration when necessary and checking $\mathrm{CO}_{2}$ tank pressure.

The influent volumetric flow rate for each pond was calculated by measuring the volume of influent entering the pond in a given period of time. The peristaltic pump speed was adjusted if the flow rate was not within $+/-10 \%$ of the desired flow rate. Water levels within the pond standpipes were checked to ensure pumps were operating fast enough to maintain a depth of $30.5 \mathrm{~cm}$. If a Round 1 pond standpipe was overflowing and not draining properly, the Round 2 pump speed was increased if this flowrate was too low or the Round 1 influent pump speed decreased if this flowrate was too high. Round 2 pond standpipes did not have this issue since these were connected directly to the disposal manifold. Peristaltic pump tubing was checked daily for any accumulation of 
debris from the ponds. Debris, such as wood chips and plastic shavings, were cleared from the lines by disconnecting the tubing from the pump and allowing the stream to flow into a bucket until the debris were dislodged and removed.

In addition to data collected by the YSI unit, a handheld $\mathrm{pH}$ meter (Oakton waterproof $\mathrm{pH} / \mathrm{mV} /{ }^{\circ} \mathrm{C} /{ }^{\circ} \mathrm{F}$ data meter 310 series, Oakton $\mathrm{pH}$ probe) was used daily to ensure correct calibration of the YSI $\mathrm{pH}$ sensor. Before measuring pond $\mathrm{pH}$, the Oakton $\mathrm{pH}$ meter was calibrated using a 3-point calibration ( $\mathrm{pH} 4,7$ and 10). Once calibrated, if simultaneous $\mathrm{pH}$ measurements from the handheld sensor and YSI sensor differed by more than 0.2 , the YSI $\mathrm{pH}$ sensor was recalibrated. After recalibration, the $\mathrm{pH} 7$ buffer was used to confirm the YSI sensor was working accurately.

Multi-sensor sondes were disassembled and cleaned daily. Probe guards were removed, sensors were rinsed, and biomass, insects, and debris were removed. After cleaning, the sondes were reassembled and returned to the respective pond.

Pond operators checked $\mathrm{CO}_{2}$ tank pressure daily. If the pressure was lower than $300 \mathrm{psi}$, the regulator was moved to a new tank. Line pressure was maintained at $35 \mathrm{psi}$. The accretion of algal biomass on the pond sidewalls was wiped off with a sponge and resuspended into the water.

\subsubsection{Tube Settler Layout}

In an effort to maximize new biomass growth in Round 2 ponds by decreasing algae concentration, algal biomass was removed from the recycled water before being used in Round 2 ponds. Biomass removal was accomplished by flowing Round 1 pond effluent through tube settlers before it was distributed to the Round 2 ponds. The tube settler layout incorporated three tube settlers. Influent lines connected to the tube settler 
at the upper portion of the tank allowed the algal biomass to settle downward and the supernatant to fill the upper portion of the tank. Once the supernatant reached the top of the tank, it was gravity fed to the Round 2 ponds via black irrigation tubing $(2.0-\mathrm{cm}$ I.D.).

Approximately three times per week sludge was removed from the tube settlers. To accomplish this, pond operators would manually open a 2" PVC ball valve at the bottom of the tube and drain the sludge into five-gallon buckets. The valve was left open until the water flow appeared transparent and free of biomass. Pond operators then poured the sludge into the disposal sump. Sludge removal prevented the accumulation of biomass that could be carried into the Round 2 ponds.

\subsubsection{Pond Operation}

The six raceways were inoculated on January 30, 2014 using the poly-culture from the 33- $\mathrm{m}^{2}$ AFS ponds located on-site, described previously in Section 3.1.2. Each pond was inoculated with a total of $12 \mathrm{~L}$ of culture. This total volume of culture consisted of $4 \mathrm{~L}$ from each of three different treatment AFS pond sets. The use of this poly-culture assured that the inoculum included algae that had previously adapted to a variety of growth conditions. The ponds were filled to $30.5-\mathrm{cm}$ depth using tap water. The water was not dechlorinated and the residual chlorination concentration was assumed to be less than $3 \mathrm{ppm}$.

Due to the continuous operation of the ponds for this experiment, influent was constantly added and effluent was constantly flowing over the standpipe. Peristaltic pumps controlled the influent flow rates for both Round 1 and Round 2, as described in 
Section 3.2.1. Volumetric flow rates and minimum/maximum thresholds for each HRT configuration are shown in Table 3.1.

Table 3.1: Target flow rate and acceptable ranges (+/-10\% of target) for pond influent

\begin{tabular}{cccc}
\hline HRT & $\begin{array}{c}\text { Target Flow } \\
\text { Rate }(\mathrm{mL} / \mathrm{min})\end{array}$ & $\begin{array}{c}\text { Minimum } \\
\text { Acceptable Flow } \\
\text { Rate }(\mathrm{mL} / \mathrm{min})\end{array}$ & $\begin{array}{c}\text { Maximum Acceptable } \\
\text { Flow Rate }(\mathrm{mL} / \mathrm{min})\end{array}$ \\
\hline 2-day & 507 & 456 & 557 \\
3-day & 338 & 304 & 372 \\
\hline
\end{tabular}

\subsubsection{Pond Sampling Procedure}

Grab samples were collected on Mondays and Thursdays between 8:15am and 9:30am for water quality analysis. Samples were collected on the western side of the ponds, downstream of the paddle wheel. The sample bottles were submerged upside down into the water to approximately half the depth of the pond. The bottles were then rotated right side up and filled completely until all air escaped before pulling the bottles straight out of the ponds. Each tube settler supernatant was sampled after pond sampling. A sample bottle was held beneath the end of each black irrigation tubes that fed each Round 2 ponds.

Samples of the tube settler supernatants, which were used as the Round 2 influents, were collected to for VSS analysis to determine the concentration of biomass that did not settle in the tube settler. Sample bottles were held beneath the black irrigation tubing that distributed the supernatant from the top of the tube settlers. Samples were brought to the laboratory for analysis at the California Polytechnic State University. 


\subsection{Growth Media Comparison Experiments}

During the first growth media comparison experiment, the ponds were configured as batch reactors wherein the ponds were inoculated with initial growth media and nutrients were not replenished during the duration of the experiment. The purpose of this was to quantify algal growth rates and nutrient removal rates using wastewater $(100 \%$ WW), reclaimed water $(100 \% \mathrm{RW})$, and a $1: 1 \mathrm{v} / \mathrm{v}$ mixture of wastewater and reclaimed water $(50 \% / 50 \% \mathrm{WW} / \mathrm{RW})$.

The purpose of this growth media comparison was to determine whether algae ponds have higher productivity and settling efficiency when grown on $100 \%$ wastewater, $100 \%$ reclaimed water, or a 50\%/50\% mixture wastewater and reclaimed water. Using a non-potable water source for algae ponds increases the feasibility of algal biofuel production. Lastly, the performance of these $4.2-\mathrm{m}^{2}$ ponds was compared to the performance of the $33-\mathrm{m}^{2}$ ponds, which operated simultaneously during this experiment.

During the second experiment, the ponds started as batch reactors and switched to semi-continuous operations once the initial growth curve reached the stationary phase. The purpose of this was to quantify algal growth rates and nutrient removal rates using wastewater and a defined growth media. The following sections describe the experimental details for both growth media comparison studies.

\subsubsection{Facility Description for $100 \% \mathrm{WW}$ vs. $100 \%$ RW vs. $50 \% / 50 \% \mathrm{WW} / \mathrm{RW}$ Experiment}

Duplicate ponds were filled with one of the three growth media used in this comparison study. Primary clarifier effluent from the SLOWRRF provided the original growth medium for the $100 \% \mathrm{WW}$ pond set and half of the growth medium for the 
$50 \% / 50 \% \mathrm{WW} / \mathrm{RW}$ pond set. Reclaimed water from the SLOWRRF provided the original growth medium for the $100 \%$ RW pond set. Details regarding the inoculation process are described below in Section 3.3.1. Figure 3.7 shows the growth media for each pond set prior to inoculation with the algae culture.

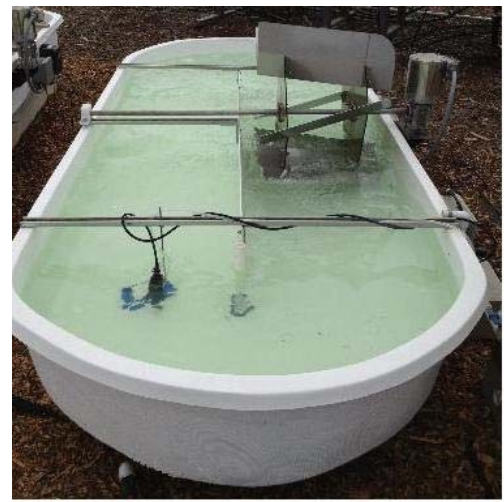

(A)

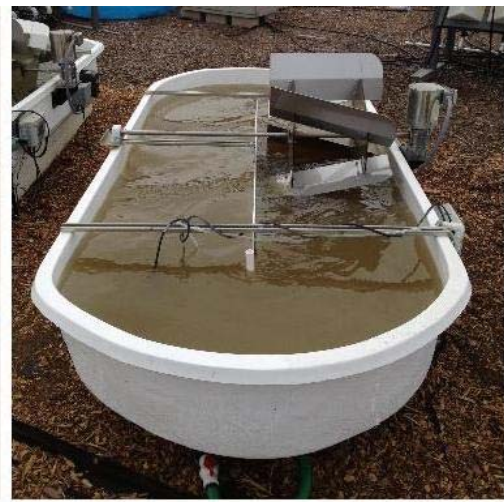

(B)

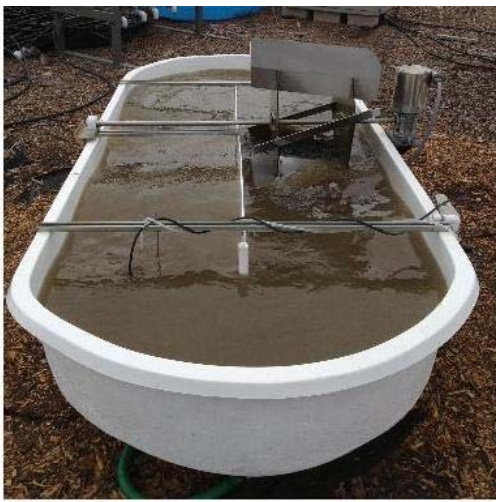

(C)

Figure 3.7: Growth media without algae inoculum: 100\% RW (A), 50\%/50\% WW/RW (B), 100\% WW (C)

Variable frequency drives (VFD) controlled the paddle wheel speeds and operated at $7.4 \mathrm{rpm}$. Three trials were performed to determine how long the paddle wheel completed 5, 7, and 9 rotations and the results were averaged. Channel velocity was approximately $16.5 \mathrm{~cm} / \mathrm{s}$. Three trials were performed to determine how long it took for a floating object to travel across the $1.93 \mathrm{~m}$ long, straight section of a pond. The results were averaged.

Details regarding the YSI multi-parameter monitoring boxes used for the duration of this experiment are above described in Section 3.2.1. When pond $\mathrm{pH}$ was greater than 7.9, an automated solenoid connected to the YSI unit opened and the ponds were sparged with $\mathrm{CO}_{2}$. The solenoids released $\mathrm{CO}_{2}$ to air-stones, which sparged the ponds with microbubbles of gas that dissolved quickly to lower the $\mathrm{pH}$. Fifty-pound, pressurized $\mathrm{CO}_{2}$ cylinders supplied the gas to the solenoids on each pond. 
Pond maintenance was performed two to three times a week for the duration of the experiment. Pond maintenance included: pond depth checks, sensor cleaning, YSI sensor calibration when necessary, and checking $\mathrm{CO}_{2}$ tank pressure.

After samples were collected, tap water was used to return the pond depth to $30.5 \mathrm{~cm}$ to account for evaporation loss. The $\mathrm{CO}_{2}$ tank pressure was confirmed to be higher than 300 psi. If the pressure was lower than $300 \mathrm{psi}$, the regulator was moved to a new tank. The line pressure was maintained at $35 \mathrm{psi}$. The accretion of algal biomass on the pond sidewalls was wiped off with a sponge and resuspended into the water. Multi-sensor sondes were disassembled and cleaned daily. Probe guards were removed, sensors were rinsed, and biomass, insects, and debris were removed. After cleaning, the sondes were reassembled and returned to the respective pond.

\subsubsection{Pond Operation for $100 \% W W$ vs. $100 \%$ RW vs. $50 / 50 \% \mathrm{WW} / \mathrm{RW}$}

\section{Experiment}

The six raceways were filled on June 23, 2013. A hose connected to the primary clarifier effluent was used to fill the wastewater ponds. A hose connected to the on-site reclaimed water was used to fill the reclaimed water ponds. All sensor probes were calibrated and placed in the ponds. YSI units were activated.

The ponds were inoculated on June 24, 2013 using the poly-culture from the Algae Field Station (AFS) ponds located on site. Each pond was inoculated with a total of $12 \mathrm{~L}$ of culture. This total volume of culture consisted of $4 \mathrm{~L}$ from each of three different treatment AFS pond sets. The use of this poly-culture assured that the inoculum included algae that had previously adapted to a variety of growth conditions. The ponds were filled to 30.5-cm depth using tap water. The water was not dechlorinated and the residual 
chlorination concentration was assumed to be less than $3 \mathrm{ppm}$. A description of the YSI unit is given above in Section 3.2.1 regarding the sensors used to collect data. The ponds were operated as batch growth reactors for the entirety of this experiment.

\subsubsection{Pond Sampling Procedure for $100 \% W W$ vs. $100 \%$ RW vs. $50 \% / 50 \%$} WW/RW Experiment

Grab samples were collected approximately twice a week between 8:30am and 9:30am for water quality analysis. Samples were collected on the western side of the ponds, downstream of the paddle wheel. The sample bottles were submerged upside down into the water to approximately half the depth of the pond. The bottles were then rotated right side up and filled completely until all air escaped before pulling the bottles straight out of the ponds. All samples were brought to the laboratory at Cal Poly to be analyzed.

\subsubsection{Facility Description for Wastewater vs. Defined Medium Experiment}

Triplicate ponds were filled with one of the two growth media used in this experiment. Primary clarifier effluent from the SLOWRRF provided the original growth medium for the $100 \% \mathrm{WW}$ triplicate pond set. A defined media was prepared in the other triplicate pond set using the NCMA BG11 growth media recipe. Figure 3.8 shows the growth media for each pond set after inoculation with the algae culture. Table 3.2 shows the final concentrations of each stock solution that comprised of the BG11 growth media in the ponds. Details regarding the inoculation process are described below in Section 3.3.5. 


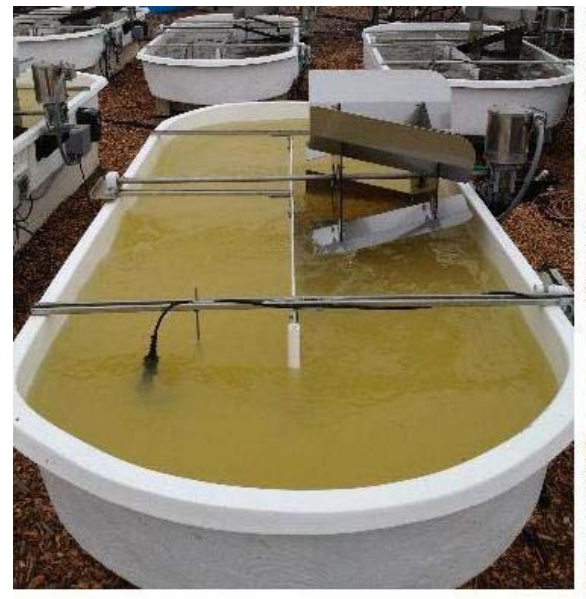

(A)

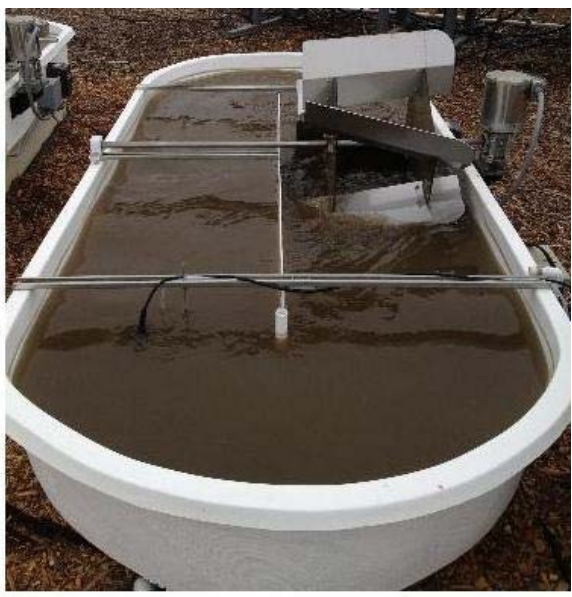

(B)

Figure 3.8: Growth media with algae inoculum: NCMA BG11 defined media (A), 100\% wastewater (B)

Table 3.2: Concentrations of each stock solution of NCMA BG11 recipe added to ponds

\begin{tabular}{clccc}
\hline $\begin{array}{c}\text { Stock Solution } \\
\text { ID }\end{array}$ & \multicolumn{1}{c}{ Compound Name } & Chemical Formula & Molecular Weight (g/mol) & $\begin{array}{c}\text { Concentration in } \\
\text { Final Medium (mg/L) }\end{array}$ \\
\hline 1 & Ammonium chloride & $\mathrm{NH}_{4} \mathrm{Cl}$ & 53.49 & 941.4 \\
2 & Dipotassium phosphate & $\mathrm{K}_{2} \mathrm{HPO}_{4}$ & 174.0 & 90.00 \\
3 & Magnesium sulfate heptahydrate & $\mathrm{MgSO}_{4} \cdot 7 \mathrm{H}_{2} \mathrm{O}$ & 246.5 & 75.00 \\
4 & Calcium chloride, dihydrate & $\mathrm{CaCl}_{2} \cdot 2 \mathrm{H}_{2} \mathrm{O}$ & 147.0 & 36.00 \\
5 & Citric acid & $\mathrm{C}_{6} \mathrm{H}_{8} \mathrm{O}_{7}$ & 192.1 & 6.000 \\
6 & Ferric ammonium citrate & $\mathrm{C}_{6} \mathrm{H}_{5+4 \mathrm{Y}} \mathrm{Fe}_{x} \mathrm{~N}_{\mathrm{y}} \mathrm{O}_{7}$ & 265.0 & 7.950 \\
7 & EDTA (dinatrium salt) & $\mathrm{Na}_{2} \mathrm{EDTA}_{2} \cdot 2 \mathrm{H}_{2} \mathrm{O}$ & 416.5 & 1.000 \\
8 & Sodium carbonate & $\mathrm{Na}_{2} \mathrm{CO}_{3}$ & 106.0 & 20.00 \\
\hline \multirow{5}{*}{ Trace Metal } & Moric acid & $\mathrm{H}_{3} \mathrm{BO}_{3}$ & 61.83 & 2.863 \\
Solution & Zinc sulfate heptahydrate & $\mathrm{MnSO}_{4} \cdot \mathrm{H}_{2} \mathrm{O}$ & 169.0 & 1.606 \\
& Copper (II) sulfate pentahydrate & $\mathrm{ZnSO}_{4} \cdot 7 \mathrm{H}_{2} \mathrm{O}$ & 287.6 & 0.2200 \\
& Ammonium molybdate dihydrate & $\mathrm{CuSO}_{4} \cdot 5 \mathrm{H}_{2} \mathrm{O}$ & 249.7 & 0.0424 \\
\hline
\end{tabular}

Variable frequency drives (VFD) controlled the paddle wheel speeds and operated at $7.4 \mathrm{rpm}$. Three trials were performed to determine how long the paddle wheel completed 5, 7, and 9 rotations and the results were averaged. Channel velocity was approximately $16.5 \mathrm{~cm} / \mathrm{s}$. Three trials were performed to determine how long it took for a floating object to travel across the $1.93 \mathrm{~m}$ long, straight section of a pond. The results were averaged. 
Details regarding the YSI multi-parameter monitoring boxes used for the duration of this experiment are above described in Section 3.2.1. When pond $\mathrm{pH}$ was greater than 7.9, an automated solenoid connected to the YSI unit opened and the ponds were sparged with $\mathrm{CO}_{2}$. The solenoids released $\mathrm{CO}_{2}$ to air-stones, which sparged the ponds with microbubbles of gas that dissolved quickly to lower the $\mathrm{pH}$. Fifty-pound, pressurized $\mathrm{CO}_{2}$ cylinders supplied the gas to the solenoids on each pond.

Pond maintenance was performed five to six times a week for the duration of the experiment. Pond maintenance included: pond depth checks, sensor cleaning, YSI sensor calibration when necessary, and checking $\mathrm{CO}_{2}$ tank pressure. After samples were collected, tap water was used to return the pond depth to $30.5 \mathrm{~cm}$ to account for evaporation loss. The $\mathrm{CO}_{2}$ tank pressure was confirmed to be higher than 300 psi. If the pressure was lower than $300 \mathrm{psi}$, the regulator was moved to a new tank. The line pressure was maintained at $35 \mathrm{psi}$. The accretion of algal biomass on the pond sidewalls was wiped off with a sponge and resuspended into the water. Multi-sensor sondes were disassembled and cleaned daily. Probe guards were removed, sensors were rinsed, and biomass, insects, and debris were removed. After cleaning, the sondes were reassembled and returned to the respective pond.

\subsubsection{Pond Operation for Wastewater vs. Defined Media Experiment}

The six raceways were filled on August 6, 2013. A hose connected to the primary clarifier effluent was used to fill the wastewater ponds. A hose connected to the tap water on-site at the SLOWRRF was used to fill the defined media ponds. NCMA BG11 growth media components were added to the defined media ponds to achieve to the 
concentrations previously listed in Table 3.2. All sensor probes were calibrated and placed in the ponds. YSI units were activated.

The ponds were inoculated on August 7, 2013 using the poly-culture from the Algae Field Station (AFS) ponds located on site. Each pond was inoculated with a total of $12 \mathrm{~L}$ of culture. This total volume of culture consisted of $4 \mathrm{~L}$ from each of three different treatment AFS pond sets. The use of this poly-culture assured that the inoculum included algae that had previously adapted to a variety of growth conditions. The ponds were filled to $30.5-\mathrm{cm}$ depth using tap water. The water was not dechlorinated and the residual chlorination concentration was assumed to be less than $3 \mathrm{ppm}$. A description of the YSI unit is given above in Section 3.2.1 regarding the sensors used to collect data.

The ponds were operated initially as batch reactors until the culture appeared to have entered a stationary phase on the growth curve. The wastewater pond set entered stationary phase first on August 19, 2013, starting the semi-continuous operation. The defined media pond set entered stationary phase on August 27, 2013, starting the semicontinuous operation. Semi-continuous operation simulated a 3-day HRT, which consisted of daily dilutions by disposing of $33 \%$ of the pond volume through a standpipe. A valve connected at the base of the standpipe was opened to lower the pond depth to $20.3 \mathrm{~cm}$. The pond effluent flowed through an underground manifold discharging into the disposal sump, as described in Section 3.2.1. The valve was closed and the pond depth was returned to $30.5-\mathrm{cm}$ depth by adding fresh media. The wastewater ponds received approximately $487 \mathrm{~L}$ of fresh primary clarifier effluent. The defined media ponds received approximately $487 \mathrm{~L}$ of tap water. Additional BG11 growth media components were added after each dilution in accordance to the concentrations listed in Table 3.2. 


\subsubsection{Pond Sampling Procedure for Wastewater vs. Defined Media Experiment}

Grab samples were collected approximately five to six times a week between 8:15am and 10:00am for pre-dilution samples and between 10:00am and 12:00pm for post-dilution samples. Samples were collected on the western side of the ponds, downstream of the paddle wheel. The sample bottles were submerged upside down into the water to approximately half the depth of the pond. The bottles were then rotated right side up and filled completely until all air escaped before pulling the bottles straight out of the ponds. All samples were brought to the laboratory at Cal Poly for water quality analyses.

\subsection{Water Analyses and Quality Control}

After the pond samples were brought to the laboratory, water quality tests were conducted to determine algae growth and nutrient concentrations. Table 3.3 outlines all the tests that were performed during the media recycling experiment. Table 3.4 and Table 3.5 outline all the tests that were performed during the growth media comparison experiments. All water quality tests were performed under the instruction of Standard Methods for the Examination of Water and Wastewater 1995, unless stated otherwise. 
Table 3.3: Water quality analyses performed for all samples for media recycling experiment

\begin{tabular}{cccccccccc}
\hline Sample & TSS & VSS & TSS & TSS & & & & \\
$(0-h r)$ & $(0-h r)$ & $(2-h r)$ & $(24-h r)$ & TAN & TKN & $\mathrm{NO}_{3}$ & $\mathrm{NO}_{2}$ \\
\hline Primary Clarifier Effluent & $\mathrm{x}$ & $\mathrm{x}$ & & & $\mathrm{x}$ & $\mathrm{x}$ & $\mathrm{x}$ & $\mathrm{x}$ \\
Pond 1 & $\mathrm{x}$ & $\mathrm{x}$ & $\mathrm{x}$ & $\mathrm{x}$ & $\mathrm{x}$ & $\mathrm{x}$ & $\mathrm{x}$ & $\mathrm{x}$ \\
Pond 2 & $\mathrm{x}$ & $\mathrm{x}$ & $\mathrm{x}$ & $\mathrm{x}$ & $\mathrm{x}$ & $\mathrm{x}$ & $\mathrm{x}$ & $\mathrm{x}$ \\
Pond 3 & $\mathrm{x}$ & $\mathrm{x}$ & $\mathrm{x}$ & $\mathrm{x}$ & $\mathrm{x}$ & $\mathrm{x}$ & $\mathrm{x}$ & $\mathrm{x}$ \\
Pond 4 & $\mathrm{x}$ & $\mathrm{x}$ & $\mathrm{x}$ & $\mathrm{x}$ & $\mathrm{x}$ & $\mathrm{x}$ & $\mathrm{x}$ & $\mathrm{x}$ \\
Pond 5 & $\mathrm{x}$ & $\mathrm{x}$ & $\mathrm{x}$ & $\mathrm{x}$ & $\mathrm{x}$ & $\mathrm{x}$ & $\mathrm{x}$ & $\mathrm{x}$ \\
Pond 6 & $\mathrm{x}$ & $\mathrm{x}$ & $\mathrm{x}$ & $\mathrm{x}$ & $\mathrm{x}$ & $\mathrm{x}$ & $\mathrm{x}$ & $\mathrm{x}$ \\
Pond 4 Influent & $\mathrm{x}$ & $\mathrm{x}$ & & & & & & \\
Pond 5 Influent & $\mathrm{x}$ & $\mathrm{x}$ & & & & & & \\
Pond 6 Influent & $\mathrm{x}$ & $\mathrm{x}$ & & & & & & \\
\hline
\end{tabular}

Table 3.4: Water quality analyses performed for all samples for growth media comparison experiment (June 24, 2013 - July 15, 2013)

\begin{tabular}{cccccccccc}
\hline & TSS & VSS & TSS & TSS & & & & \\
Sample & $(0-h r)$ & $(0-h r)$ & $(2-h r)$ & $(24-h r)$ & TAN & $\mathrm{NO}_{3}$ & $\mathrm{NO}_{2}$ & DRP \\
\hline Pond 1 & $\mathrm{x}$ & $\mathrm{x}$ & $\mathrm{x}$ & $\mathrm{x}$ & $\mathrm{x}$ & $\mathrm{x}$ & $\mathrm{x}$ & $\mathrm{x}$ \\
Pond 2 & $\mathrm{x}$ & $\mathrm{x}$ & $\mathrm{x}$ & $\mathrm{x}$ & $\mathrm{x}$ & $\mathrm{x}$ & $\mathrm{x}$ & $\mathrm{x}$ \\
Pond 3 & $\mathrm{x}$ & $\mathrm{x}$ & $\mathrm{x}$ & $\mathrm{x}$ & $\mathrm{x}$ & $\mathrm{x}$ & $\mathrm{x}$ & $\mathrm{x}$ \\
Pond 4 & $\mathrm{x}$ & $\mathrm{x}$ & $\mathrm{x}$ & $\mathrm{x}$ & $\mathrm{x}$ & $\mathrm{x}$ & $\mathrm{x}$ & $\mathrm{x}$ \\
Pond 5 & $\mathrm{x}$ & $\mathrm{x}$ & $\mathrm{x}$ & $\mathrm{x}$ & $\mathrm{x}$ & $\mathrm{x}$ & $\mathrm{x}$ & $\mathrm{x}$ \\
Pond 6 & $\mathrm{x}$ & $\mathrm{x}$ & $\mathrm{x}$ & $\mathrm{x}$ & $\mathrm{x}$ & $\mathrm{x}$ & $\mathrm{x}$ & $\mathrm{x}$ \\
\hline
\end{tabular}

Table 3.5: Water quality analyses performed for all samples for growth media comparison experiment (August 7, 2013 - September 8, 2013)

\begin{tabular}{cccccc}
\hline & TSS & VSS & TSS & TSS & \\
Sample & $(0-h r)$ & $(0-h r)$ & $(2-h r)$ & $(24-h r)$ & TAN \\
\hline Pond 1 & $\mathrm{x}$ & $\mathrm{x}$ & $\mathrm{x}$ & $\mathrm{x}$ & $\mathrm{x}$ \\
Pond 2 & $\mathrm{x}$ & $\mathrm{x}$ & $\mathrm{x}$ & $\mathrm{x}$ & $\mathrm{x}$ \\
Pond 3 & $\mathrm{x}$ & $\mathrm{x}$ & $\mathrm{x}$ & $\mathrm{x}$ & $\mathrm{x}$ \\
Pond 4 & $\mathrm{x}$ & $\mathrm{x}$ & $\mathrm{x}$ & $\mathrm{x}$ & $\mathrm{x}$ \\
Pond 5 & $\mathrm{x}$ & $\mathrm{x}$ & $\mathrm{x}$ & $\mathrm{x}$ & $\mathrm{x}$ \\
Pond 6 & $\mathrm{x}$ & $\mathrm{x}$ & $\mathrm{x}$ & $\mathrm{x}$ & $\mathrm{x}$ \\
\hline
\end{tabular}


All water quality tests included one or more of the following quality control checks: blank, matrix spike, split, and standard check. No matrix spikes were run in TSS and VSS analyses for all experiments. For the media recycling experiment, 24-hr TSS was only performed once a week, while all other tests were run twice a week. For the growth media experiments, TSS and VSS tests were run five to six times a week, while all other tests were run at least once a week.

Sample dilutions were prepared using deionized (DI) water if the pond concentrations exceeded the test detection limit or the highest concentration of the standard calibration curve. Reverse osmosis (RO) water was used for dilutions in the BOD test. DI water was filtered through a Millipore Milli-Q unit; RO was filtered through a Millipore Elix5 unit. Graduate students or research supervisors were responsible for the preparation of all reagents and stock solutions.

\subsubsection{Suspended Solids Testing}

This section discusses the different suspended solids analysis performed on samples during the media recycling and growth media comparison studies. During the media recycling study, duplicates of all samples were analyzed for all suspended solids tests and the resulted were averaged for each sample. During the growth media comparison study, one sample in each analytical batch was tested in triplicate and all other samples in the batch were tested as single replicates. The triplicate set was averaged and given as the final result for that sample. Mass measurements were recorded using a Mettler Toledo AG245 balance set to show $0.00001 \mathrm{~g}$. All samples were vigorously shaken in the sample bottles before aliquots were taken for TSS testing or poured into the 
Imhoff cones. The vigorous shaking was necessary to homogenize the samples to increase the precision of the water quality analyses.

\subsubsection{Total Suspended Solids}

Total suspended solids (TSS) analysis was performed in accordance with APHA Method 2540 D. Glass fiber filters (Fisherbrand G4 filters, Cat No.: 09-804-42C, $1.2 \mu \mathrm{m}$ nominal pore size) used for this analysis were pretreated before the test was performed by rinsing each filter with DI water over a vacuum pump and placing the filters in a $550^{\circ} \mathrm{C}$ muffle furnace (Fisherbrand Isotemp oven, Model No. 550-58) for 15 minutes. This pretreatment process was performed to reduce error in mass measurements by removing debris and oils on the filter from the manufacturer before filters were used for analysis. When the filters were not being dried in the oven or muffle furnace, they were stored in desiccators that contained color-indicating Acros Organics Drierite desiccant. Desiccant was recharged when the blue granules turned pink by drying the desiccant at $218^{\circ} \mathrm{C}$ for one hour.

The filters were placed on aluminum trays (Fisherbrand, $43 \mathrm{~mm}$ diameter), which were labeled and used to manage filter identification. To remove moisture from the filters, all samples were dried in a $105^{\circ} \mathrm{C}$ gravity convection oven (VWR Symphony, Part No. 414005-110) for a minimum of two hours. Filters were removed from the oven and placed in a desiccator to cool to room temperature prior to recording the final TSS weight.

\subsubsection{Volatile Suspended Solids}

Volatile suspended solids (VSS) analysis was performed in accordance to APHA Method 2540 E. After the final TSS weight was recorded, the filters were placed in the 
$550^{\circ} \mathrm{C}$ muffle furnace for 15 minutes. Filters were returned to a desiccator to be cooled to room temperature prior to recording the final VSS weight.

\subsubsection{Imhoff Cone Settling}

Settling efficiency of pond samples were tested weekly using laboratory Imhoff cones. An Imhoff cone was filled with $1 \mathrm{~L}$ of pond sample and placed on a vertical stand to allow algae to settle undisturbed. Samples from the Imhoff cones were collected after the algae settled for 2 hours and 24 hours. Prior to sampling, the cone was twisted clockwise and counterclockwise several times to loosen any algal biomass that attached to the side of cone and the cone was left to settle for an additional five minutes. Each Imhoff cone was sampled using a $50-\mathrm{mL}$ pipette to collect $150 \mathrm{~mL}$ of supernatant. To avoid collecting any biomass floating on the surface or that settled to the bottom of the cone, the tip of the pipette was submerged $3-5 \mathrm{~cm}$ below the supernatant surface.

\subsubsection{Nitrogen Determination}

This section discusses the different nitrogen analyses performed for each experiment. For the media recycling experiment, the following tests were performed: nitrate, nitrite, total ammonia, and total Kjeldahl nitrogen (TKN). Standard calibration curves were used to correlate the analytical signals for the nitrate, nitrite, and total ammonia tests into concentrations. Concentrations for all nitrogen tests were reported as $\mathrm{mg} / \mathrm{L}$ as $\mathrm{N}$.

During both the media recycling experiment and the growth media comparison experiment, one sample in each analytical batch was tested in triplicate and all other samples in the batch were tested as single replicates. The triplicate set was averaged and given as the final result for that sample. 


\subsubsection{Nitrate Determination}

Nitrate analysis was performed in accordance with APHA Standard Methods 1995 sections 4500-NO3- A and D. The apparatuses used for this test included a nitrate ion selective electrode (Orion, Model RO1-14563) and a $\mathrm{pH} /$ ion analyzer meter (Corning, Model 355). The low-level calibration curve required for this test was prepared from various dilutions of a $100-\mathrm{mg} / \mathrm{L}-\mathrm{N}$ stock solution of sodium nitrate. This stock solution was prepared from a ten-fold dilution of a 1000-mg/L stock solution of sodium nitrate. Interference Suppression Solution (ISS) was added to the standards and the pond samples to minimize the interference in electrode readings caused by ions in the samples, such as nitrite, phosphate, carbonate, and bicarbonate. ISS was prepared using the Orion preparation procedure, discussed in Appendix A. A 150-mL beaker contained $100 \mathrm{~mL}$ of DI water and $11.1 \mathrm{~mL}$ of ISS. The calibration curve was generated by recording the $\mathrm{mV}$ readings after adding known volumes of $100-\mathrm{mg} / \mathrm{L}$ stock solution in increments to the $150-\mathrm{mL}$ beaker.

Before analyzing a pond sample, sample dilutions were prepared as needed so $\mathrm{mV}$ readings were below the maximum point on the calibration curve. Dilutions were prepared in 50-mL volumetric flasks, shaken, and then transferred to $100-\mathrm{mL}$ beakers. Magnetic stir bars were placed in each beaker to keep the sample well mixed and 5.5-mL of ISS was added to the $50-\mathrm{mL}$ of diluted sample. The electrode was placed in the beaker and $\mathrm{mV}$ readings were recorded once two consecutive $\mathrm{mV}$ readings were within $0.01 \mathrm{mV}$

of each other. The nitrate concentrations were correlated from the $\mathrm{mV}$ readings using the calibration curve. 


\subsubsection{Nitrite Determination}

Nitrite analysis was performed in accordance with APHA Standard Methods 1995 sections $4500-\mathrm{NO} 2$ A \& B. The apparatus used for this test was a Shimadzu UV-1700 PharmaSpec spectrophotometer, which was set at a 543-nm wavelength. The calibration curve required for this test was prepared from various dilutions of a $250 \mathrm{mg} / \mathrm{L}-\mathrm{N}$ stock solution of sodium nitrite. This colorimetric analysis required that all samples were filtered through $0.45-\mu \mathrm{m}$ mixed cellulose ester membrane filters (Fisherbrand Cat No. 09719-2E) to remove particles in the sample that would interfere with the absorbance measurements. The coloring reagent used in this analysis was prepared with $85 \%$ phosphoric acid, sulfanilamide, and N-(1-napthyl)-ethylenediamine.

If nitrite concentrations in the ponds were higher than the maximum of the calibration curve, dilutions were prepared using $25-\mathrm{mL}$ volumetric flasks. Samples were then transferred to $40-\mathrm{mL}$ plastic snap-top vials and $1 \mathrm{~mL}$ of coloring reagent was added to each vial. This solution reacted for at least 15 minutes before being analyzed in the spectrophotometer. An aliquot of each reacted sample was added to a $10-\mathrm{mm}$ path length cuvette (PLASTIBRAND, Cat No. 759076D) and used to rinse the inside of the cuvette to prevent dilution from any residual water in the cuvette. An additional aliquot of sample was added to the rinsed cuvette and inserted into the spectrophotometer to measure the absorbance of the sample. Absorbance values were not recorded until the values were stabilized by not fluctuating for at least 10 seconds. The nitrite concentrations were correlated from the absorbance values using the calibration curve. 


\subsubsection{Total Ammonia Determination}

Total ammonia analysis was performed in accordance with APHA Methods 4500NH3 A and D. The apparatuses used for this test included an ammonia selective electrode (Thermo Scientific, RS1-12618) and a pH/ion analyzer (Corning Model 355) meter. The calibration curve required for this test was prepared from various dilutions of a 2500 $\mathrm{mg} / \mathrm{L}$ stock solution of ammonium chloride. In the beginning of the analysis, each sample was vigorously shaken in the bottle and poured into a $150-\mathrm{mL}$ beaker, which was stirred with a magnetic stir bar to keep the sample homogenized. Drops of sodium hydroxide were added to the pond samples until the $\mathrm{pH}$ exceeded 11 before recording the electrode reading. Electrode readings were recorded once two consecutive $\mathrm{mV}$ readings were within $0.3 \mathrm{mV}$ of each other. An average of the two readings was recorded as the final result. Total ammonia nitrogen (TAN) concentrations were reported for this analysis, which includes $\mathrm{NH}_{3}$ and $\mathrm{NH}_{4}$. TAN concentrations were correlated from the $\mathrm{mV}$ readings using the calibration curve.

\subsubsection{Total Kjeldahl Nitrogen Determination}

Total Kjeldahl Nitrogen (TKN) analysis was performed in accordance with APHA Standard Methods 1995 4500-NORG B for only the media recycling experiment. The main apparatus used for this analysis was an 18-burner combination digestiondistillation fume hood (Labconoco, No. 2117803). The first stage of the TKN analysis was digestion wherein the samples were boiled with a digestion agent (sulfuric acid, copper sulfate, potassium sulfate) until 30 minutes after 800 -mL Kjeldahl roundbottomed flasks began to fill with white vapor. The last stage of the analysis was distillation wherein the digested samples were diluted, and a concentrated solution of 
sodium hydroxide and sodium thiosulfate was added. Caution was taken during this stage to prevent a violent acid-base reaction. The flasks were placed in the distillation apparatus to be mixed and boiled. The distillation process was terminated once a minimum of $200 \mathrm{~mL}$ of ammonia distillate had been captured in the boric acid indicator solution. Acid was titrated into each sample, changing the color from green to purple. The volume of acid used for this titration was correlated to the concentration of TKN within each sample.

\subsubsection{Phosphorus Determination}

This section discusses the phosphorus analysis performed for the first growth media experiment. No phosphorus analysis was performed for the second growth media experiment due to limited laboratory assistance. No phosphorus analysis was performed for the media recycling experiment because the primary focus was on the evolution of nitrogen species when the media is used in a second round of growth. Standard calibration curve was used to correlate the analytical signals for the dissolved reactive test into concentrations. Concentrations for this test were reported as $\mathrm{mg} / \mathrm{L}$ as $\mathrm{P}$.

During both the media recycling experiment and the growth media comparison experiment, one sample in each analytical batch was tested in triplicate and all other samples in the batch were tested as single replicates. The triplicate set was averaged and given as the final result for that sample.

\subsection{Lipid Determination Method Comparison}

Three different lipid determination methods were performed on the same algal biomass to compare the results and efficiency of each method. Samples were collected from the $33-\mathrm{m}^{2}$ wastewater ponds described in Section 3.1.2 on three separate days to 
compare the lipid determination over time. The sampling dates include: April 10, 2014, April 28, 2014, and May 16, 2014. The methods used for lipid determination each used different solvents and processes to separate the lipid content from the remaining biomass.

The hexane-ether extraction and the chloroform-methanol extraction methods used an Accelerated Solvent Extractor (ASE). Lipids and other components soluble in an organic solvents mixture were extracted from algal biomass using an automated process. Both methods consisted of phase separations to remove the non-lipid fraction of extract solution from the lipid fraction. Final lipid content was determined by gravimetric analysis for both extraction methods. These methods focus on the extractable lipids that can be used for biofuel processes.

The fatty acid methyl esters (FAMEs) quantification method accessed all fatty acids in the biomass by transesterifying lipids to FAMEs. This method identified and quantified all fatty acids as FAMEs in algal biomass (Laurens, et al. 2012). This process reflects an accurate potential for biofuels from algal biomass by quantifying FAMEs relevant to biofuel production (Appendix D). Unlike the aforementioned methods, FAMEs quantification did not require extraction. Instead, the transesterification reaction occurred in situ within the biomass matrix (Laurens, et al. 2012).

\subsubsection{Algal Biomass Collection, Centrifugation, and Lyophilization}

Samples were collected from the $33-\mathrm{m}^{2}$ wastewater ponds described in Section 3.1.2. Ponds analyzed during this lipid extraction method comparison included the 3-day Round 1 pond set (Ponds 4, 5, 6) and the 3-day Round 2 pond set (Ponds 1, 2, 3). Sample bottles were submerged into the water to collect suspended biomass. Samples were spun at 5,500 rpm for 10 minutes using a swing bucket centrifuge (Thermo Scientific IEC 
MultiRF). After centrifugation, the supernatant was disposed and the algal biomass in the bottle was placed in the freezer overnight. Frozen biomass was lyophilized for at least 48 hours at $-54^{\circ} \mathrm{C}$ and $0.12 \mathrm{mBar}$ using a freeze-drier (Labconco FreeZone 2.5) to remove all moisture from the biomass. A thick glass stir rod was used to ground the algal biomass into fine powder. The ground algal biomass was transferred to 50-mL Falcon conical centrifuge tubes. The tubes were capped and stored in the freezer until needed for lipid extraction.

\subsubsection{Hexane-Ether Extraction}

Hexane-ether lipid extraction method was performed in accordance with the Total Lipid Determination Using the Dionex ASE 350 laboratory analytical procedure provided by Arizona State University (Appendix B). Known masses of ground, freeze-dried algal biomass (approximately $150 \mathrm{mg}$ ) from the $33-\mathrm{m}^{2}$ wastewater ponds were added into 5mL stainless steel extraction cells. Diatomaceous earth (Dionex ASE Prep DE) was used to fill the empty space in each cell, as recommended by Thermo Scientific technicians. The cells were loaded onto a Thermo Scientific Dionex Accelerated Solvent Extractor (ASE) 350. One sample in each extraction batch was tested in triplicate and all other samples in the batch were tested as single replicates. The triplicate set was averaged and given as the final result for that sample. This method of extraction using the ASE required one extraction using 9:1 v/v methanol/dimethyl sulfoxide (DMSO). After this extraction was complete, the method required two extractions using 1:1 v/v hexanediethyl ether. The final extracts for each biomass sample were dispensed into 60-mL vials, which were removed from the ASE to be further processed under a fume hood. 
Approximately $15 \mathrm{~mL}$ of DI water was added to each vial. Vials were spun at 1,000 rpm for 10 minutes using a swing bucket centrifuge (Thermo Scientific Sorvall Legend XTR). Phases in the sample separated into two layers: an upper nonpolar, lipophilic solvent layer containing lipids, and a lower polar aqueous layer. Figure 3.9 shows the phase separation in the 60 -vials after centrifugation.

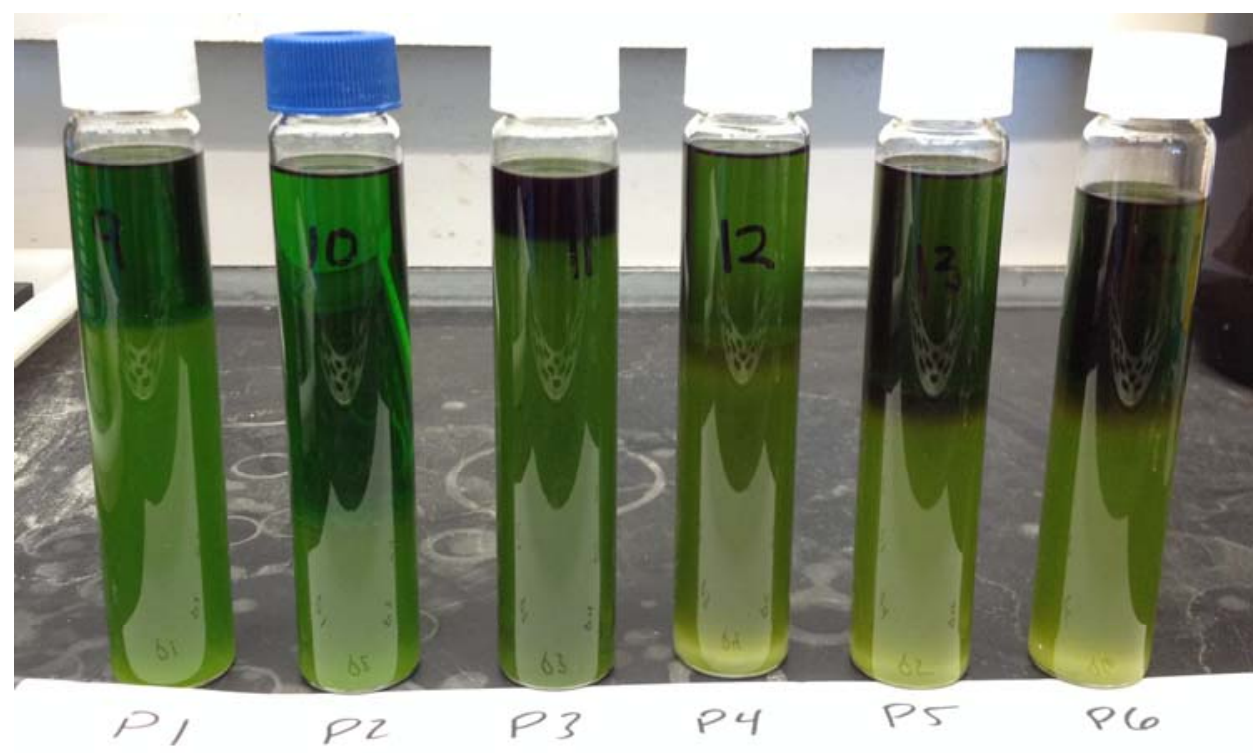

Figure 3.9: 60-mL vials containing extract after centrifuging. Hexane-ether extracts varied in appearance due to the different algal biomass conditions in each pond.

The upper layer was transferred into pre-weighed 40 -mL vials using Pasteur pipettes and caution was taken to not transfer any contents from the lower layer. Approximately $3 \mathrm{~mL}$ of hexane was added to each vial, then the vials were inverted, and centrifuged again for additional separation. The upper layer was transferred into the respective 40 -mL vial. This process was repeated once more. After the final transfer, approximately $1-2 \mathrm{~mL}$ of the upper layer remained in the $60-\mathrm{mL}$ vial due to the difficulty of removing this volume without removing part of the lower layer with it. Lipid content 
in this neglected volume of solvent was not included in the final mass, which may be a reason behind the large relative standard error between the triplicate sets.

After the entire upper solvent layer was transferred, the $40-\mathrm{mL}$ vials were dried under an evaporator (Organomation N-EVAP 112) using nitrogen gas. The water bath for the evaporator was set to $30^{\circ} \mathrm{C}$ to accelerate the evaporation process. Lipid content was seen as a dried residue on the bottom portion of each vial (Figure 3.10).

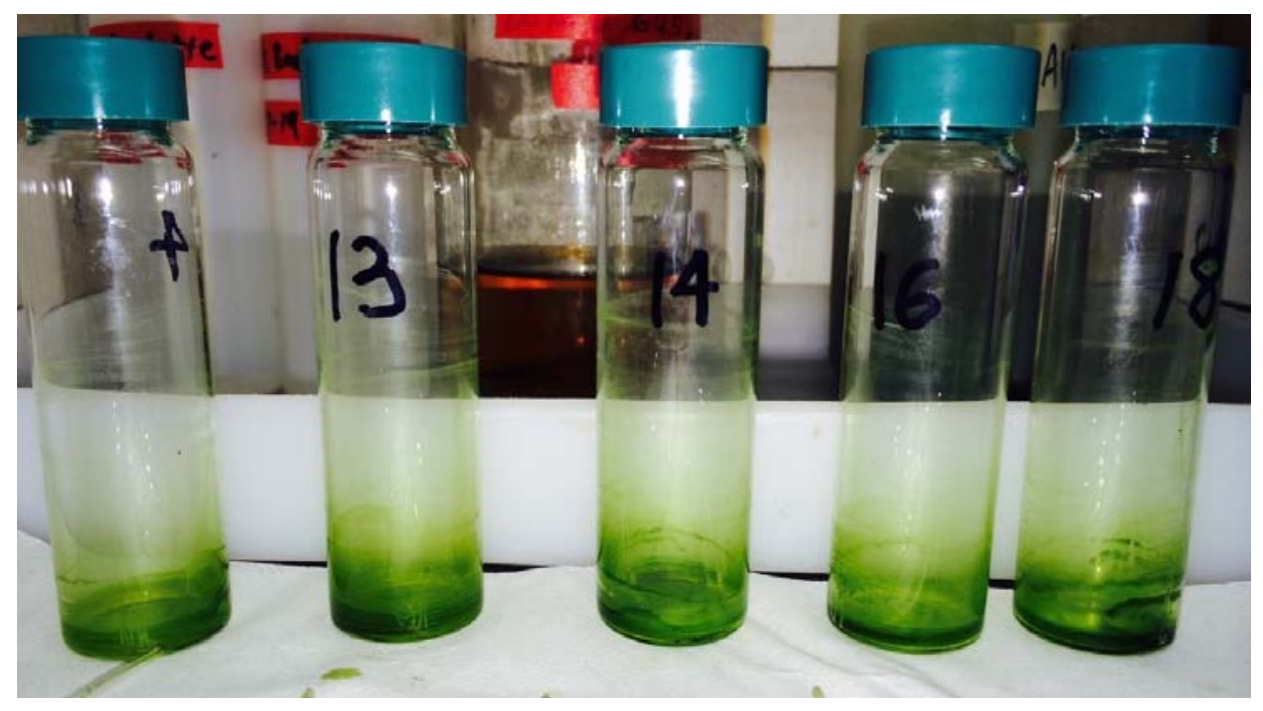

Figure 3.10: Lipid content was a dried residue in the vials after solvent was evaporated.

Once dried, the final mass of the vial was recorded. The mass of the lipid content was equivalent to the difference between final and initial vial masses. Total lipid content percentage was calculated as follows:

$\%$ Total Lipid $=\frac{(\text { weight of vial and lipids })-(\text { weight of vial })}{\text { weight of biomass sample }} * 100$ 


\subsubsection{Chloroform-Methanol Extraction}

The chloroform-methanol lipid extraction method was performed in accordance with the High-Throughput Lipid Determination for Bulk Algae Material: the Dionex and Phase Separation laboratory analytical procedure provided by Cellana, Inc. (Appendix C). Known masses of ground, freeze-dried algal biomass (approximately $80 \mathrm{mg}$ ) from the $33-\mathrm{m}^{2}$ wastewater ponds were added into $5-\mathrm{mL}$ stainless steel extraction cells. Dionex ASE Prep DE was added to each cell. Cells were loaded onto the ASE. One sample in each extraction batch was tested in triplicate and all other samples in the batch were tested as single replicates. The triplicate set was averaged and given as the final result for that sample. This method of extraction using the ASE required three extractions using 0.35:0.65 v/v chloroform/methanol. The final extracts for each biomass sample were dispensed into 60-mL vials, which were removed from the ASE to be further processed under a fume hood (Figure 3.11). Color variation between extracts was due to the variations in algal cultures in the ponds.

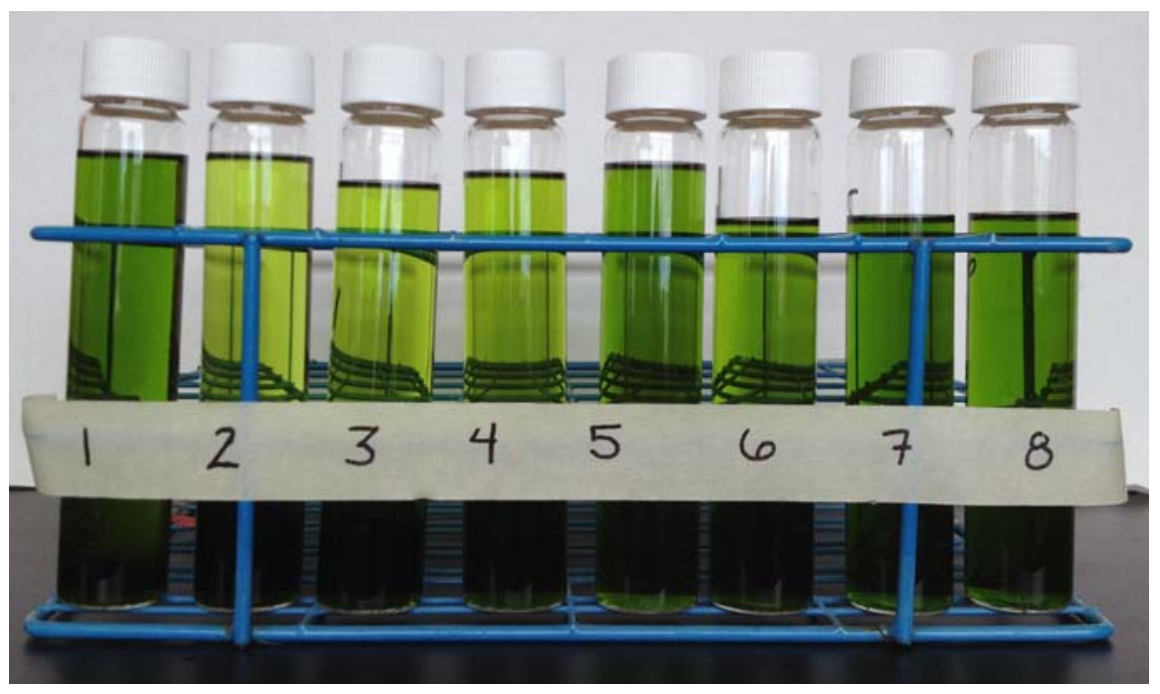

Figure 3.11: $60-\mathrm{mL}$ vials containing lipid extract from ASE. Different concentrations of extract in each vial were most likely caused by variability in extraction process using the ASE. Biomass for Pond 6 (Vials 6, 7, and 8) was tested in triplicate for this analytical batch. 
DI water and additional chloroform were added to each vial based on the extract volume to provide more volume for the phase separation. The volume of water and chloroform added was calculated as follows:

Volume $(\mathrm{mL})$ of water $=0.3 *$ extract volume $(\mathrm{mL})$

(Equation 3.2)

Volume $(\mathrm{mL})$ of chloroform $=0.9 * 0.65 *$ extract volume $(\mathrm{mL}) \quad$ (Equation 3.3)

The contents in each vial were poured into $125-\mathrm{mL}$ separatory funnels. The separatory funnels were capped with a glass stopper and carefully inverted for approximately ten seconds. The glass stoppers were removed and each separatory funnel was sealed with parafilm to prevent solvent evaporation. The separatory funnels were placed on a rack for gravity separation of an upper polar aqueous layer and a lower nonpolar, organic solvent layer containing lipids (Figure 3.12).

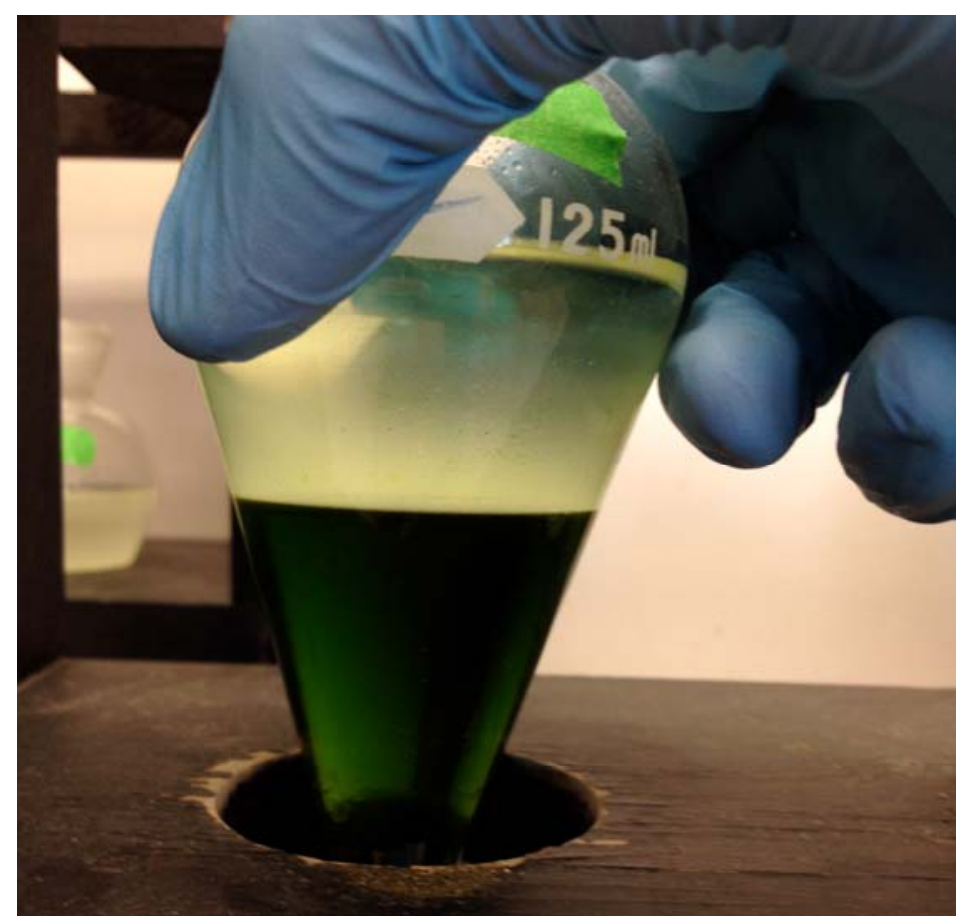

Figure 3.12: Upper and lower phases clearly displayed after one hour of settling. 
After settling for at least one hour, the lower layer was transferred into clean, preweighed $60-\mathrm{mL}$ vials by opening the stopcocks of the separatory funnels. The contents were slowly released to prevent transferring any contents from the upper layer.

After the entire lower solvent layer was transferred, the $40-\mathrm{mL}$ vials were dried under an evaporator (Organomation N-EVAP 112) using nitrogen gas. The water bath for the evaporator was set to $30^{\circ} \mathrm{C}$ to accelerate the evaporation process. Once dried, the final mass of the vial was recorded. The mass of the lipid content was equivalent to the difference between final and initial vial masses. Lipid content was seen as a dried residue on the bottom portion of each vial (Figure 3.13).

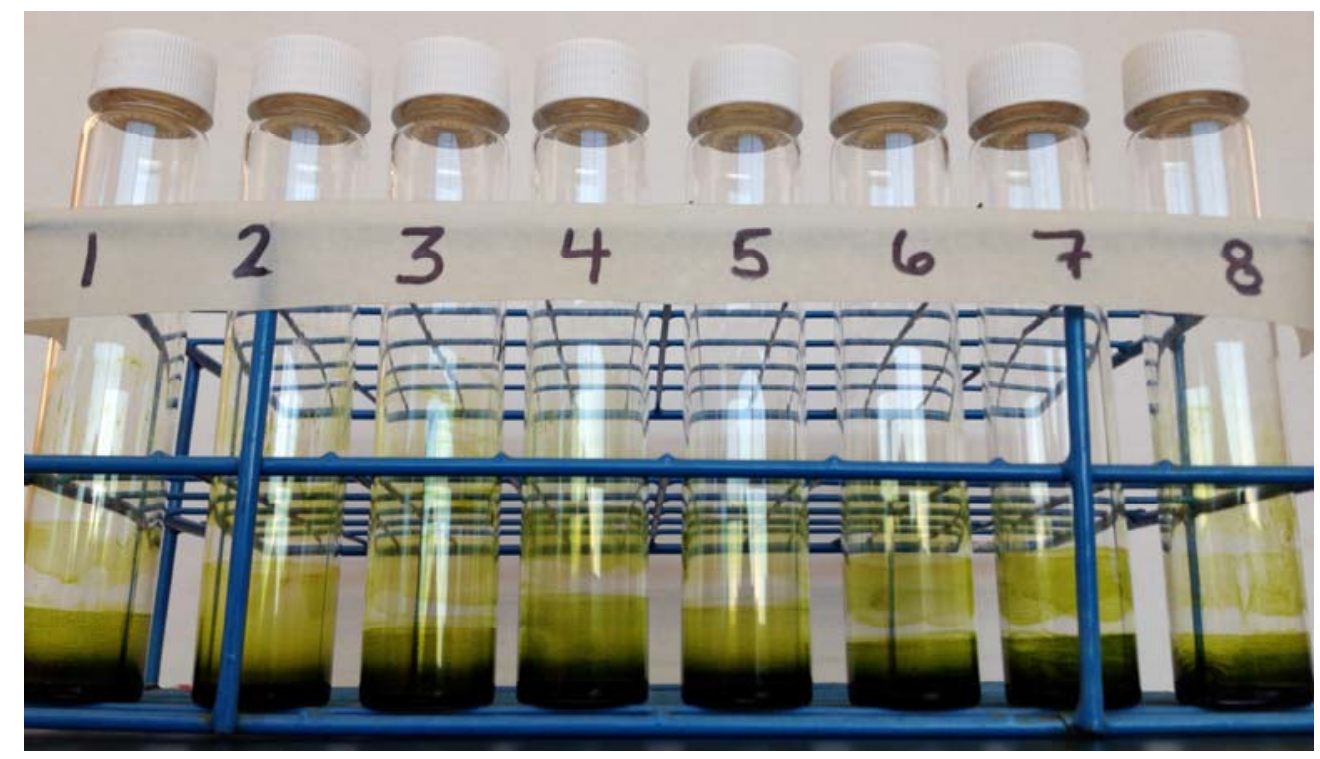

Figure 3.13: Lipid content was a dried residue in the vials after solvent was evaporated.

\subsubsection{Fatty Acid Methyl Esters (FAMEs)}

FAMEs quantification analysis was performed in accordance with the Determination of Total Lipids as Fatty Acid Methyl Esters (FAME) by in situ Transesterification laboratory analytical procedure provided by NREL (Appendix D). 
Known masses of ground, freeze-dried algal biomass (5 to $10 \mathrm{mg}$ ) from the $33-\mathrm{m}^{2}$ wastewater ponds were added to $1.5-\mathrm{mL} \mathrm{GC}$ vials. All biomass was analyzed as duplicate samples and the average of each duplicate set was given as the final result. For quality control, a triplicate set of algal biomass (Nannochloropsis) with known FAMEs concentration was analyzed with the batch of samples. A recovery standard was added to each sample prior to transesterification and was used to quantify the total FAMEs content on a GC-FID. This recovery standard was identifiable on the chromatograms amongst algal FAMEs due to its odd-chain fatty acid (C13), which does not exist in algal cells. Transesterification required the addition of $25 \mu \mathrm{L}$ of $\mathrm{C} 13$ recovery standard, 200 $\mu \mathrm{L}$ of $2: 1 \mathrm{v} / \mathrm{v}$ chloroform:methanol, and $300 \mu \mathrm{L}$ of $5 \% \mathrm{HCl}$ :methanol using gas-tight syringes. The vials were sealed with PTFE/silicone/PTFE crimp caps, mixed using a vortex mixer, and placed in a VWR digital dry heating block set to $85^{\circ} \mathrm{C}$ for one hour. Vials were removed and cooled for 15 to 60 minutes. After cooling, $1 \mathrm{~mL}$ of HPLC grade hexane was added to each vial using a gas-tight syringe. Vials were mixed and set undisturbed for one to four hours. Dilutions were required to keep FAMEs results within the calibration curve. A two-fold dilution was made by adding $100 \mu \mathrm{L}$ of the upper portion of the transesterified sample and $100 \mu \mathrm{L}$ of hexane to a $300-\mu \mathrm{L}$ GC vial with a conical insert. For the quality control biomass, a five-fold dilution was made by adding $40 \mu \mathrm{L}$ of transesterified sample and $160 \mu \mathrm{L}$ of hexane to a $300-\mu \mathrm{L}$ GC vial with a conical insert. An internal standard of 1:10 diluted pentadecane was prepared and $5 \mu \mathrm{L}$ was added to each vial. The vials were sealed with a crimp cap and mixed. A series of calibration standards was prepared from a 37-compound mixture (Sigma Aldrich \#189191AMP), which contained C4-C24 chains. 
Samples were loaded onto the sampling tray for the GC (Hewlett Packard HP 6890 Series GC system) equipped with a flame ionization detector (FID). This GC-FID analysis required a waxed column (DB-WAX $30 \mathrm{~m}$ x $0.25 \mathrm{~mm}$ I.D. x $0.25 \mu \mathrm{m}$ F.T.). Details for the GC temperature and flow program settings are shown in Appendix D. Quantification was completed using Agilent Chemstation. The total FAMEs content of each sample was normalized for the $\mathrm{C} 13$ recovery standard initially added, as follows:

Total FAMEs $s_{C 13 \text { normalized }}=\sum_{C 4-C 24} \frac{\text { Amount of Measured FAMEs Ci }}{\text { Amount of Measured FAMEs C13 }} *$ Amount of Added FAMES C13 (Equation 3.4)

where

Total FAMEs ${ }_{\mathrm{C} 13 \text { normalized }}=$ sum of total FAMEs content corrected for addition of $\mathrm{C} 13$ (mg)

Total FAMEs content was represented as a percentage of the dry weight of the algal biomass sample, as follows:

$\%$ Total FAMEs $=\frac{\text { Total FAMES } \text { C13 normalized }}{D W} * 100$

(Equation 3.5)

where

$$
\begin{aligned}
& \mathrm{DW}=\text { dry weight of freeze-dried algal biomass initially weighed prior to } \\
& \text { transesterification reaction }(\mathrm{mg}) \\
& \% \text { Total FAMEs = percentage of FAMEs content in biomass (g FAMEs per } \mathrm{g} \\
& \text { biomass) }
\end{aligned}
$$




\section{Results and Discussion}

This chapter describes results from the three experiments aforementioned. The media recycling results are comprised of four sections. The first section describes analysis results of the influents for Round 1 and Round 2 ponds. The remaining three sections discuss the algal productivity, settling efficiency, and total soluble nitrogen removal for the $4.2-\mathrm{m}^{2}$ ponds and $33-\mathrm{m}^{2}$ ponds. The growth media comparison results are comprised of five sections. The first three sections discussed the comparison of volatile suspended solids, algal productivity, and settling efficiency for $4.2-\mathrm{m}^{2}$ ponds and $33-\mathrm{m}^{2}$ ponds. The last two sections discuss the total ammonia removal, as well as nitrogen and phosphorus uptake in the $4.2-\mathrm{m}^{2}$ ponds and $33-\mathrm{m}^{2}$ ponds. Lastly, the lipid determination comparison results are comprised of one section, wherein the results of each lipid determination method are discussed and compared.

\subsection{Media Recycling Results}

The laboratory analysis results used to compare the performance of $4.2-\mathrm{m}^{2}$ ponds to $33-\mathrm{m}^{2}$ ponds during the media recycling experiment are described below. The goal of the media recycling experiment was to determine if $4.2-\mathrm{m}^{2}$ reactors predict the performance of larger reactors. Ideally, the results from the $4.2-\mathrm{m}^{2}$ reactors will be used for design of larger reactors suitable for wastewater treatment and algal biofuel production. Biomass productivity, settling efficiency, and nitrogen removal were evaluated during this experiment, which compared pond size, HRT, and media recycling potential. Biomass productivity was the main parameter used to determine the relationship between $4.2-\mathrm{m}^{2}$ ponds and $33-\mathrm{m}^{2}$ ponds. Round 1 and Round 2 influents were analyzed to characterize the constituents entering each pond set. 


\subsubsection{Influent Analysis}

The primary clarifier effluent, which was used as the influent for the Round 1

ponds, was analyzed with the pond samples for each water quality analysis. It was

important to characterize the constituents of this wastewater since the flow and composition of municipal wastewater changes daily. The characteristics of the influent during the media recycling experiment are shown in Table 4.1.

Table 4.1: Round 1 influent characterization from January 30, 2014 to March 13, 2014

\begin{tabular}{cccccc} 
& \multicolumn{5}{c}{ 2-day and 3-day Round 1 Influent Characterization } \\
\cline { 2 - 6 } & TAN & NO3 & NO2 & TSS & VSS \\
\hline Average (mg/L) & 46.7 & 1.25 & 0.02 & 59.6 & 51.1 \\
Standard Deviation (mg/L) & 14.0 & 0.99 & 0.02 & 29.9 & 23.5 \\
Minimum (mg/L) & 28.8 & 0.09 & 0.00 & 29.2 & 24.5 \\
Maximum (mg/L) & 78.5 & 3.95 & 0.08 & 140 & 124 \\
Number of Sample Days & 11 & 11 & 10 & 13 & 13 \\
\hline
\end{tabular}

The tube settler supernatant was used as the influent for the Round 2 ponds, as described in Section 3.2.2. The supernatant was analyzed only for the TSS/VSS analysis to determine the concentration of biomass added to the Round 2 ponds. In Table 4.2 and Table 4.3, the additional influent characteristics are the averages of the Round 1 pond samples. It was assumed that the total ammonium nitrogen, nitrate, and nitrite concentrations in the ponds were equivalent to the concentrations in the tube settlers due to the short residence time within the tube settlers. The maximum TSS and VSS concentrations for the 2-day Round 2 ponds were nearly four times higher than the average TSS and VSS concentrations. This was most likely caused by algal biomass in the tube settlers escaping with the supernatant if the tube settler sludge was not removed beforehand. Influent VSS concentrations were used in the determination of net 
productivity, as discussed in Section 2.2. Biomass productivity is discussed in the following section.

Table 4.2: Round 2 pond influent (2-day) characterization from January 30, 2014 to March 13, 2014

\begin{tabular}{cccccc} 
& \multicolumn{5}{c}{ 2-day Round 2 Pond Influent Characterization } \\
\cline { 2 - 6 } & TAN & NO3 & NO2 & TSS & VSS \\
\hline Average (mg/L) & 27.2 & 2.90 & 1.04 & 138 & 120 \\
Standard Deviation (mg/L) & 7.77 & 2.31 & 0.75 & 146 & 118 \\
Minimum (mg/L) & 16.4 & 0.57 & 0.04 & 37.5 & 37.4 \\
Maximum (mg/L) & 39.9 & 7.83 & 2.82 & 536 & 428 \\
Number of Sample Days & 11 & 13 & 13 & 9 & 9 \\
\hline
\end{tabular}

Table 4.3: Round 2 pond influent (3-day) characterization from January 30, 2014 to March 13, 2014

\begin{tabular}{cccccc} 
& \multicolumn{5}{c}{ 3-day Round 2 Pond Influent Characterization } \\
\cline { 2 - 6 } & TAN & NO3 & NO2 & TSS & VSS \\
\hline Average (mg/L) & 19.8 & 5.99 & 1.38 & 91.3 & 82.7 \\
Standard Deviation (mg/L) & 10.8 & 6.88 & 1.02 & 28.0 & 23.1 \\
Minimum (mg/L) & 4.47 & 0.58 & 0.04 & 41.3 & 39.3 \\
Maximum (mg/L) & 33.2 & 18.64 & 3.53 & 117 & 107 \\
Number of Sample Days & 11 & 13 & 13 & 9 & 9 \\
\hline
\end{tabular}

\subsubsection{Net Biomass Productivity}

As defined in Section 2.3, net productivity is the net mass of algal VSS grown per pond surface area per time ( $\mathrm{g}$ VSS $\left.\mathrm{m}^{-2} \mathrm{day}^{-1}\right)$. Net productivity was used to determine pond performance because this subtracted the VSS in the wastewater influent to account for net biomass growth.

The net productivity for the Round 1 ponds was determined by subtracting the VSS of the primary clarifier effluent (Round 1 influent) from the VSS of the Round 1 pond samples. The net productivity for the Round 2 ponds was determined by subtracting the VSS of the tube settler supernatant (Round 2 influent) from the VSS of the Round 2 pond samples. Figure 4.1 shows the average net productivity for the $4.2-\mathrm{m}^{2}$ ponds and 
33- $\mathrm{m}^{2}$ ponds during the experiment. The vertical black line represents the estimated start of steady state conditions in the $4.2-\mathrm{m}^{2}$ ponds. The $33-\mathrm{m}^{2}$ ponds began operating in steady state conditions before the $4.2-\mathrm{m}^{2}$ pond experiment initiated. Start of steady state conditions was estimated at three times the 3-day HRT, which was equivalent to 9 days after the inoculation date. The three-times 3-day HRT heuristic was used as a conservative assumption for the 3-day and 2-day pond sets. Therefore, algal biomass growth was at steady state and the productivity was less variable due to adjustments to the new pond conditions. As shown in Figure 4.1, the net productivity of the 4.2- $\mathrm{m}^{2}$ ponds was below the net productivity of the $33-\mathrm{m}^{2}$ ponds for a majority of the experiment.

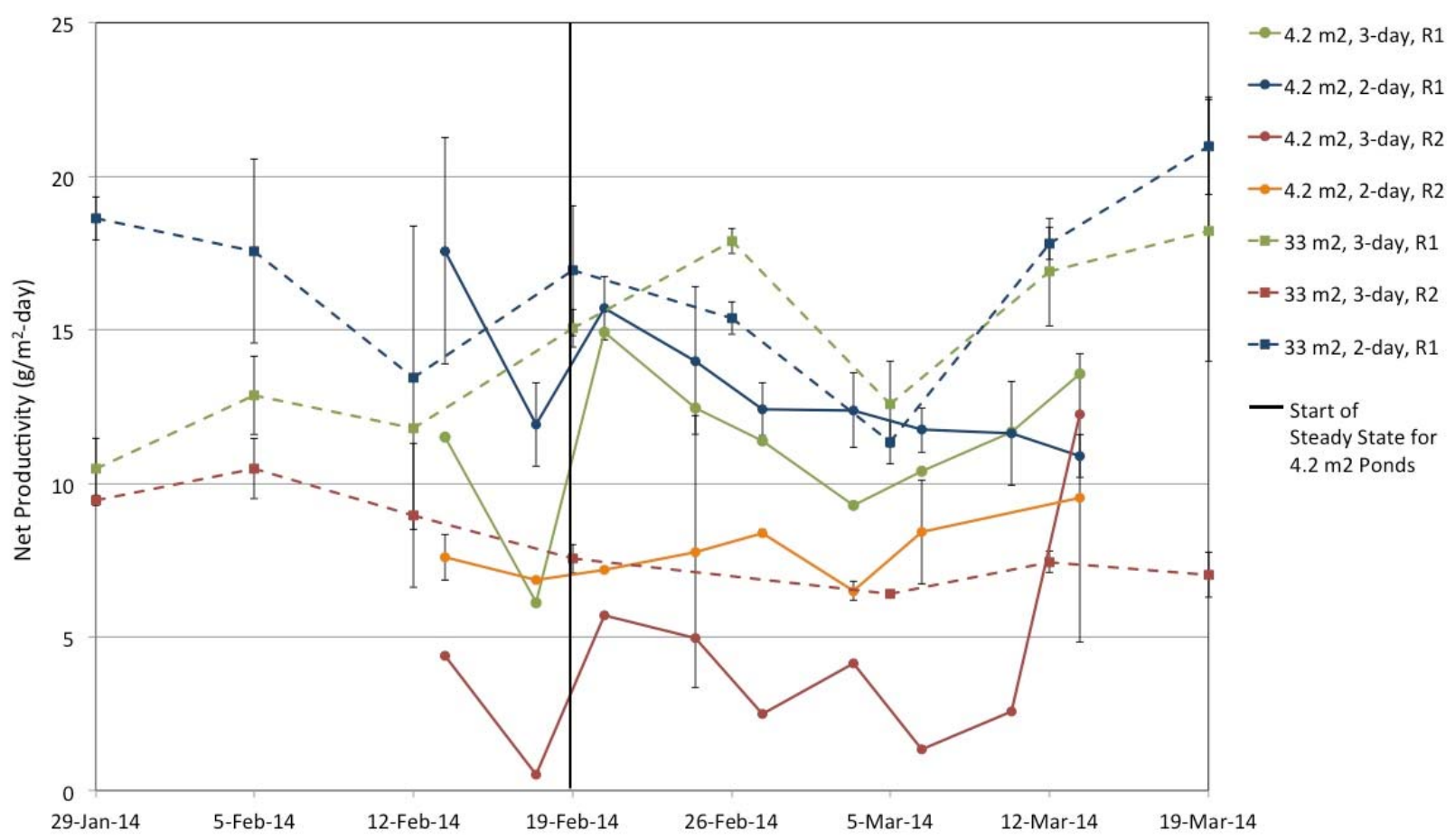

Figure 4.1: Net productivity comparison for $4.2-\mathrm{m} 2$ ponds and $33-\mathrm{m} 2$ ponds. The vertical black line represents the estimated start of steady state conditions for the algae. Steady state was reached at approximately three times the 3-day HRT (9 days) after the inoculation date. 


\subsubsection{Settling Efficiency}

High settling efficiency is essential for economically feasible biofuel production due to the lack of additional chemical or equipment costs used to harvest algal biomass. Two-hour settling efficiency represented the percent removal of TSS after two hours of settling in Imhoff cones. The percent removal was determined by dividing the difference between the zero-hour TSS concentration and the two-hour TSS concentration by the zero-hour TSS concentration. Settling efficiencies of each $4.2-\mathrm{m}^{2}$ pond treatment set were averaged once ponds reached steady state conditions, which began February 19, 2014. Round 1 growth in $4.2-\mathrm{m}^{2}$ ponds and $33-\mathrm{m}^{2}$ ponds had higher settling efficiencies for 2day and 3-day treatments than settling efficiencies for Round 2 growth (Figure 4.2). Settling efficiencies for $4.2-\mathrm{m}^{2}$ ponds and $33-\mathrm{m}^{2}$ ponds were nearly identical for all treatment types except for the 2-day Round 1 treatment.

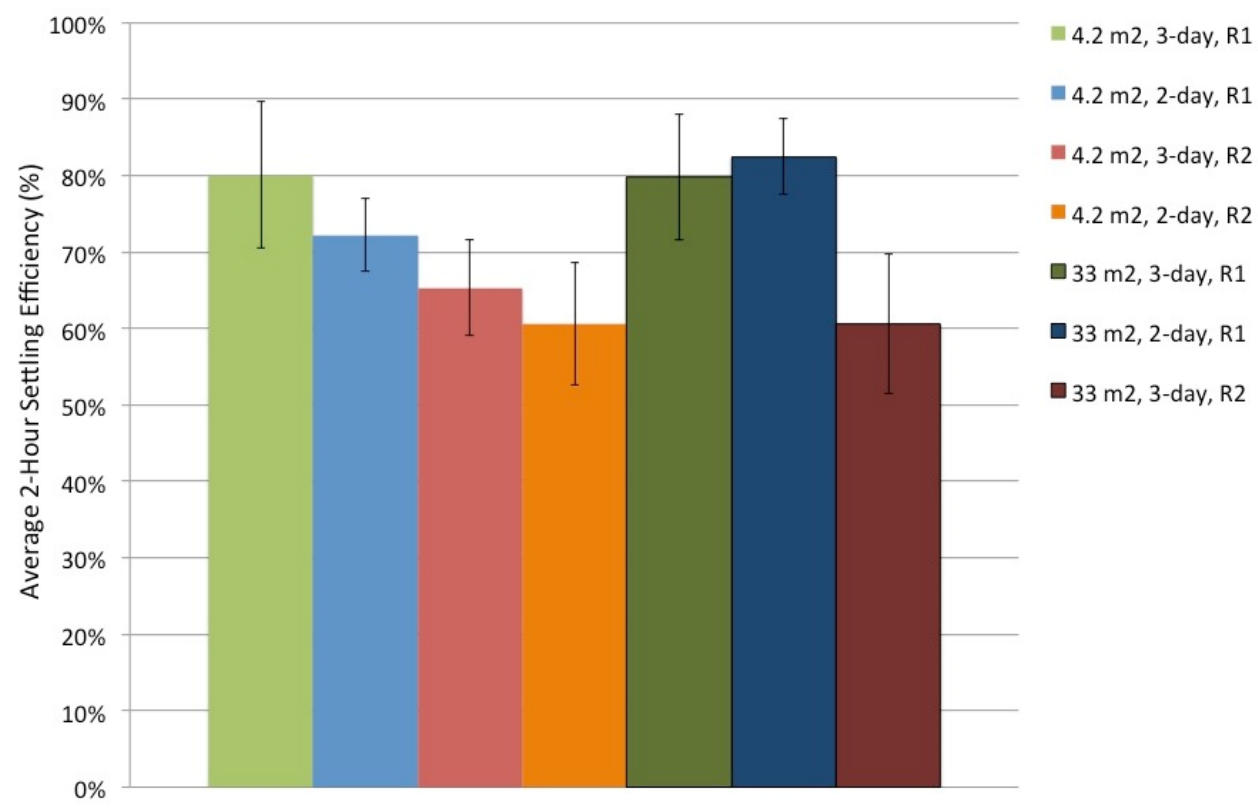

Figure 4.2: Settling efficiencies for 4.2-m2 ponds were averaged during steady state conditions from February 19, 2014 to March 13, 2014. Settling efficiencies for 33-m2 ponds were averaged from January 29, 2014 to March 19, 2014. 


\subsubsection{Nitrogen Results}

Total soluble nitrogen represented the sum of nitrate, nitrite, and ammonia concentrations measured in the ponds. Figure 4.3 shows the average total soluble nitrogen concentrations for the $4.2-\mathrm{m}^{2}$ ponds and $33-\mathrm{m}^{2}$ ponds during the experiment. The vertical black line represents the estimated start of steady state conditions in the $4.2-\mathrm{m}^{2}$ ponds, as described in Section 4.1.2. Total soluble nitrogen decreased for all treatments in both the 4.2- $\mathrm{m}^{2}$ ponds and $33-\mathrm{m}^{2}$ ponds due to the decrease in total soluble nitrogen. Total soluble nitrogen decreased due to algal cell uptake, volatilization, and denitrification.

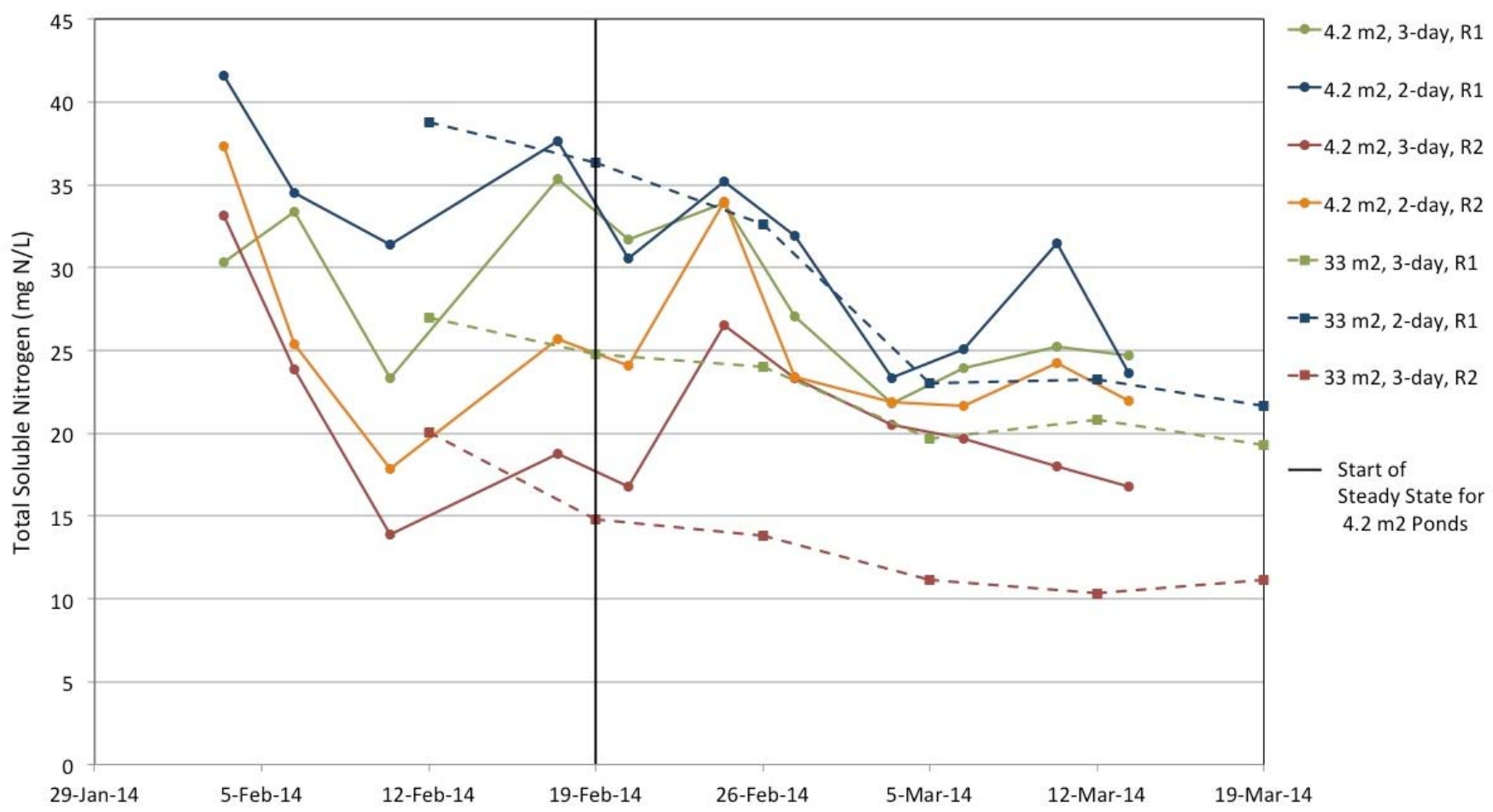

Figure 4.3: Total soluble nitrogen decreased in $4.2 \mathrm{~m} 2$ ponds and $33 \mathrm{~m} 2$ ponds due to decrease in TAN from volatilization and nitrification. 


\subsection{Growth Media Comparison Results}

The laboratory analysis results used to compare the performance of $4.2-\mathrm{m}^{2}$ ponds to $33-\mathrm{m}^{2}$ ponds during the growth media comparison experiment are described below. The goal of the growth media comparison experiment was to determine if $4.2-\mathrm{m}^{2}$ reactors predict the performance of larger reactors growing algae using wastewater, reclaimed water, or a mixture of the two. A defined media was used as a control to compare to growth in the wastewater ponds. The results from the $4.2-\mathrm{m}^{2}$ reactors can be used for design of larger reactors suitable for wastewater treatment and algal biofuel production. Volatile suspended solids, biomass productivity, settling efficiency, and nitrogen removal were evaluated during this experiment. Biomass productivity was the main parameter used to determine the relationship between $4.2-\mathrm{m}^{2}$ ponds and $33-\mathrm{m}^{2}$ ponds.

\subsubsection{Volatile Suspended Solids}

Influent VSS for the $100 \% \mathrm{WW} 4.2-\mathrm{m}^{2}$ pond set was not measured during this experiment. Influent VSS for the $33-\mathrm{m}^{2}$ pond set was averaged for this time frame and assumed to be the same for the $100 \% \mathrm{WW} 4.2-\mathrm{m}^{2}$ pond set. Average influent VSS from August 7, 2013 to September 11, 2013 for the $33-\mathrm{m}^{2}$ pond set was $38 \mathrm{mg} / \mathrm{L}$. Net VSS was calculated to account for biomass growth without the inclusion of suspended solids from the primary clarifier effluent. However, there was no distinction between algal and bacterial biomass.

During the growth media comparison using wastewater and NCMA BG11 defined media, net VSS concentrations increased steadily until reaching a stationary phase (Figure 4.4). Maximum net VSS for the defined media pond set was nearly twice the maximum net VSS for the wastewater pond set. The defined media pond set took eight 
more days to reach stationary phase compared to the wastewater pond set. Once the daily dilutions began for the wastewater pond set, net VSS fluctuated between 130-230 mg/L. Net VSS in the defined media pond set decreased by over $50 \%$ within three days once daily dilutions began. After this significant decrease in net VSS, net VSS fluctuated between 150-200 mg/L. Once the ponds reached steady state conditions, net VSS in both growth media pond sets were nearly identical. Since the defined media pond set was used as a control, the similarity in net VSS suggested that semi-continuous operation produced the same biomass growth rates in both growth media.

An increasing trend of net VSS for the last five daily dilutions may represent steady state conditions in both growth media pond sets. If semi-continuous operation was continued for this experiment, net VSS may have continued to increase which would be beneficial for pond productivity. Lastly, net VSS of the $4.2-\mathrm{m}^{2}$ ponds and $33-\mathrm{m}^{2}$ ponds eventually reached the same concentrations once the $4.2-\mathrm{m}^{2}$ ponds stabilized, showing that these reactors can be used to predict growth of large reactors.

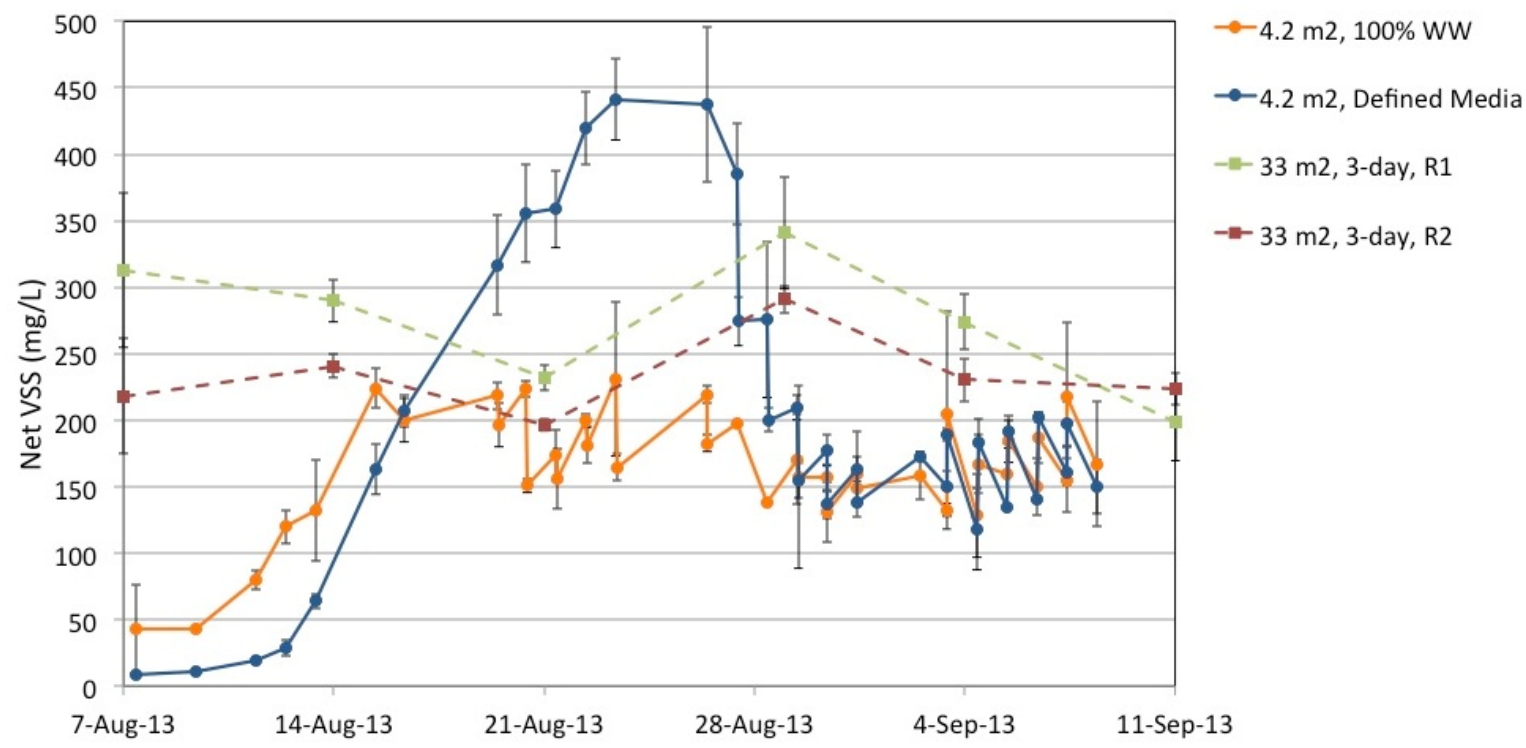

Figure 4.4: Defined media pond set was in the exponential growth phase for nine days longer than the wastewater pond set. Daily dilutions caused a decrease in net VSS for both pond sets. 
During the growth media comparison using $100 \% \mathrm{RW}, 50 \% / 50 \% \mathrm{WW} / \mathrm{RW}$, and $100 \% \mathrm{WW}$, the $50 \% / 50 \% \mathrm{WW} / \mathrm{RW}$ pond set achieved the highest VSS concentrations during this batch experiment (Figure 4.5). This pond set also appeared to have less of a lag phase during the initial growth compared to the $100 \% \mathrm{WW}$ pond set and the $100 \%$ RW pond set. VSS concentrations of the $100 \%$ RW decreased on the last sampling event of the experiment; however, additional sampling events would have been needed to determine if this anomaly reflected a crash in the ponds or if the growth would have reoccurred. The steepest portion of the VSS growth curve for each pond set was used to determine the productivity using different media types.

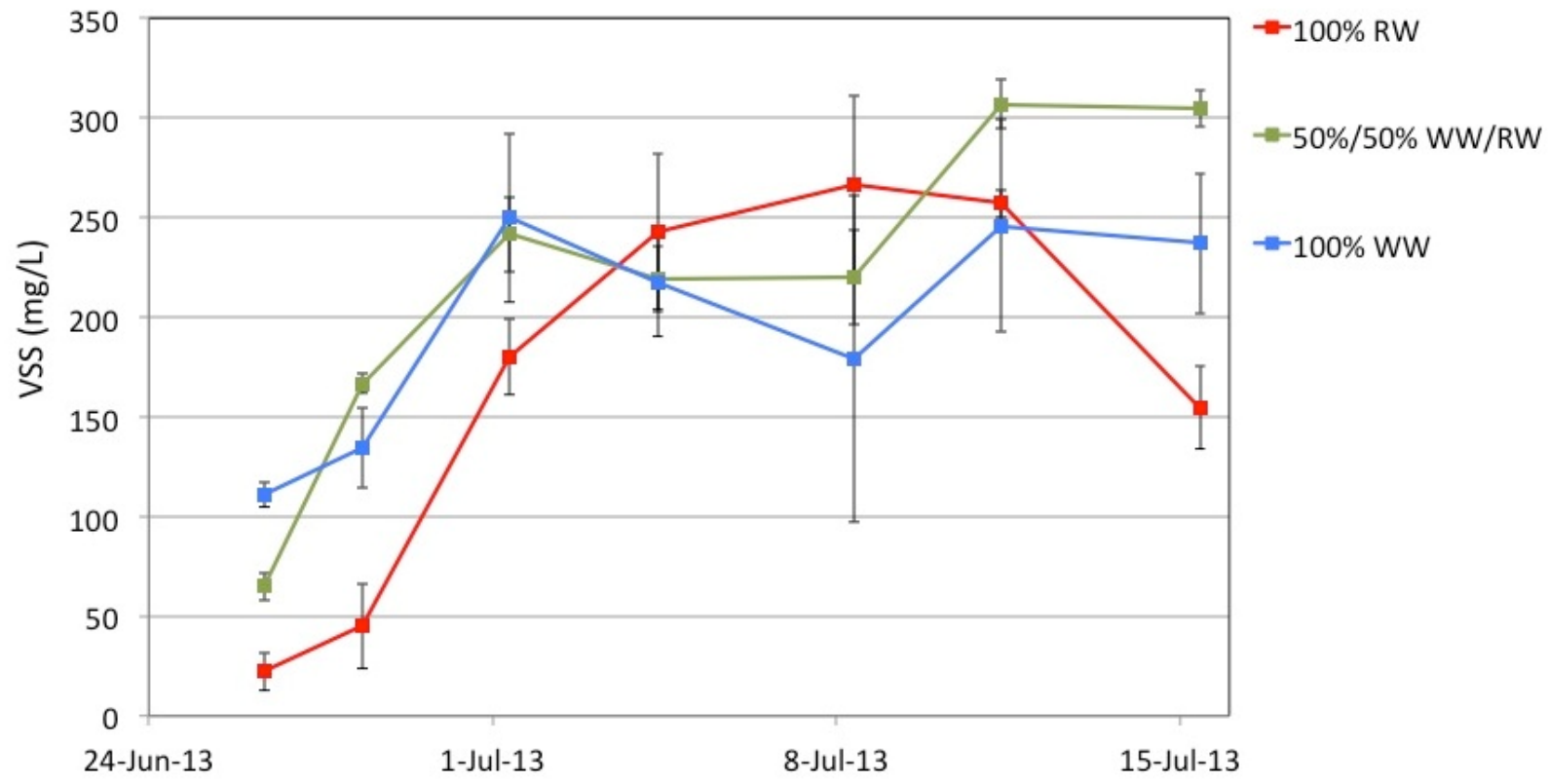

Figure 4.5: $50 \% / 50 \% \mathrm{WW} / \mathrm{RW}$ pond set achieved fastest growth rate before other pond sets and resulted in a higher final VSS concentration. 


\subsubsection{Net Biomass Productivity}

Net Productivity was used to determine pond performance because it accounted for biomass growth in the ponds after each daily dilution and deducted VSS from the influent for the wastewater ponds. Net VSS was used to determine the net productivity of the $100 \% \mathrm{WW} 4.2-\mathrm{m}^{2}$ pond set.

Initial net productivity of both $4.2-\mathrm{m}^{2}$ pond sets started significantly lower than net productivities later in the experiment, as shown in Figure 4.6. Initial net productivity was lower because it accounted for the duration of the grow-out period before daily dilutions began, which included the lag phase. For the $100 \% \mathrm{WW}$ ponds, the grow-out period lasted 12 days before daily dilutions. For the defined media ponds, the grow-out period lasted 20 days before daily dilutions. After the first daily dilution, net productivities for the $100 \% \mathrm{WW}$ pond set and the defined media pond set increased to approximately $29 \mathrm{~g} \mathrm{VSS} \mathrm{m}^{-2}$ day $^{-1}$ and $33 \mathrm{~g} \mathrm{VSS} \mathrm{m}^{-2}$ day $^{-1}$, respectively. As daily dilutions continued, net productivity gradually decreased. Net Productivity of the $100 \%$ WW ponds was approximately $19 \mathrm{~g} \mathrm{VSS} \mathrm{m}^{-2}$ day $^{-1}$ for the last four consecutive days of the experiment. This stabilization in productivity may suggest steady state conditions in the $100 \%$ WW ponds. The defined media ponds did not reach steady state conditions due to more variability in net productivity. With the exception of the last productivity data point for the defined media set, net productivity of both growth media sets had an increasing trend. Increasing net productivity correlated to the increasing VSS, as seen previously in Figure 4.4. Lastly, net productivity of the $100 \% \mathrm{WW} 4.2-\mathrm{m}^{2}$ ponds was within the standard deviation of the $33-\mathrm{m}^{2}$ ponds. 


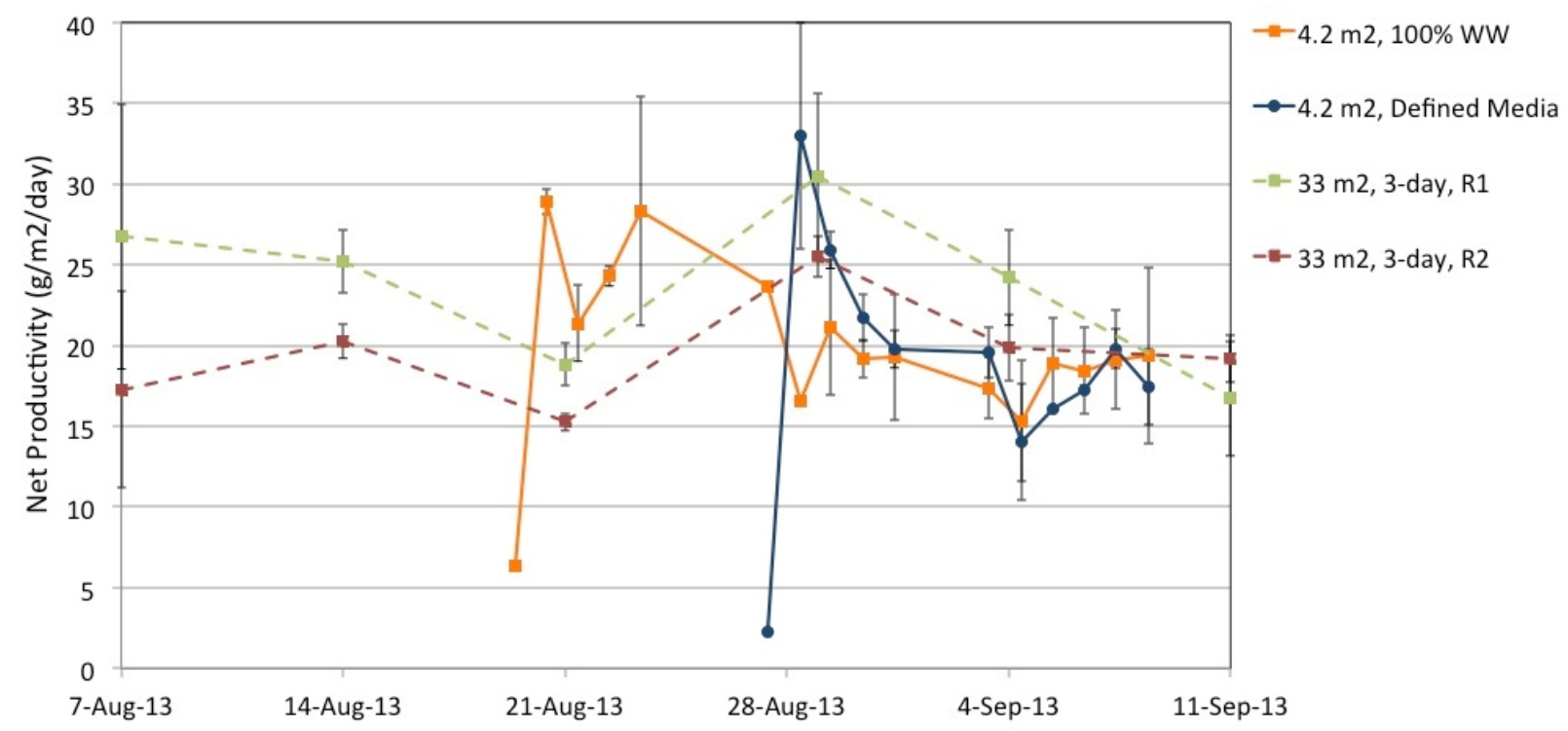

Figure 4.6: Net biomass productivity of the $4.2-\mathrm{m} 2$ ponds decreased after daily dilutions initiated until the ponds reached steady state and achieved stable productivities.

During the growth media comparison using $100 \% \mathrm{RW}, 50 \% / 50 \% \mathrm{WW} / \mathrm{RW}$, and $100 \% \mathrm{WW}$, the steepest portion of the VSS growth curve for each pond set was used to determine net productivity. The steepest portion of the VSS growth curve represented the maximum net productivity because VSS increased at the fastest rate during this portion of the experiment. Table 4.4 shows the maximum net productivities of each growth media pond set and the respective date range.

Table 4.4: Net productivities for this experiment were determined from the steepest portion of the VSS growth curve.

\begin{tabular}{ccc}
\hline $\begin{array}{c}\text { Growth Media } \\
\text { Pond Set }\end{array}$ & $\begin{array}{c}\text { Net Productivity } \\
\left(\mathrm{g} \mathrm{VSS} \mathrm{m}^{-2} \text { day }^{-1}\right)\end{array}$ & Date Range \\
\hline $100 \%$ RW & 15.6 & $6 / 28 / 13-7 / 1 / 13$ \\
$50 \% / 50 \%$ WW/RW & 17.7 & $6 / 26 / 13-6 / 28 / 13$ \\
$100 \%$ WW & 13.4 & $6 / 28 / 13-7 / 1 / 13$ \\
\hline
\end{tabular}




\subsubsection{Settling Efficiency}

Settling efficiency represented the percent removal of TSS after two hours of settling in Imhoff cones. The percent removal was determined by dividing the difference between the zero-hour TSS concentration and the two-hour TSS concentration by the zero-hour TSS concentration. Settling efficiencies for the $100 \% \mathrm{WW}$ ponds and defined media ponds were lower in the beginning of the experiment. Settling efficiency for the 100\% WW ponds increased until daily dilutions began on August 19, 2013. Likewise, the settling efficiency in the defined media ponds increased until daily dilutions began on August 27, 2013. Figure 4.7 shows the downward trend in settling efficiency for both growth media sets of ponds once daily dilutions were initiated. Daily dilutions for this experiment represented a 3-day HRT continuous operation. Due to the decrease in settling efficiency once daily dilutions began, an increased HRT may result in higher settling efficiency.

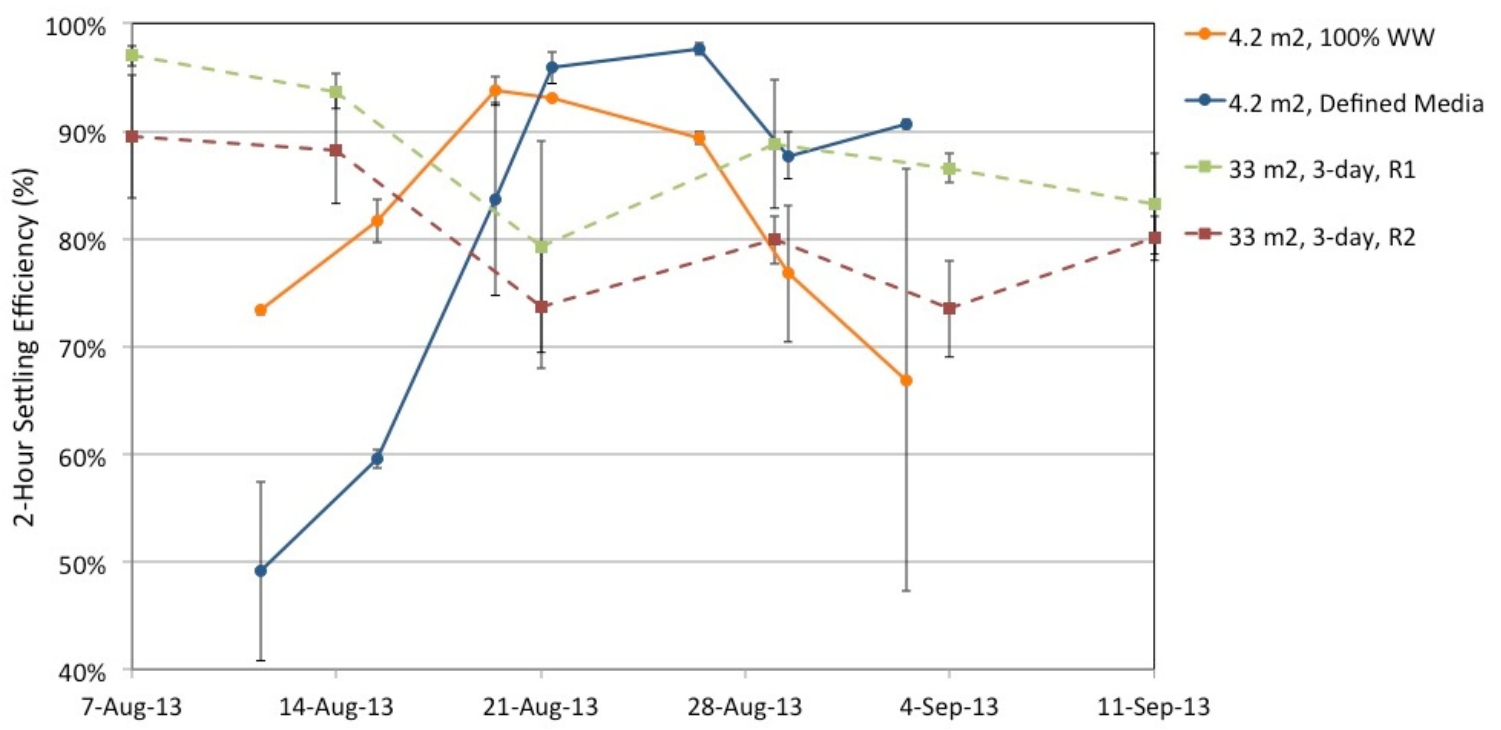

Figure 4.7: Settling efficiency increased for both growth media sets in 4.2-m2 ponds until daily dilutions initiated. Daily dilutions in 100\% WW ponds began August 19, 2013. Daily dilutions in defined media ponds began August 28, 2013. 
During the media comparison between $100 \% \mathrm{RW}, 50 \% / 50 \% \mathrm{WW} / \mathrm{RW}$, and $100 \%$ WW, settling efficiencies varied between each growth media set (Figure 4.8). Of the three growth media sets, the $50 \% / 50 \% \mathrm{WW} / \mathrm{RW}$ set was the only set to start with high settling efficiency and gradually decrease for the remainder of the experiment. The combination of reclaimed water and wastewater provided better conditions for algal biomass settling compared to reclaimed water or wastewater independently.

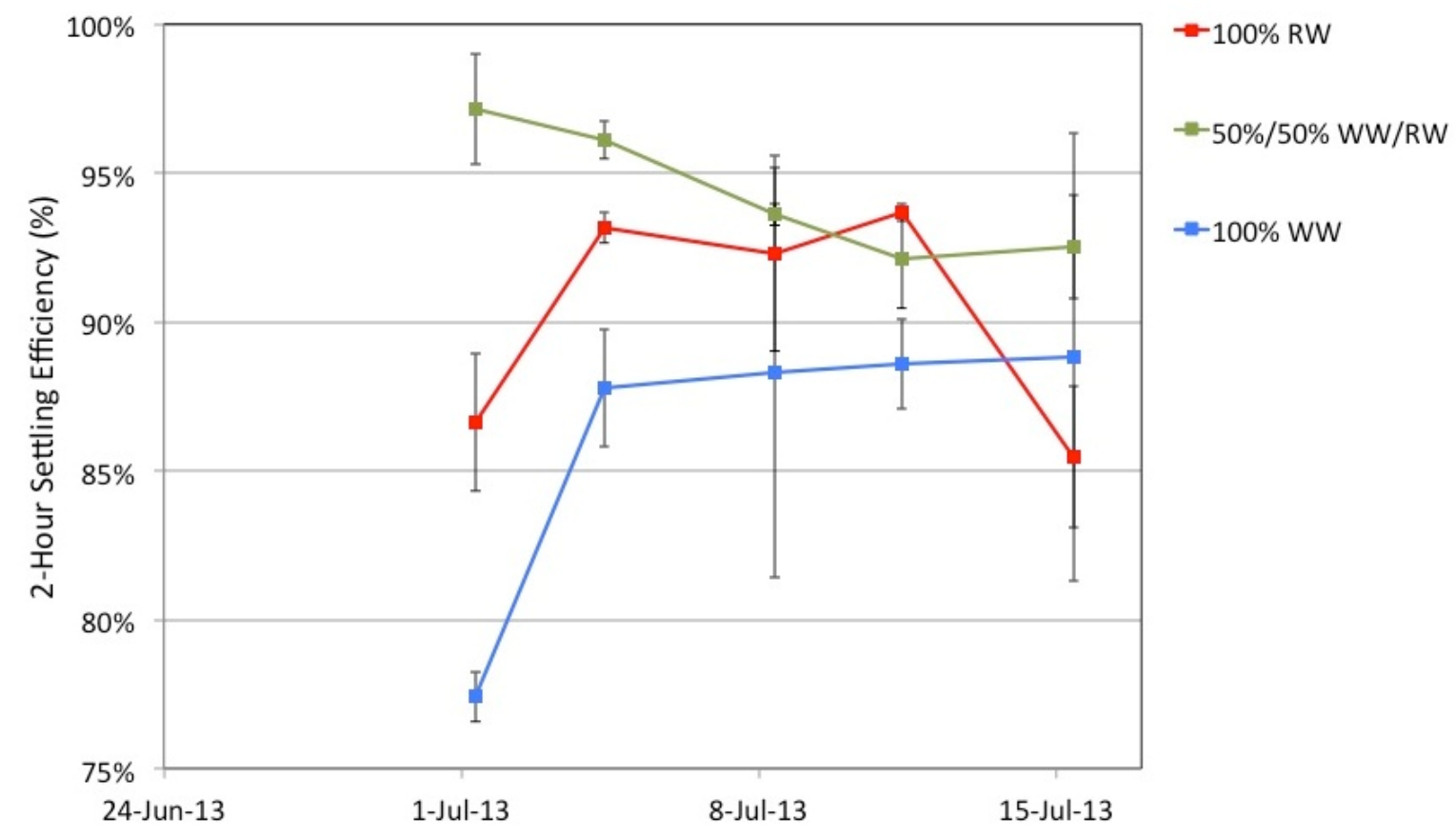

Figure 4.8: Settling efficiency for $50 \% / 50 \% \mathrm{WW} / \mathrm{RW}$ was higher than the other pond sets for a majority of the experiment.

\subsubsection{Nitrogen Results}

During the growth media comparison using wastewater and NCMA BG11 defined media, TAN in both growth media pond sets decreased to depleted conditions by the end of the batch operation as expected due to nitrogen consumption in algal cells (Figure 4.9). Once daily dilutions began, TAN decreased due to daily ammonia consumption and increased due to daily replenishment with fresh media. 


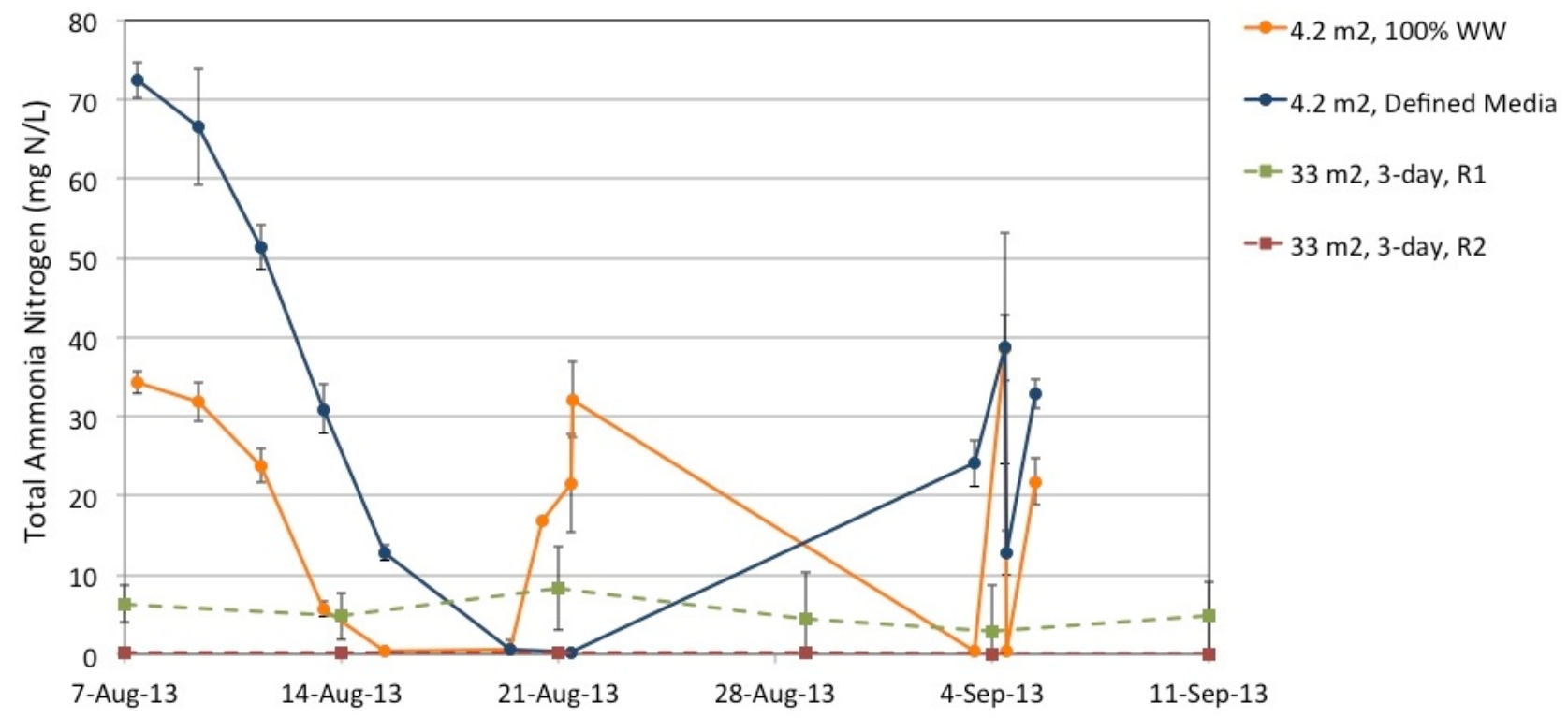

Figure 4.9: TAN reached depleted conditions before daily dilutions began. TAN increased after daily dilutions began due to additional nutrients in the fresh media.

During the media comparison between $100 \% \mathrm{RW}, 50 \% / 50 \% \mathrm{WW} / \mathrm{RW}$, and $100 \%$ WW, total soluble nitrogen was determined for four sampling events by analyzing nitrate, nitrite, and ammonia. All growth media pond sets experienced a decrease in total soluble nitrogen concentrations as expected and reached approximately $3 \mathrm{mg}-\mathrm{N} / \mathrm{L}$ by July 11 , 2013 (Figure 4.10). The experiment continued on until July 15, 2013 without additional nitrogen added to the ponds; therefore, the ponds were in nitrogen-depleted conditions for the last four days of the experiment. VSS of the $100 \%$ RW pond set may have decreased due to the depleted conditions. However, the $50 \% / 50 \% \mathrm{WW} / \mathrm{RW}$ and $100 \% \mathrm{WW}$ pond sets did not experience a decrease in VSS. 


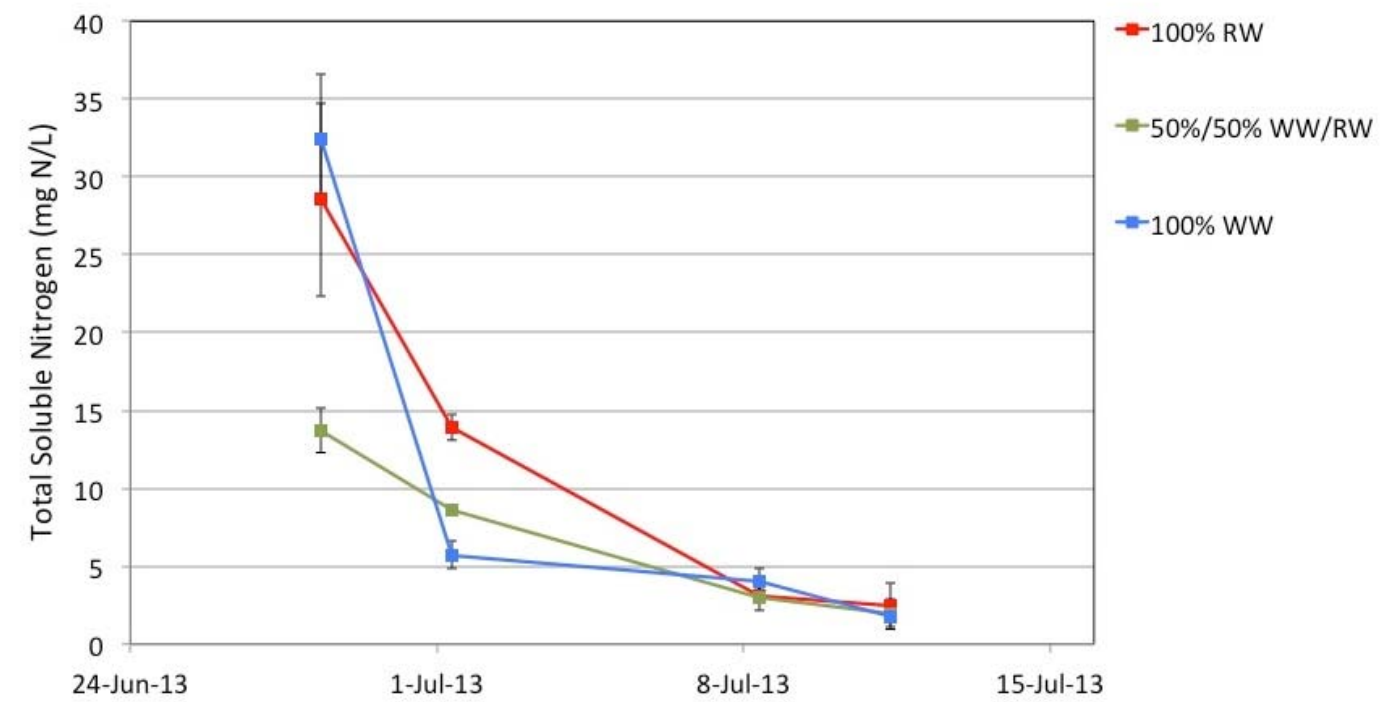

Figure 4.10: Total soluble nitrogen decreased in ponds as expected due to batch operation. Ponds were nearly nitrogen-depleted by July 11, 2013, which may have caused the VSS growth curve to enter stationary phase.

\subsubsection{Phosphorus and Nitrogen Uptake}

Phosphorus and nitrogen uptake was determined during the exponential growth phase of the VSS growth curve for each pond set. Phosphorus uptake was determined by dividing the difference between DRP concentrations by the difference between TSS concentrations during the specified date range. Nitrogen uptake was determined by dividing the difference between total soluble nitrogen concentrations by the difference between TSS concentrations during the specified date range. This process determined the percentage of phosphorus and nitrogen in the total composition of algal biomass. Table 4.5 shows the difference in nutrient uptake between the different growth media pond sets. $100 \% \mathrm{WW}$ pond set had the highest nitrogen and phosphorus content of the three pond sets. Phosphorus contents for all pond sets were within $15 \%$ of each other. However, nitrogen content in the $100 \% \mathrm{WW}$ pond set was over three times the nitrogen contents of the other pond sets. 
Table 4.5: Nitrogen and phosphorus contents were highest in the $100 \% \mathrm{WW}$ pond set.

\begin{tabular}{cccc}
\hline Growth Media & $\begin{array}{c}\text { Average Phosphorus } \\
\text { Content in Biomass }\end{array}$ & $\begin{array}{c}\text { Average Nitrogen } \\
\text { Content in Biomass }\end{array}$ & Date Range \\
\hline $100 \%$ RW & $1.31 \%$ & $10.8 \%$ & $6 / 28 / 13-7 / 1 / 13$ \\
$50 \% / 50 \%$ WW/RW & $1.37 \%$ & $6.20 \%$ & $6 / 28 / 13-7 / 1 / 13$ \\
$100 \%$ WW & $1.51 \%$ & $32.6 \%$ & $6 / 28 / 13-7 / 1 / 13$ \\
\hline
\end{tabular}

\subsection{Lipid Determination Comparison Results}

This experiment focused on the comparison of lipid contents using three different lipid determination methods. Algal biomass from the AFS wastewater ponds was collected on three separate sampling events: April 10, 2014, April 28, 2014, and May 16, 2014. Lipid content in each pond varied between sampling events over time due to changes in environmental conditions and nutrient concentrations in the ponds. Figure 4.11 shows the changes in lipid content for all three determination methods. Lipid content trends were similar between all three determination methods. For example, lipid contents in Pond 1 and Pond 2 algal biomass determined by all three methods show an increase between April 10 and April 28, as well as a decrease between April 28 and May 16. This similarity in trends shows that all three determination methods correctly reflected the changes of lipid content in the algal biomass. 
4.12a: Lipid content from Chloroform:Methanol extraction

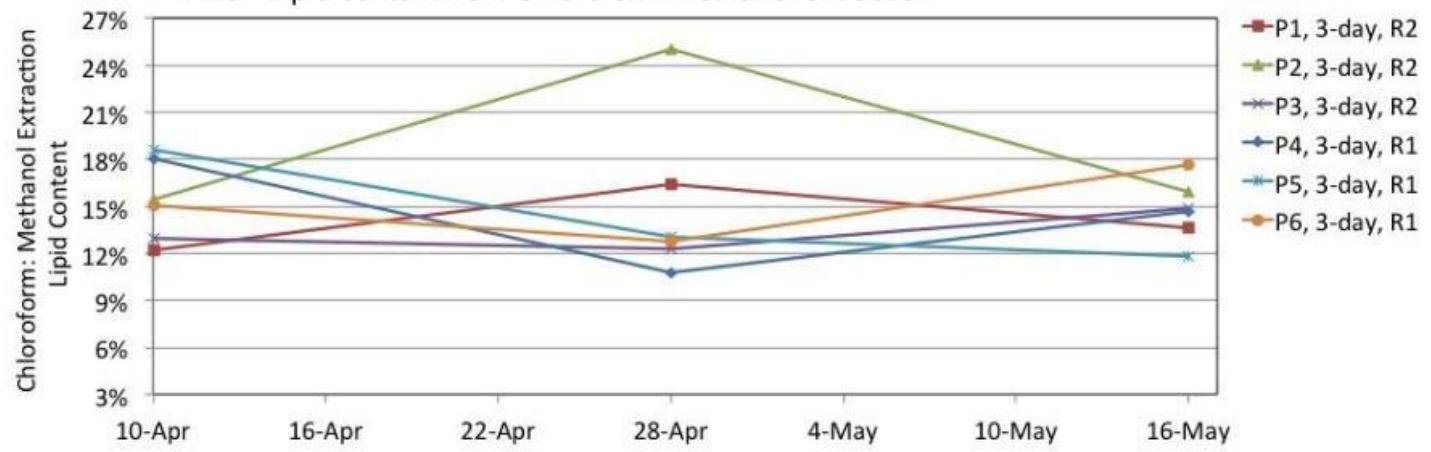

4.12b: Lipid content from Hexane:Diethyl Ether extraction

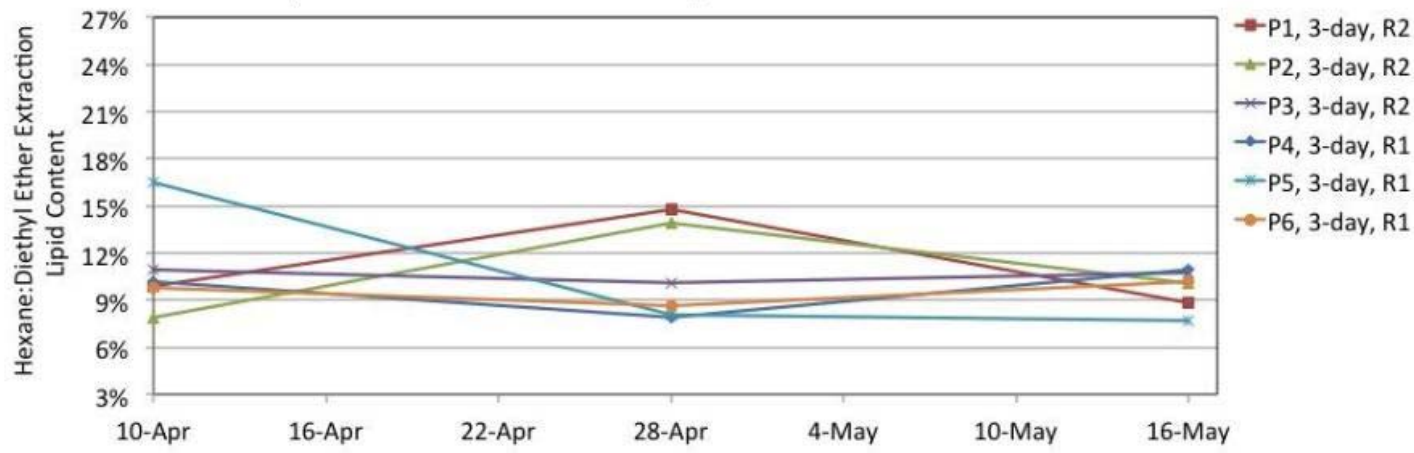

4.12c: Lipid content from FAMEs quantification

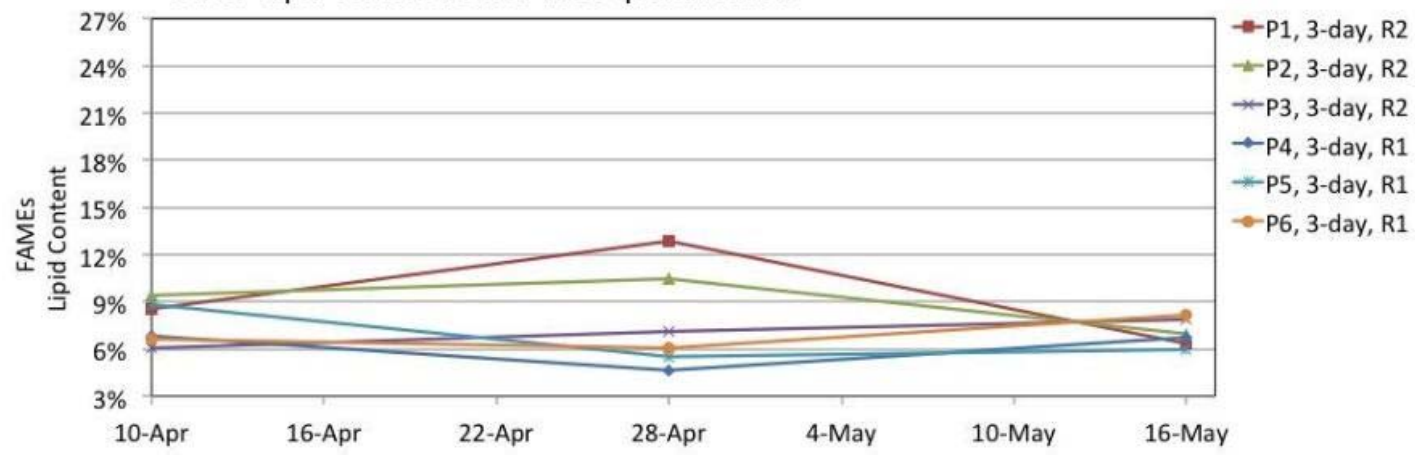

Figure 4.11: Lipid content trends were similar between all three determination methods. Methods arranged from highest to lowest lipid content determination: Chloroform:Methanol (4.12a), Hexane:Diethyl ether (4.12b), FAMEs (4.12c). 


\section{Conclusions}

This chapter discusses the conclusions from the results of each experiment. The main objectives of this research were to determine if smaller ponds predict the performance of larger ponds and to compare lipid contents from three different lipid determination methods.

\subsection{Media Recycling}

The $4.2-\mathrm{m}^{2}$ ponds under predicted the net productivity of larger ponds due to the constantly higher productivities in the $33-\mathrm{m}^{2}$ ponds. Regardless of the size of the pond reactor, net productivity was always higher for Round 1 growth compared to Round 2 growth. After media is recycled for a second of growth, the productivity may be lower than the first round due to a growth limiting inhibitor present in the culture. Increased HRT shows a pattern of lower productivity.

The effect of HRT on net productivity was further investigated for the $4.2-\mathrm{m}^{2}$ ponds and 33- $\mathrm{m}^{2}$ ponds (Figure 5.1). Effective HRT represents the total retention time for a volume of water within both rounds of growth. As effective HRT increased, the net productivity decreased in both pond sizes. For example, the 3-day Round 2 retention time was equivalent to 6-day effective HRT. Shorter retention times produced more algal biomass and have the potential for quicker harvesting and pond growth restart. Algal biomass productivity could be increased if Round 1 ponds operated at a 1 to 2 day HRT. 


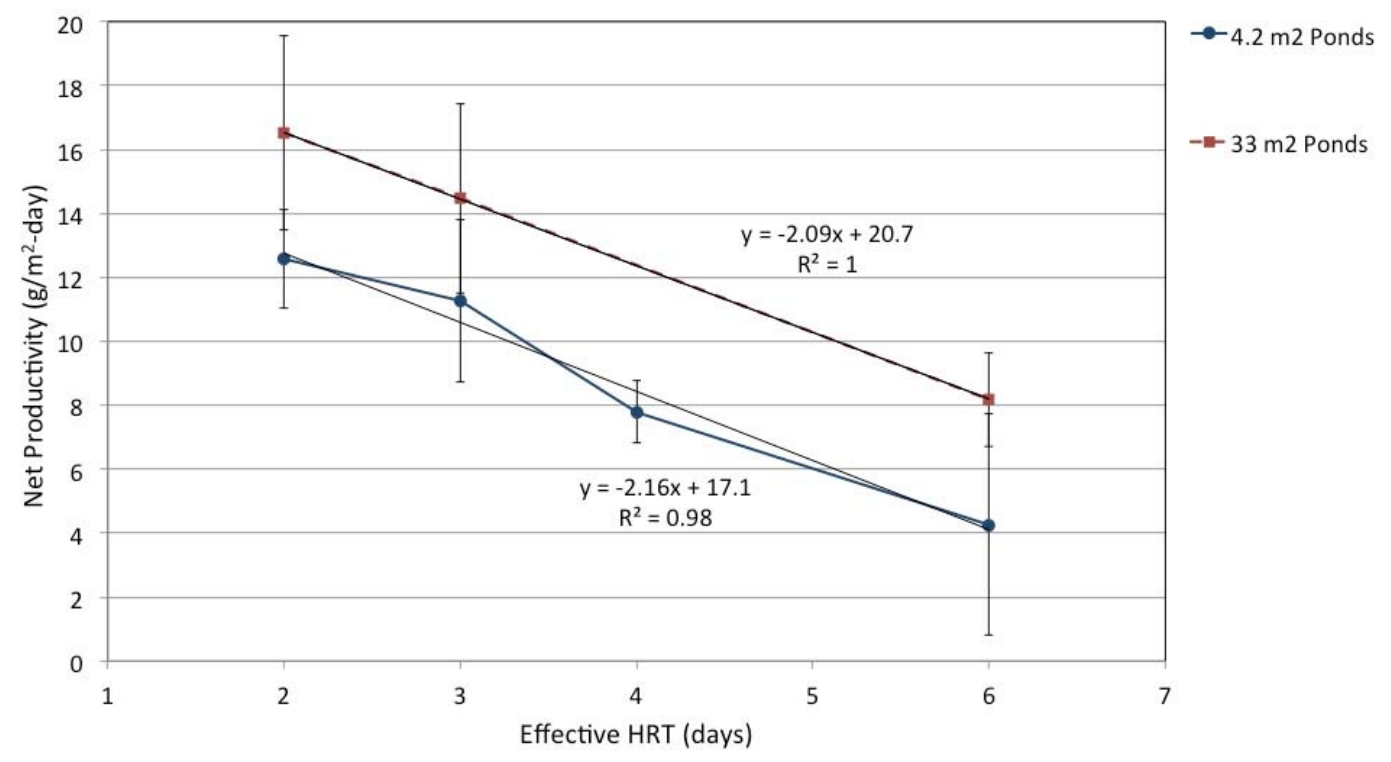

Figure 5.1: Net productivity decreased as effective HRT increased. Effective HRT represents the total retention time for a volume of water spent in both rounds of growth

The $4.2-\mathrm{m}^{2}$ ponds predicted or slightly under predicted the settling efficiency of larger ponds. Settling efficiency of the 2-day Round 2 was the lowest of all treatment types; however, there was no equivalent $33-\mathrm{m}^{2}$ pond set for comparison. Lastly, total soluble nitrogen was lower in Round 2 pond sets for both the $4.2-\mathrm{m}^{2}$ ponds and $33-\mathrm{m}^{2}$ ponds. Therefore, reuse of pond media improved the removal of total soluble nitrogen. Higher settling efficiency and nutrient removal are achieved in Round 2 ponds at a higher HRT.

\subsection{Growth Media Comparison}

During the comparison between $100 \% \mathrm{WW}$ and defined media, the wastewater $4.2-\mathrm{m}^{2}$ ponds predicted the net productivity performance of $33-\mathrm{m}^{2}$ ponds. However, the $4.2-\mathrm{m}^{2}$ ponds did not predict the settling efficiency of the $33-\mathrm{m}^{2}$ ponds. A longer study is necessary to determine if settling efficiency can be predicted for larger reactors using the 
4.2- $\mathrm{m}^{2}$ ponds. Semi-continuous operation was not studied long enough during this experiment to determine if $4.2-\mathrm{m}^{2}$ ponds could predict ammonia removal in $33-\mathrm{m}^{2}$ ponds.

During the growth media comparison using $100 \% \mathrm{RW}, 50 \% / 50 \% \mathrm{WW} / \mathrm{RW}$, and $100 \% \mathrm{WW}$, the maximum net productivity of the $50 \% / 50 \% \mathrm{WW} / \mathrm{RW}$ pond set was higher than the other growth media pond sets. As discussed previously in Section 4.2.1, the VSS concentration for the $50 \% / 50 \% \mathrm{WW} / \mathrm{RW}$ pond set did not have a lag phase like the other pond sets. This pond set reached maximum net productivity before the other pond sets due to the lack of this lag phase. Future pond experiments could investigate the use of $50 \% / 50 \% \mathrm{WW} / \mathrm{RW}$ as a growth media and expand to a semi-continuous operation to determine if productivity remains high. Additional total soluble nitrogen analysis would be necessary to confirm nitrogen-depleted conditions in all ponds during that last week of the experiment.

\subsection{Lipid Determination Comparison}

During each analytical batch for the chloroform-methanol extraction and the hexane-diethyl ether extraction, one sample was tested as a triplicate set to determine the precision of each method. Standard deviations and relative standard errors were determined for each triplicate set of each sampling event, as shown in Table 5.1 and Table 5.2. Likewise, all samples in the FAMEs analysis were tested in duplicate to determine the precision of this method. Standard deviations and relative standard errors were determined for each duplicate set of each sampling event. For each sampling event, the standard deviations and relative standard errors of all six duplicate sets were averaged, as shown in Table 5.3. In conclusion, FAMEs analysis produced the least amount of relative standard error between samples. The hexane-diethyl ether extraction 
method produced the highest relative standard error between triplicates. This error was most likely caused during the process of transferring the upper organic solvent layer from the extraction vials into new vials to be dried, as discussed in Section 3.5.2.

Table 5.1: Average lipid content, standard deviation and relative standard error were reported for the triplicate biomass sample analyzed on each sampling event for the chloroform-methanol extraction method.

\begin{tabular}{ccccc}
\hline \multicolumn{4}{c}{ Chloroform-Methanol Extraction Statistics } \\
$\begin{array}{c}\text { Triplicate } \\
\text { Sample }\end{array}$ & Date & Average Lipid Content & Standard Deviation & Relative Standard Error \\
\hline Pond 5 & $4 / 10 / 14$ & $18.6 \%$ & $0.4 \%$ & $2.3 \%$ \\
Pond 4 & $4 / 28 / 14$ & $10.8 \%$ & $0.7 \%$ & $6.2 \%$ \\
Pond 5 & $5 / 16 / 14$ & $11.8 \%$ & $1.1 \%$ & $9.3 \%$ \\
\hline
\end{tabular}

Table 5.2: Average lipid content, standard deviation, and relative standard error were reported for the triplicate biomass sample analyzed on each sampling event for the hexane-diethyl ether extraction method.

\begin{tabular}{|c|c|c|c|c|}
\hline \multicolumn{5}{|c|}{ Hexane-Diethyl Ether Extraction Statistics } \\
\hline $\begin{array}{c}\text { Triplicat } \\
\text { e } \\
\text { Sample }\end{array}$ & Date & Average Lipid Content & Standard Deviation & Relative Standard Error \\
\hline & $4 / 10 / 1$ & & & \\
\hline Pond 5 & $\begin{array}{c}4 \\
4 / 28 / 1\end{array}$ & $16.5 \%$ & $3.8 \%$ & $23.1 \%$ \\
\hline Pond 6 & $\begin{array}{c}4 \\
5 / 16 / 1\end{array}$ & $8.6 \%$ & $0.4 \%$ & $4.4 \%$ \\
\hline Pond 6 & 4 & $10.2 \%$ & $0.6 \%$ & $5.4 \%$ \\
\hline
\end{tabular}

Table 5.3: Average lipid contents, standard deviations, and relative standard errors were averaged for all duplicates for each sampling event for the FAMEs quantification method.

\begin{tabular}{ccccc}
\hline $\begin{array}{c}\text { Duplicate } \\
\text { Sample }\end{array}$ & Date & $\begin{array}{c}\text { Average Lipid } \\
\text { Content }\end{array}$ & $\begin{array}{c}\text { Average Standard } \\
\text { Deviation }\end{array}$ & $\begin{array}{c}\text { Average Relative } \\
\text { Standard Error }\end{array}$ \\
\hline Average of All & $4 / 10 / 14$ & $7.7 \%$ & $0.3 \%$ & $3.2 \%$ \\
Samples & $4 / 28 / 14$ & $7.8 \%$ & $0.2 \%$ & $2.0 \%$ \\
& $5 / 16 / 14$ & $7.5 \%$ & $0.5 \%$ & $6.8 \%$ \\
\hline
\end{tabular}

For each pond, lipid contents of all three sampling events were averaged for further comparison of each lipid determination method. Figure 5.2 compares average lipid contents from each pond determined from all three methods. Average lipid contents 
for all three methods were within the standard deviations for each pond. For example, the chloroform-methanol extraction method produced lipid contents that were similar for all six ponds. The durations between sampling events for this experiment were not long enough to determine if seasonal changes contributed to the variability in lipid contents.

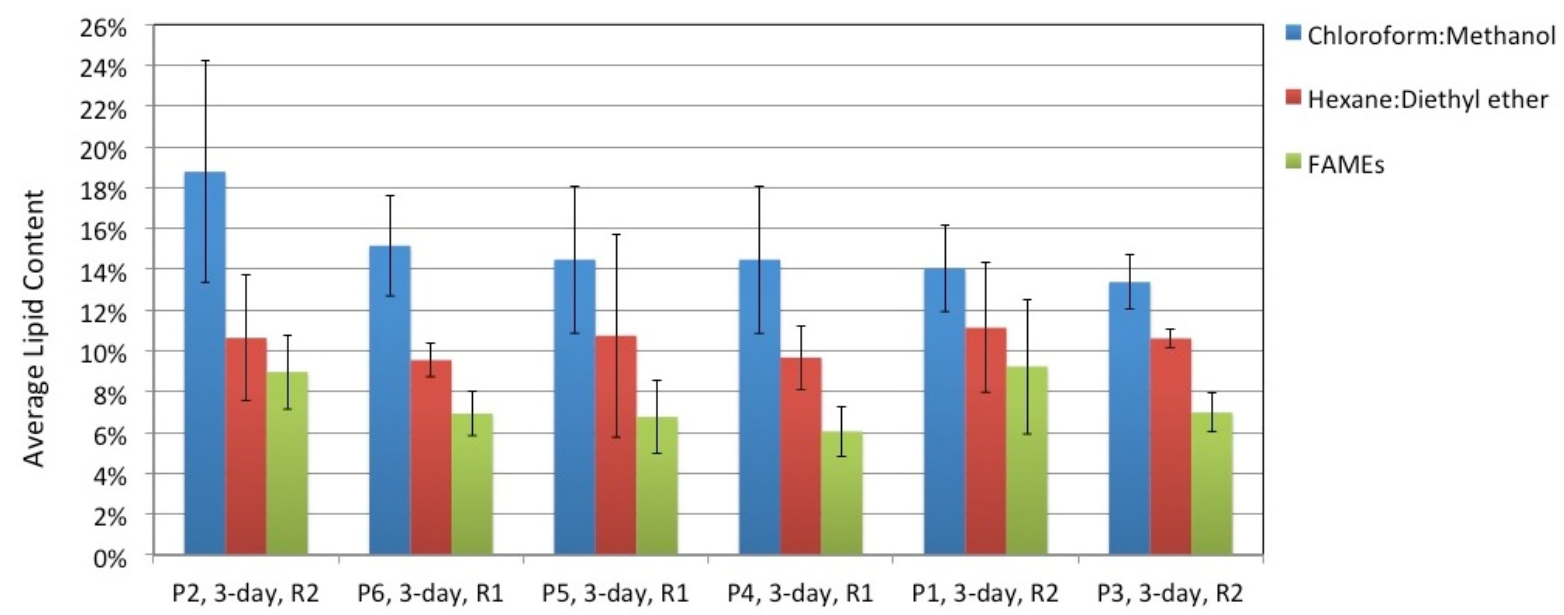

Figure 5.2: Samples arranged from highest to lowest average lipid content. Comparison of lipid content for all three determination methods averaged for all three sampling events.

Although the FAMEs quantification resulted in the lowest lipid content for all pond samples, this lipid determination method is the most reliable. As previously discussed in Section 2.3, this in situ transesterification process determines the lipid content from the TAGs in algal biomass without including other constituents from the cells. 


\subsection{Limitations of the Study}

The limitations of this study were as follows:

Pond operation limitations:

1. All samples analyzed during these experiments were grab samples and did not represent an average concentration of biomass throughout the day

Experimental limitations:

1. Productivity calculations accounted for algal and bacterial cells

2. Only three sampling events were performed for the lipid determination study

3. No standards or blanks were included in lipid determination study

\subsection{Further Research}

The research conducted for this thesis produced questions about the experiments previously discussed. The following is a list of questions to be pursued in further research:

1. Additional analysis of the FAMEs quantification data is needed to determine if the changes in concentrations of specific FAMEs followed a trend in any or all pond samples.

2. Conduct a longer lipid determination comparison study to see if each method correctly represents the change in lipid content as nutrient concentration change and seasonal weather change.

3. Compare pond performance of wastewater ponds and saline or brackish water ponds. 


\section{References}

Andersen, R. (2005). Algal Culturing Techniques. Academic Press.

Benemann, J. (2009). Algae Biofuels: Challenges in Scale-up, Productivity, and Harvesting (and Economics too!).

Biomass Magazine. (2014). Open Ponds versus Closed Bioreactors. Retrieved December 6, 2014, from http://biomassmagazine.com/articles/3618/open-ponds-versusclosed--bioreactors

CDPH. (2014, June 18). Regulations Related to Recycled Water. Retrieved December 4, 2014, from California Department of Public Health:

http://www.waterboards.ca.gov/drinking_water/certlic/drinkingwater/documents/1 awbook/RWregulations_20140618.pdf

Chang, M. (2014). Water and Nutrient Recycling by High Rate Algae Ponds in Primary Treated Municipal Wastewater.

Christie, W. W. (2003). Lipid Analysis: Isolation, Separation, Identification and Structural Analysis of Lipids (3rd ed.). Bridgewater, England: The Oily Press.

DOE. (2006). Energy demands on water resources: Report to Congress on the unterdependency of energy and water. Washington, DC: US Department of Energy.

DOE. (2010). National Algal Biofuels Technology Roadmap. Washington, DC: US Department of Energy.

EBTP. (2011). Biofuels Fact Sheet - Fatty Acid Methyl Esters (FAME). Retrieved December 7, 2014, from European Biofuels Technology Platform: http://www.biofuelstp.eu/factsheets/fame-fact-sheet.pdf

EPA. (2012, September). 2012 Guidelines for Water Reuse.

EPA. (2013). EPA Proposed 2014 Renewable Fuel Standards, 2015 Biomass-Based Diesel Volume. US Environmental Protection Agency, Department of Transportation and Air Quality.

EPA. (2014). Inventory of U.S. Greenhouse Gas Emissions and Sinks: 1990-2012. US Environmental Protection Agency.

EPA. (1999). Total Petroleum Hydrocarbons (TPH) as Gasoline and Diesel: SW-846 Method 8015B. US Environmental Protection Agency. 
Golueke, C., \& Oswald, W. (1959). Biological conversion of light energy to the chemical energy of methane. Applied Microbiology , 7 (4), 219-227.

Guieysse, B., \& Muñoz, R. (2006). Algal-bacterial processes for treatment of hazardous contaminants: A review. Water Research , 40 (15), 2799-2815.

Hu, Q. (2008). Biofuel from Algae: Technical Challenges and Opportunities. Arizona State University, Laboratory for Algae Research \& Biotechnology.

Laurens, L. M., Quinn, M., Van Wychen, S., Templeton, D. W., \& Wolfrum, E. J. (2012). Accurate and reliable quantification of total microalgal fuel potential as fatty acid methyl esters by in situ transesterification. Analytical and bioanalytical chemistry, 403 (1), 167-178.

Levine, A., \& Asano, T. (2004, June 1). Recovering Sustainable Water from Wastewater. Environmental Science \& Technology, 201A-208A.

Lundquist, T., Woertz, I., Quinn, N., \& Benemann, J. (2010). A Realistic Technology and Engineering Assessment of Algae Biofuel Production.

Metcalf \& Eddy, Inc. (2003). Wastewater Engineering Treatment and Reuse. New York: McGraw-Hill Companies, Inc.

Moser, B. R. (2009). Biodiesel Production, Properties, and Feedstocks. In Vitro Cellular \& Developmental Biology -Plant (45), 229-266.

National Drought Mitigation Center, T. (2014, December 2). Retrieved December 4, 2014, from US Drought Monitor: http://droughtmonitor.unl.edu/

National Research Council, T. (2012). Sustainable Development of Algal Biofuels in the United States. Washington, DC: The National Academies Press.

NOAA. (2014, December 5). Trends in Atmospheric Carbon Dioxide. Retrieved December 6, 2014, from Earth System Research Laboratory: http://www.esrl.noaa.gov/gmd/ccgg/trends/

Oilgae. (2014). Biodiesel from Algae. Retrieved December 6, 2014, from Oilgae : http://www.oilgae.com/algae/oil/biod/biod.html

Scott, S. A., Davey, M. P., Dennis, J. S., Horst, I., Howe, C. J., Lea-Smith, D. J., et al. (2010). Biodiesel from Algae: Challenges and Prospects. Current Opinion in Biotechnology , 21, 277-286.

Stoker, H. S. (2011). General, Organic, and Biological Chemistry (6th ed.). Cengage Learning. 
VisitSLO. (2013). San Luis Obispo Chamber of Commerce. Retrieved November 25, 2014, from http://visitslo.com/Library/factsheet.pdf

WRCC. (2010). 1981-2010 Monthly Normals for San Luis Obispo, California. Retrieved November 25, 2014, from Western Regional Climate Center: http://www.wrcc.dri.edu/cgi-bin/cliNORMNCDC2010.pl?ca7851 


\section{Appendix A}

This appendix outlined the nitrate interference suppressor solution (ISS) preparation procedure.

Into a 500-mL volumetric flask, fill about half way with DI water, add the following chemicals and shake to dissolve.

\subsection{3 g Aluminum sulfate, $\mathrm{Al}_{2}\left(\mathrm{SO}_{4}\right) * 18 \mathrm{H}_{2} \mathrm{O}$}

$1.56 \mathrm{~g}$ Silver sulfate, $\mathrm{AgSO}_{4}$

$0.62 \mathrm{~g}$ Boric acid, $\mathrm{H}_{3} \mathrm{BO}_{3}$

0.96 g Sulfamic Acid, $\mathrm{NH}_{3} \mathrm{SO}_{3}$

Adjust the $\mathrm{pH}$ to 3 by adding $0.1 \mathrm{~N} \mathrm{NaOH}$. Dilute to $500 \mathrm{~mL}$ with DI water. 


\section{Appendix B}

This appendix outlined the hexane-diethyl ether extraction process using the Total Lipid Determination Using the Dionex ASE 350 laboratory analytical procedure.

Materials Needed:

-40mL glass vials (one for each sample)

- $60 \mathrm{~mL}$ glass vials with screw cap and septa for ASE 350 (one for each sample)

- 27mm glass fiber filters (two for each sample) (Dionex: 068092)

- $5 \mathrm{~mL}$ stainless steel extraction cells (one for each sample)

- 1.5-2mL centrifuge tubes - dried in an oven and cooled in a desiccator (one for each sample) (VWR: 20170-170)

· Borosilicate glass Pasteur pipettes (one for each sample) (VWR: 14372-200)

- Rubber bulbs for Pasteur pipettes (may be interchanged on pipettes) (VWR: 82024-550)

- Cotton (for cushioning sample positions in the centrifuge rotor) Instruments Needed:

$\cdot \operatorname{ASE} 350$

- Freezer $(-80)$

- Freeze Dryer

- Fume Hood

- Evaporator

- Centrifuge Chemicals Needed:

- DI Water

· Hexane (VWR: BDH1129-19L)

• 9:1 Methanol/DMSO (VWR: BDH1135-19, VWR: BDH1115-4LP)

• 1:1 Hexane/Diethyl ether (VWR: BDH1129-19L, VWR: BDH1121-19L)

- Nitrogen Gas Cylinder 
Overview:

To determine the total lipid a series of steps must be taken to get the final result. The samples are first weighed and placed into extraction cells. From there, the samples are loaded onto the ASE 350 and the sequence and method(s) are run. Once the samples are completely extracted on the ASE 350, water is added to the extract to separate the lipid. The lipid layer is removed and dried for the determination of total lipid on a dry weight basis.

To use the ASE 350 a method and sequence must first be created in order to continue with the process. If a general sequence has already been created go to Determination of Total Lipid using the ASE 350 and continue from there. If a method and sequence have not been generated the following steps show this process.

Creating a Method with the ASE 350 Chromeleon Software:

1. Open the Chromeleon 7 software either by the desktop icon or start menu.

2. To create a method, go to Create $>$ Instrument Method... in the menu bar. An Instrument Method Wizard window will open.

3. The first option is the instrument selection. The page should say, 'The Instrument Method Wizard guides you through the creation of instrument methods. To start, select the instrument where the method will run.' Select ASE 350 and click the Next $>$ button.

4. The second option is to choose the rinse settings for the particular method. To rinse the system, check the 'Rinse system between extractions' box and adjust the volume, cycles, and solvent ratio settings as preferred. To bypass the system rinse, uncheck the box and click the Next $>$ button.

5. The third option is to choose the settings for the extraction method. Here the mode, cell type, oven temperature, static cycle, purge, and solvent ratios can be adjusted. Choose the desired settings and click the Next $>$ button.

6. The fourth option is to insert any comments and descriptions about the method. Once the desired information has been input, click the Finish button to continue.

7. A New Instrument Method will open that contains all the settings that were input during the wizard.

8. Before saving the instrument method, click Check Method in the menu toolbar. If the Method Check Results gives the message, 'Ready check result: Successful' the method can be saved. If the check is unsuccessful, locate the issue under Overview, Extractor, System, and Script Editor in the Instrument Method column and make the necessary changes to correct it. Check the method again before saving. 
9. Save the method by clicking the Save icon in the menu toolbar. The Save Instrument Method window will open. Select the desired folder to save the method and method name then click the Save button.

Creating a Sequence with the ASE 350 Chromeleon Software:

1. To create a sequence, go to Create $>$ Sequence... in the menu bar. A New Sequence Wizard window will open.

2. The first option is to choose an instrument where the sequence will run. Select ASE 350 and click the Next $>>$ button.

3. The second option is to change the Extraction Configuration. Here the Pattern for Extraction Name, Start Cell Position, Star t Vial Position, and Number of Extractions can be adjusted as preferred. To view what the sequence will look like, click the Apply to Preview button and make changes as necessary. Once all the desired settings have been chosen, click the Next $>>$ button.

4. The third option is to choose the method and reporting preferences. For the ASE350 only the Instrument Method is necessary. Once the desired method has been selected, click the Next $>>$ button.

5. The fourth option is to insert any comments about the sequence. Once this is complete, click the Finish button.

6. A Save Sequence window will open. Choose the desired folder and sequence name then click the Save button.

7. To add another method to the sequence it must be created by following steps 2-9 of Creating a Method with the ASE 350 Chromeleon Software section.

Determination of Total Lipid using the ASE 350:

1. Label (if not already labeled) a $5 \mathrm{~mL}$ extraction cell for each sample.

2. Unscrew both ends of each extraction cell. Place two $27 \mathrm{~mm}$ glass fibers on the frit of one screw cap and screw it back on the cell hand-tight. The filtered side designates the bottom.

3. On a tared sheet of weighing paper weigh approximately $150 \mathrm{mg}$ and record the weight of each sample. After each sample has been weighed, transfer it to the extraction cell by inserting one end of the paper down the opening. Ensure that the entire sample is transferred by tapping or using a brush.

4. After adding the sample to the extraction cell, screw the other screw cap on the open end. Tighten both end screw caps snuggly by simultaneously twisting them tight. Make sure the filters remain on the bottom of the cell during the entire process. 
5. After all the samples have been weighed and recorded, place the extraction cells onto the ASE 350 cell tray. Start from position 1 and sequentially add them in numerical order. To do this, the Trays button on the hardware keypad may need to be pressed to get the green light on the left-hand side. Once it is on the left-hand side, the tray can be manually spun. If the light is on the right-hand side and the tray is spun, serious damage may be done to the instrument.

6. Label and add a $60 \mathrm{~mL}$ vial to each position on the sample collection tray corresponding to the cell tray (start at position 1 and sequentially add them in numerical order). Again, the Trays light must be on the left-hand side. Be sure to close the shield after loading the tray.

7. Open the regulator valve on the nitrogen source.

8. Check to make sure there is enough of each reagent to do the analyses. The reagent bottles should be at least $1 / 4$ full to run a full tray of samples. If there is not enough reagent, contact the appropriate personnel.

9. Open the Chromeleon 7 software and open the sequence 'TL Sequence' located under the Data section on the left-hand side of the software worksheet. Ensure that all the statuses in the sequence are set to 'Idle.'

10. Add or delete rows (using right-click options) to correspond to the number of samples to analyze. Each sample should have 3 rows that will have the same number in triplicate for both the Cell and Vial. The Instrument Method for each sample should sequentially be $1^{\text {st }}$ extractionà ${ }^{\text {nd }}$ extractionà $2^{\text {nd }}$ extraction. If the list does not reflect this, address the problem or seek help. The first two samples in a queue should have a sequence that looks like the following table:

$\begin{array}{llcccc}\# & \text { Name } & \text { Cell } & \text { Vial } & \text { Instrument Method } & \text { Status } \\ 1 & \text { TL } & 1 & 1 & 1^{\text {st }} \text { Extraction } & \text { Idle } \\ 2 & \text { TL } & 1 & 1 & 2^{\text {nd }} \text { Extraction } & \text { Idle } \\ 3 & \text { TL } & 1 & 1 & 2^{\text {nd }} \text { Extraction } & \text { Idle } \\ 4 & \text { TL } & 2 & 2 & 1^{\text {st }} \text { Extraction } & \text { Idle }\end{array}$



$5 \mathrm{TL}$
2
2
$2^{\text {nd }}$ Extraction
Idle
$6 \quad \mathrm{TL}$
2
2
$2^{\text {nd }}$ Extraction
Idle

11. Once the sequence has been modified, click the start button.

12. When the samples are done, turn off the regulator valve on the nitrogen source.

13. Close the Chromeleon 7 software.

14. Remove the $60 \mathrm{~mL}$ vials that now contain extract and place them under a fume hood for further processing.

15. Label a $40 \mathrm{~mL}$ vial respective to each $60 \mathrm{~mL}$ vial containing extract.

16. To each $60 \mathrm{~mL}$ vial containing extract add approximately $15 \mathrm{~mL}$ of water and cap again with screw cap and septa. The ratio of methanol to water should be 1:1. It may be necessary to use an empty $60 \mathrm{~mL}$ vial and fill it with water to the level of the extract meniscus to determine the total volume. Take $1 / 3$ of that volume as the approximate volume of methanol to determine how much water to add.

17. After the water has been added and the vials are capped, invert the vial a few times and centrifuge at 1000RPM for 10min. Ensure that the bottoms of the sample positions on the rotor are cushioned with cotton. The $60 \mathrm{~mL}$ vials are tall and can only be placed in select locations in the rotor. Simply place the vials and swing the rotor out, if the vial hits the frame move it to a more appropriate location.

18. Once the samples are finished centrifuging, carefully transfer them back under the fume hood to avoid mixing the layers.

19. Label a Pasteur pipette to correspond to each sample.

20. Using the corresponding Pasteur pipette, transfer the upper organic layer from the $60 \mathrm{~mL}$ vial into the respective $40 \mathrm{~mL}$ vial. Do this for each sample and take care to avoid transferring any of the bottom aqueous layer along with residual sample.

21. After all the transfers are complete, add $2-3 \mathrm{~mL}$ of hexane to the $60 \mathrm{~mL}$ vial. Cap the vial and invert a few times.

22. Centrifuge the $60 \mathrm{~mL}$ vials at $1000 \mathrm{RPM}$ for $10 \mathrm{~min}$ and carefully place back under the fume hood. 
23. Using the corresponding Pasteur pipette, transfer the upper organic layer into the respective $40 \mathrm{~mL}$ vial combining it with the previously extracted organic layer.

24. Repeat steps 20-22 once more.

25. When all the layers have been combined, place the $40 \mathrm{~mL}$ vial in the evaporator to be dried under nitrogen protection. Dry the sample until glistening.

26. Label a $1.5-2 \mathrm{~mL}$ centrifuge tube for each sample.

27. Weigh and record the weight of each centrifuge tube.

28. Transfer each dried down sample to the respective centrifuge tube. To do this, add a few drops of hexane to the sample to wet it and transfer it over to the respective centrifuge tube using the corresponding Pasteur pipette. Repeat adding a few drops of hexane and transferring until all sample has been moved to the centrifuge tube.

29. Dry down the samples contained in the centrifuge tube under nitrogen protection on the evaporator.

30. Once all the samples have dried, place them in the -80 freezer for 1 hour.

31. After the samples are frozen, place them in the freeze-dryer overnight.

32. The next day, take the samples off the freeze-dryer. Weigh and record the weight of each sample.

33. Dispose of any hazardous waste and clean up the mess (including the extraction cells).

34. Calculate the \% Total Lipid for each sample using the equation below:

Calculations:

$\%$ Total Lipid $=\frac{\lfloor\text { weight of centrifuge tube }+ \text { lipid }(g)\rfloor-\lfloor\text { weight of centrifuge tube }(g)\rfloor}{\text { weight of sample }(g)} * 100$ 


\section{Appendix C}

This appendix outlines the chloroform-methanol extraction process using the High-

Throughput Lipid Determination for Bulk Algae Material: the Dionex and Phase Separation standard operating procedure. This procedure is confidential and can be obtained with the permission of Cellana, Inc. 
Appendix D

This appendix outlines the Determination of Total Lipids as Fatty Acid Methyl Esters (FAME) by in situ Transesterification laboratory analytical procedure.

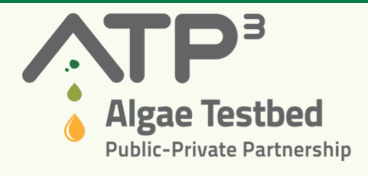

Determination of Total Lipids as Fatty

\section{Acid Methyl Esters (FAME) by in situ}

\section{Transesterification}

S. Van Wychen, L. ML. Laurens

Laboratory Analytical Procedure (LAP)

Issue Date: July $26^{\text {th }}, 2013$

\section{GNREL}




\section{DISCLAIMER}

The Standard Algal Biomass Analytical Methods (Methods) are provided by the National Renewable Energy Laboratory (NREL), which is operated by Alliance for Sustainable Energy, LLC (Alliance) for the U.S. Department of Energy (DOE). The methods are distributed to partners in the Algae Testbed Public Private Partnership (ATP ${ }^{3}$ ) consortium for the purpose of harmonized data reporting. These methods were developed and written for commercial research and educational use only.

Access to and use of these Methods shall impose the following obligations on the user. The user is granted the right, without any fee or cost, to use, copy, modify, alter, enhance and distribute these Methods for any purpose whatsoever, except commercial sales, provided that this entire notice appears in all copies of the Methods. The user agrees to credit NREL/Alliance and $\mathrm{ATP}^{3}$ in any publications that result from the use of these Methods. The user also understands that NREL/Alliance and ATP $^{3}$ is not obligated to provide the user with any support, consulting, training or assistance of any kind with regard to the use of these Methods or to provide the user with any updates, revisions or new versions.

THESE METHODS ARE PROVIDED BY NREL/Alliance and ATP ${ }^{3}$ "AS IS" AND ANY EXPRESS OR IMPLIED WARRANTIES, INCLUDING BUT NOT LIMITED TO, THE IMPLIED WARRANTIES OF MERCHANTABILITY AND FITNESS FOR A PARTICULAR PURPOSE ARE DISCLAIMED. IN NO EVENT SHALL NREL/Alliance/DOE or ATP ${ }^{3}$ BE LIABLE FOR ANY SPECIAL, INDIRECT OR CONSEQUENTIAL DAMAGES OR ANY DAMAGES WHATSOEVER, INCLUDING BUT NOT LIMITED TO CLAIMS ASSOCIATED WITH THE LOSS OF DATA OR PROFITS, WHICH MAY RESULT FROM AN ACTION IN CONTRACT, NEGLIGENCE OR OTHER TORTIOUS CLAIM THAT ARISES OUT OF OR IN CONNECTION WITH THE ACCESS, USE OR PERFORMANCE OF THESE METHODS. 
1. Introduction

1.1 This procedure covers the determination of total lipids expressed as fatty acid methyl esters (FAME). Results are reported as the percent FAME content based on the dry weight of the sample. The procedure is based on a whole biomass transesterification procedure of lipids to FAME, which eliminates the need for extraction and therefore is able to access all fatty acids in the biomass and represent an accurate reflection of the biofuels potential.

1.2 Lipids are present in many forms and play various roles within an algal cell, from cell wall phospholipids to energy stored as triacylglycerols. The ability to identify and accurately quantify the fatty acid content of these lipids, as well as free fatty acids, is essential to evaluating fuel potential and establishing a comprehensive compositional analysis of algae.

1.3 Acid catalyzed transesterification is one way to measure total fatty acid content. The procedure first solubilizes the lipids and then frees the fatty acids by transferring a methyl group from methanol onto the -acyl chains of the lipids. During this reaction, the ester bond between the fatty acids and the glycerol backbone (e.g. triacylglycerol) will be replaced by an ester bond between the fatty acid and a methyl group, producing methyl esters of the fatty acids (FAME) and free glycerol.

1.4 The FAMEs are then extracted from the polar methanol phase with hexane, leaving the polar compounds, e.g. glycerol or phosphatidic acid, behind.

1.5 A surrogate/recovery standard consisting of an odd chain fatty acid (e.g. C13) that does not naturally occur in algae is transesterified with the sample and used to quantify the total FAME content on a gas chromatograph.

1.6 A full description of the method, precision and bias and optimization with respect to catalyst can be found in reference [1]

2. Scope

2.1 This procedure is developed and optimized specifically for microalgal biomass, residual algal biomass after extraction, and algal extractives.

\section{Terminology}

3.1 Oven dry weight (ODW) - the weight of the biomass corrected for the percent moisture determined by drying the biomass at $105^{\circ} \mathrm{C}$ or overnight at $40^{\circ} \mathrm{C}$

3.2 Lipids - Based on the definition of lipids as 'Fatty acids and their derivatives' ${ }^{\text {(2] }}$. The lipid determination as total FAME is an accurate reflection and quantification of total lipids. 
3.3 Transesterification - The process of exchanging the organic group of an ester with the organic group of an alcohol.

3.4 Extractives/extracted lipids - The portion of algal biomass that is soluble in any type of solvent used to extract the sample. Extractives may include sugars, proteins, lipids, glycolipids, and glycoproteins, as well as an array of other compounds.

3.5 Extractives-free/Residuals - Algal biomass that has been exhaustively extracted with any solvent (e.g. chloroform:methanol) that solubilizes and removes some portion of the algal lipids.

3.6 Fatty acid methyl esters - The result of the transesterification of lipids, where a methyl group from methanol forms an ester bond with a fatty acid.

3.7 Surrogate/Recovery Standard - The inclusion of a known amount of surrogate/recovery standard allows for the correction of the FAME quantification for FAME extraction variability and evaporation of the extraction solvent during the FAME procedure.

3.8 Internal Standard - The inclusion of a known amount of internal standard in samples and standards allows for the correction of the FAME quantification for analytical instrument variability and solvent evaporation during the FAME analysis on the instrument.

\section{Significance and Use}

4.1 This procedure is used, in conjunction with other procedures, to determine the amounts of biofuel-relevant fatty acids present in algal biomass.

4.2 This procedure may be used in conjunction with other compositional analysis procedures to determine the summative mass closure of algal biomass

\section{Interferences}

5.1 Samples that are moldy, wet or have been exposed to an oxygen-rich environment may be compromised, resulting in erroneous lipid values.

5.2 Samples with greater than $20 \%$ moisture may undergo hydrolysis during the reaction, resulting in erroneous lipid values.

6. Apparatus

6.1 Analytical balance, accurate to $1 \mathrm{mg}$ or $0.1 \mathrm{mg}$

6.2 Vacuum oven set to $40 \pm 2^{\circ} \mathrm{C}$ or drying oven set to $40 \pm 2^{\circ} \mathrm{C}$

6.3 Digital dry block, capable of maintaining $85^{\circ} \mathrm{C}$

6.4 Gas chromatograph (GC) equipped with a variable split-flow injector or equivalent device: Agilent 7890A GC system equipped with S/SL inlet or equivalent 
$\mathbf{A T P}^{3}$

Algae Testbed

Public-Private Partnership

FAME Quantification LAP v. July 26, 2013

6.5 Automated sampler compatible with the chosen GC system: Agilent 7693A Automatic Liquid Sampler or equivalent

6.6 Detector compatible with the chosen GC system and type of analysis: Agilent 7890A equipped with a flame ionization detector (FID) or equivalent

6.7 Capillary column with polyethylene glycol stationary phase: Agilent J\&W GC Column DB-Wax length $30 \mathrm{~m}$, internal diameter $0.25 \mathrm{~mm}$, film thickness $0.25 \mu \mathrm{m}$ or equivalent

7. Reagents and Materials Needed

7.1 Reagents

7.1.1 Chloroform, HPLC grade

7.1.2 Methanol, HPLC grade

7.1.3 Hexane, HPLC grade

7.1.4 Hydrochloric acid $(\mathrm{HCl})$, concentrated (36.5-38\%)

7.1.5 Chloroform: methanol solution $(2: 1, \mathrm{v} / \mathrm{v})$

7.1.6 $\mathrm{HCl}$ : methanol solution $(5 \% \mathrm{HCl}$ in methanol $(\mathrm{v} / \mathrm{v}))$

7.1.7 Tridecanoic acid methyl ester (C13Me) standard (Sigma Aldrich \#91558-5ML)

7.1.8 Pentadecane (Sigma Aldrich \#76509-5ML)

7.1.9 F.A.M.E. Mix, C4-C24 (Sigma Aldrich \#18919-1AMP), alternative acceptable calibration mixes are C8-24 mix (Sigma Aldrich \# 18918-1AMP) and GLC-80 (Sigma Aldrich \#1898)

7.2 Materials

7.2.1 Volumetric flask (class A), $10 \mathrm{~mL}$

7.2.2 Gas-tight syringes, covering ranges from 5-1000 $\mu \mathrm{L}$

7.2.3 Adjustable pipet, covering ranges from 100-300 $\mu \mathrm{L}$

7.2.4 Vials, clear, crimp tops, $1.5 \mathrm{~mL}$ fill volume (Agilent \#5182-0543 or equivalent)

7.2.5 Vials with inserts, clear, crimp tops, $300 \mu \mathrm{L}$ fill volume (Agilent \#9301-1388 or 51886572(amber))

7.2.6 Crimp caps, PTFE/silicone/PTFE septa (Agilent \#5181-1211)

\section{ES\&H Considerations and Hazards}

8.1 Methanol is a slight health hazard and is moderately flammable.

8.2 Hydrochloric acid is toxic and corrosive.

8.3 Hexane is a significant health hazard and extremely flammable

8.4 Chloroform is a trihalomethane and is considered a possible human carcinogen 
8.5 Follow all applicable site-specific chemical handling procedures.

9. Sampling, Test Specimens and Test Units

9.1 Care must be taken to ensure a representative sample is taken for analysis.

9.2 Limit sample contact with oxygen, heat and moisture to lessen the possibility of lipid degradation.

10. Procedure

\subsection{Preparation of the samples for transesterification}

10.1.1 Label $1.5 \mathrm{ml} \mathrm{GC}$ vials using a permanent marker for each of the samples to be analyzed. Each sample should be analyzed in triplicate, at minimum (unless the amount of sample prohibits this). In addition, a quality control standard should be included in triplicate with each batch of samples.

10.1.2 Record the weights of all labeled vials to the nearest $0.1 \mathrm{mg}$, written labels should be dry before recording a weight.

10.1.3 Whole or residual biomass: weigh between 5 to $10 \mathrm{mg}$ of sample into the labeled and pre-weighed GC vials. Record the weight to the nearest $0.1 \mathrm{mg}$. Dry samples in vials overnight in a $40^{\circ} \mathrm{C}$ oven under vacuum. After drying, take a final weight to calculate the moisture-free sample amount.

10.1.4 Neat lipids or extracts: weigh or aliquot a known volume (estimated lipid weight of 5 to $10 \mathrm{mg}$ ) into a labeled and pre-weighed GC vial. If during transfer, the sample drips on the outside of the vial, label and weigh a new vial. Dry lipids/extracts in vials overnight or until the samples are completely dry in a $40^{\circ} \mathrm{C}$ oven under vacuum. After drying, take a final weight to calculate the moisture-free sample amount. If no vacuum oven is available, dry a representative aliquot of biomass for moisture determination on the same day and correct the biomass weights prior to calculating the FAME concentration.

NOTE: Steps 10.1.3 and 10.1.4: allow samples to cool in a desiccator under vacuum before recording a final weight.

\subsection{Preparation of the surrogate/recovery standard}

10.2.1 To make up a $10 \mathrm{mg} \mathrm{mL}^{-1}$ solution, weigh out approximately $100 \mathrm{mg}$ of the methyl tridecanoate (C13Me) into a $10-\mathrm{ml}$, class A, volumetric flask. Record the weight of the C13Me to the nearest $0.1 \mathrm{mg}$. 
10.2.2 Bring to volume with HPLC grade hexane and mix well.

10.2.3 Transfer the hexane-C13Me mixture into $1.5 \mathrm{ml} \mathrm{GC}$ vials and seal immediately with PTFE/silicone/PTFE crimp caps. Take extra care while transferring to limit evaporation, as it is very important to maintain the recorded surrogate concentration.

10.2.4 Record the date of preparation, concentration, and any other pertinent information on the vials and place upright in a laboratory freezer $\left(-20^{\circ} \mathrm{C}\right)$ for storage.

10.3 Transesterification of the Samples

10.3.1 Preheat a digital dry block, or equivalent, to $85^{\circ} \mathrm{C}$.

10.3.2 While the block is preheating, add the following to each of the sample vials:

- $25 \mu \mathrm{L}$ of the pre-prepared C13Me surrogate $\left(10 \mathrm{mg} \mathrm{mL}^{-1}\right)$ using a gas tight syringe (this amount may need to be adjusted to more accurately reflect the estimated fatty acid content of the sample)

- $200 \mu \mathrm{L}$ of chloroform:methanol $(2: 1, \mathrm{v} / \mathrm{v})$ using a gas tight syringe

- $300 \mu \mathrm{L}$ of $5 \% \mathrm{HCl}$ :methanol using a pipet with a plastic or glass pipet tip

10.3.3 Seal all vials with the PTFE/silicone/PTFE crimp caps and vortex well to mix the contents.

10.3.4 Place the sealed vials into the preheated block at $85 \circ \mathrm{C}$ for one hour. Once the reagents have been added to the samples, the samples must be heated. Do not allow samples to sit around as this may affect the reaction.

10.3.5 After one hour on the digital dry block, remove the vials and allow to cool for at least fifteen minutes, but no longer than an hour at room temperature. If the rest of the procedure cannot be completed on the same day, cooled samples may be stored overnight in a freezer $\left(-20^{\circ} \mathrm{C}\right)$. Always store vials upright.

10.4 Isolation and preparation of FAMEs for GC analysis

10.4.1 After cooling, add $1 \mathrm{ml} \mathrm{HPLC}$ grade hexane to each of the vials using a gas tight syringe. This can be done without removing the vial caps by using a small hollow-core needle to penetrate the cap while adding the hexane with the syringe through a second hole in the cap. Be sure the opening in the hollow-core needle faces away from the direction of the added hexane to avoid hexane being expelled back up through the needle. 
10.4.2 Vortex well to mix the vial contents and let them stand undisturbed at room temperature for at least one hour but no more than four hours to allow the phases to separate. If the rest of the procedure cannot be completed on the same day, samples must be re-capped and then stored overnight in a freezer $\left(-20^{\circ} \mathrm{C}\right)$. Always store vials upright.

10.4.3 Arrange and label new $1.5 \mathrm{~mL} \mathrm{GC}$ vials for each sample.

10.4.4 Arrange and label new $300 \mu \mathrm{L} \mathrm{GC}$ vials with inserts for each sample.

10.4.5 Samples may need to be diluted to fall within the calibration curve. The following is a general dilution outline - add the following to the labeled $1.5 \mathrm{~mL}$ GC vial from step 10.4.3, using gas tight syringes:

- Whole biomass - estimated low lipid content (e.g. early harvest): $400 \mu L$ HPLC grade hexane and $100 \mu \mathrm{L}$ of the upper phase of the sample.

- Whole biomass - estimated high lipid content (e.g. late harvest): $450 \mu \mathrm{L}$ HPLC grade hexane and $50 \mu \mathrm{L}$ of the upper phase of the sample.

- Residual biomass (extractives-free): Use the upper phase of the sample undiluted. At least $300 \mu \mathrm{L}$ is needed in the new vial.

- Extracts/isolated lipids: Add the following using gas tight syringes: $450 \mu \mathrm{L}$ HPLC grade hexane and $50 \mu \mathrm{L}$ of the upper phase of sample.

The upper phase of the sample can be withdrawn without removing the caps. Use caution not to disturb the lower phase when drawing the upper phase of the sample. Rinse the syringe thoroughly with hexane between samples. Work in groups of ten samples or less to minimize evaporation of hexane and cap immediately after adding the sample.

10.4.6 Seal the $1.5 \mathrm{~mL}$ vials containing the dilutions with PTFE/rubber crimp caps.

10.5 Preparation and addition of the internal standard

10.5.1 Weigh out approximately $10 \mathrm{mg}$ of pentadecane standard into a labeled $1.5 \mathrm{~mL}$ vial. Record the weight to the nearest $0.1 \mathrm{mg}$.

10.5.2 Add $1 \mathrm{~mL}$ of HPLC grade hexane to the vial and seal with a PTFE/silicone/PTFE crimp cap.

10.5.3 Dilute this standard 1:10 before adding to samples and standards.

10.5.4 To each labeled $300 \mu \mathrm{L} \mathrm{GC}$ vial from step 10.4.4 add: 
$\mathbf{A T P}^{3}$

Algae Testbed

Public-Private Partnership

FAME Quantification LAP v. July 26, 2013

- $5 \mu \mathrm{L}$ of the 1:10 diluted pentadecane. Only add pentadecane to 10 vials at a time.

- $200 \mu \mathrm{L}$ of diluted sample from the vials prepared in step 10.4.6.

10.5.5 Cap the vials immediately with PTFE/rubber crimp caps.

10.5.6 Label a set of amber $300 \mu \mathrm{L}$ insert vials for the standards. To each standard vial add:

- $5 \mu \mathrm{L}$ of the SAME 1:10 diluted pentadecane used for the samples in step 10.5.4.

- $200 \mu \mathrm{L}$ of standard prepared in step 10.6.1 (refer to Table 1).

10.5.7 Cap the standard vials with PTFE/silicone screw caps.

10.5.8 Once all the samples and standards have been prepared with the internal standard,

vortex all vials to mix the contents.

\subsection{Preparation of the FAME standards}

10.6.1

Prepare a series of calibration standards containing the compounds that are to be quantified, i.e., C4-C24 (37 compound calibration mix, Sigma Aldrich \#18919-1AMP) Refer to Table 1 below for suggested calibration standards. The range will depend on the compound amount in the original neat standard mix, but it will typically range from 1-6 ug/mL to $100-200 \mathrm{ug} / \mathrm{mL}$ depending on the individual FAME concentration.

10.6.2 If using the C4-C24 neat mix (18919-1AMP), prepare a $10 \mathrm{mg} / \mathrm{mL}$ working solution using the following steps:

- Using HPLC grade hexane, transfer the neat mix as quantitatively as possible to a clean, $10 \mathrm{~mL}$, class $\mathrm{A}$, volumetric flask.

- Bring to volume with HPLC grade hexane and mix well.

- Transfer the mixture to labeled $1.5 \mathrm{~mL} \mathrm{GC}$ vials, working quickly and carefully to avoid evaporation. Seal vials immediately with PTFE/silicone/PTFE crimp caps.

\begin{tabular}{|c|c|c|}
\hline $\begin{array}{c}\text { Standard } \\
\text { Level }\end{array}$ & $\begin{array}{c}\text { C4-C24 } \\
\text { Working } \\
\text { Solution }\end{array}$ & $\begin{array}{c}\text { HPLC Grade } \\
\text { Hexane }\end{array}$ \\
\hline & $u l$ & $u l$ \\
5 & 500 & 500 \\
4 & 250 & 750 \\
3 & 100 & 900 \\
2 & 30 & 970 \\
1 & 10 & 990 \\
\hline CVS & 90 & 910 \\
\hline
\end{tabular}

Table 1: Standards Prepared using the C4-C24 Working Solution from step 10.6.2. 
NOTE: Standards, once prepared as calibration concentrations can be stored up to 6 months.

NOTE: Actual standard concentrations will depend on the batch of calibration mix and can be calculated based on the certificate of analysis (see calculation spreadsheet in Appendix A)

10.6.3 In addition to the standards, a calibration verification standard (CVS) containing all the compounds in the standards should also be prepared at a level that is not included in the calibration curve, preferably from an independent batch of FAME standards.

10.6.4 Store all working solutions and standards in $1.5 \mathrm{~mL}$ vials sealed with PTFE/silicone/PTFE crimp caps in a freezer $\left(-20^{\circ} \mathrm{C}\right)$. Always store vials upright.

10.7 Setting up the GC for FAME analysis

10.7.1 Suggested GC analysis follows temperature and flow program as detailed below for DB-WAX $30 \mathrm{~m} \times 0.25 \mathrm{~mm}$ ID $\times 0.25 \mu \mathrm{m} \mathrm{FT}$ :

- $\quad 1 \mu \mathrm{l}$ injection at $10: 1$ split ratio, inlet temperature of $250^{\circ} \mathrm{C}$

- Constant flow: $1 \mathrm{~mL} / \mathrm{min}$ helium

- Oven temperature: $50^{\circ} \mathrm{C}$ for $1 \mathrm{~min}, 25^{\circ} \mathrm{C} / \mathrm{min}$ up to $200^{\circ} \mathrm{C}$ and hold for $1 \mathrm{~min}$, $3^{\circ} \mathrm{C} / \mathrm{min}$ up to $230^{\circ} \mathrm{C}$ and hold for $18 \mathrm{~min}$

- Flame ionization detector: $280^{\circ} \mathrm{C}, 450 \mathrm{~mL} / \mathrm{min}$ zero air, $40 \mathrm{~mL} / \mathrm{min} \mathrm{H}_{2}, 30 \mathrm{~mL} / \mathrm{min}$ helium

10.7.2 Quantification by Chemstation (Agilent) or respective GC software, use calibration response factors (corrected for internal standard recovery - in this case, pentadecane) for each individual fatty acid and only work up data when calibration quality of correlation is 0.999 or better. Response factors can be significantly different between different fatty acids, use only respective response factors for quantification and for novel fatty acids that are not present in the calibration mix, determine respective response factors

11. Calculations 
11.1 Export the FAME concentrations (as $\mu \mathrm{g} \mathrm{mL}^{-1}$ for each individual fatty acid methyl ester [C4 - C24]) from GC software and normalize for the quantity of the recovery standard C13. The outcome is the sum or total FAME content normalized for the recovery of the surrogate standard added at the start of the reaction (step 10.3.2):

$$
\text { Total FAME } E_{C 13 \text { normalized }}=\sum_{C 4-C 37} \frac{\text { Amount }_{\text {Measured FAME } C_{i}}}{\text { Amount }_{\text {Measured } F A M E_{C 13}}} \times \text { Amount }_{\text {Added FAME } E_{C 13}}
$$

11.2 Calculate the total FAME as a percent of the dry weight of the sample. For the FAME analysis, the dry weight refers to the weight after drying the sample overnight at $40^{\circ} \mathrm{C}$ in a vacuum oven:

$$
\% \text { Total FAME }=\frac{\text { Total } F A M E_{C 13 \text { normalized }}}{O D W_{\text {sample }}} \times 100
$$

11.3 To report or calculate the root mean square deviation (RMS) or the standard deviation (STDEV) of the samples, use the following calculation:

$$
R M S=x_{m}=\sqrt{\left(\frac{\sum_{1}^{n} x}{n}\right)^{2}}
$$

RMSdeviation $=\sigma=\sqrt{\frac{\sum_{1}^{n}\left(x_{i}-x_{m}\right)^{2}}{n}}$

Where:

$x_{m}=$ the root mean square of all $\mathrm{x}$ values in the set

$n=$ number of samples in set

$x_{i}=$ measured value from the set

\section{MNREL}


11.4 To report or calculate the relative standard deviation (RSD) of the triplicates, use the following calculation:

$R S D=\left(\frac{s t d e v}{X_{\text {mean }}}\right) \times 100$

Where:

stdev $=$ RMSdeviation from the calculation in step 11.3

$X_{\text {mean }}=$ the mean $\%$ total FAME of the triplicates

\section{Report Format}

12.1 For replicate analyses of the same sample, report the average, standard deviation, and \%RPD.

12.2 Report the triplicate average percent FAME in the sample on a dry weight basis. Standard deviation and relative standard deviation of the triplicates may also be reported. Report relative percent difference for duplicates

\section{Precision and Bias}

13.1 An inherent error in any moisture determination involving drying of the sample is that volatile substances other than water may be removed from the sample during drying

13.2 Precision and bias need to be determined by a round robin experiment using standard method verification biomass. The target RSD and RPD should be less than $10 \%$

13.3 Improper sample preparation and/or storage may bias the results low due to the degradation of oxygen or heat-sensitive lipids

\section{Quality Control}

14.1 Reported results: Report results with two decimal places. Report the average, standard deviation, and \%RPD.

14.2 Replicates: Run all samples in triplicate

14.3 Relative standard deviation criteria: Each set of triplicates must reproduce \% total FAME at $<10 \%$ RSD.

14.4 Sample size: Approximately 5 to $10 \mathrm{mg}$ of sample or lipid should be weighed out for transesterification. 
$\hat{A T P}^{3}$

Algae Testbed

14.5 Sample storage: Before transesterification, all samples containing lipids should be freeze-dried or dried under nitrogen and stored in an air-tight container in a freezer $\left(-20^{\circ} \mathrm{C}\right.$ or $-80^{\circ} \mathrm{C}$ : depending on preservation needs).

14.6 Blank: HPLC grade hexane - the same batch of hexane used during sample analyses.

14.7 Standard preparation: Standards and CVS (calibration verification standard) should be prepared with HPLC grade hexane.

14.8 Standard storage: GC standards should be stored in a freezer $\left(-20^{\circ} \mathrm{C}\right)$, upright, until needed.

14.9 QA/QC material should be control charted to verify reproducibility

\section{Appendices}

15.1 Calibration standards concentration [TBD]

15.2 GC method and settings for Agilent 6890N GC-FID [TBD]

15.3 List of revisions/updates

- Distribution of May 16, 2013 DRAFT version

- July $26^{\text {th }}$, Updated with calibration mixture preparation solutions and moisture correction

\section{References}

[1] Laurens, L. M.L., Quinn, M., Van Wychen, S., Templeton, D. W., Wolfrum, E. J. 2012 Anal. Bioanal. Chem. 403(1), 167-178 (Open Access: http://www.springerlink.com/content/g214r02011861712)

[2] Christie, W. W. Lipid Analysis: Isolation, Separation, Identification and Structural Analysis of Lipids, 3rd ed.; Oily Press: Bridgwater, England, 2005 